TALKING OURSELVES INTO OUTCOMES:

TEACHING, LEARNING, AND EQUITY IN CALIFORNIA COMMUNITY

COLLEGES

A dissertation submitted to the faculty of

San Francisco State University

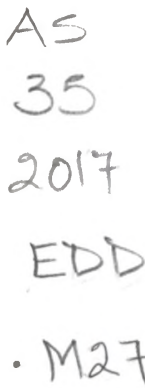

In partial fulfillment of

The Requirements for

The Degree

Doctor of Education

In

Educational Leadership

by

Lillian Elizabeth Marrujo-Duck

San Francisco, California

October, 2017 
Copyright by

Lillian Elizabeth Marrujo-Duck 2017 


\section{CERTIFICATION OF APPROVAL}

I certify that I have read Talking Ourselves into Outcomes: Teaching, Learning, and Equity in California Community Colleges by Lillian Elizabeth Marrujo-Duck, and that in my opinion this work meets the criteria for approving a thesis submitted in partial fulfillment of the requirement for the degree: Doctor of Education in Educational Leadership at San Francisco State University.

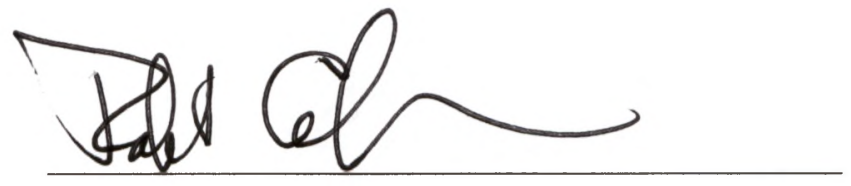

Robert Gabriner, Ph.D.

Professor, Educational Doctoral Program, Graduate College of Education San Francisco State University

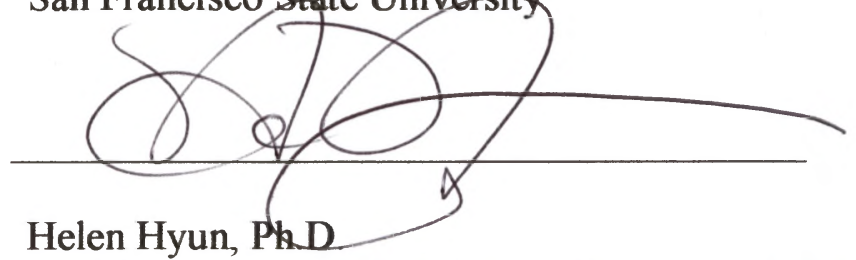

Professor, Educational Doctoral Program, Graduate College of Education

San Francisco State University

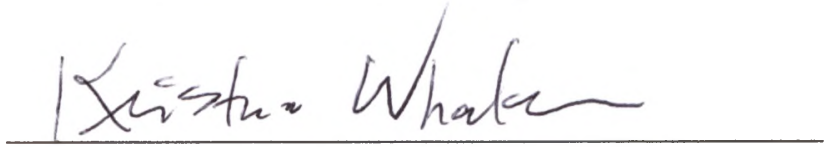

Kristina Schriver-Whalen, Ph.D.

Dean, School of Fine and Communication Arts City College of San Francisco 


\title{
TALKING OURSELVES INTO OUTCOMES: \\ TEACHING, LEARNING, AND EQUITY IN CALIFORNIA COMMUNITY \\ COLLEGES
}

\author{
Lillian Elizabeth Marrujo-Duck \\ San Francisco, California \\ 2017
}

This qualitative collective case study explored the experiences of community college faculty members in the social and behavioral sciences and SLO coordinators at community colleges in California as they engaged in student learning outcomes assessment (SLOA). Semi-structured interviews with eight faculty members and five student learning outcomes coordinators revealed common goals among the participants to use education to inform social change. Participation in SLOA led to an invigoration of the teaching experience based on creating strategic dialogue among students in the classroom, faculty within departments, and across divisions within the institutions. Engagement in SLOA led to changes in teaching practice that align with research findings on best practices in higher education and participants perceived themselves to be better teachers as a result. However, participants were reluctant to claim responsibility for student learning or to identify improvements in student learning as a result of SLOA. Still, they were willing to consider the potential of SLOA as a tool to close achievement gaps. Recommendations focus on policy, leadership, and institutional strategies for increasing faculty engagement in SLOA.

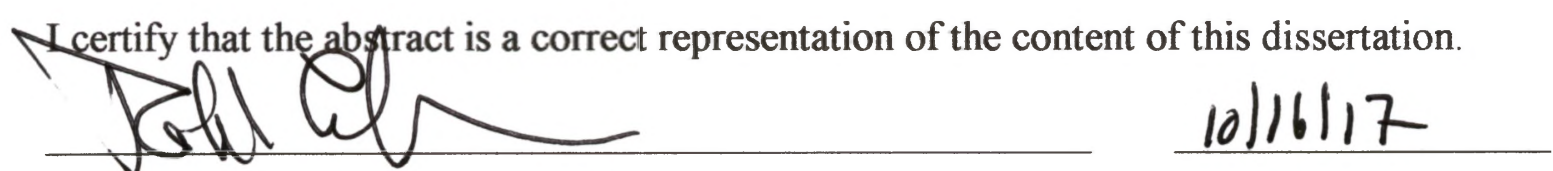

Chair, Dissertation Committee

Date 


\section{ACKNOWLEDGEMENTS}

At risk of making a first impression of relying on clichés, it really did take a village to support my endeavors to achieve this educational goal. I must first acknowledge my deep appreciation for the thirteen participants in this study. Their willingness to take risks and make themselves vulnerable to another's analysis to further our collective understanding of the teaching experience is an attitude toward life that I can only hope to emulate. I am also grateful to my committee members for all their support. Dr. Gabriner's willingness to push me beyond my original goals, while fully supporting my efforts when I struggled with the research, helped raise the level of this dissertation beyond my expectations. Dr. Hyun's exacting attention to the methods provided a guide when I could only focus on one step at a time. And Dr. SchriverWhalen's consistent focus on critical thought, both as a colleague and a committee member, kept me focused on sharp analysis at times when I was tempted to merely describe my findings. I am one of those lucky individuals truly surrounded by a web of loving support. My three children provided endless patience and encouragement, and were willing participants in the random crazy moments of fun that I demanded upon completion of critical milestones. Brennen proudly served his country, and when home chaperoned his younger sisters when necessary while I studied. Tommi cooked and supported her younger sister while I gathered data. And Cambria took advantage of every 
moment I had free to share herself with me so that I did not completely miss out on her last years of high school while I took advantage of this educational opportunity. I might never have finished analyzing my data and writing this final draft if my dad, Juan Armando Marrujo, had not taken it upon himself to intentionally pester me every day and force me to be accountable to making progress, bit by bit, even when I wanted to quit. But by far, I could not have completed this work without the completely self-sacrificing support of my husband, Thomas Steven Duck. Besides taking care of everything on the home front — ordering books for classes, printing articles I needed to read, packing my lunch, delivering forgotten items to both work and school, listening to me talk through all the ideas swirling around in my head, and carefully reading everything I wrote- - he was my partner. He shared in my determination, drive, exhaustion from the low points, and thrills of success. This dissertation is dedicated to Thomas. 


\section{TABLE OF CONTENTS}

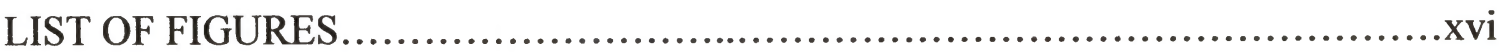

LIST OF APPENDICES ...........................................................

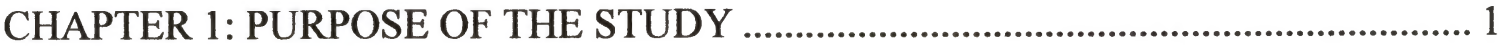

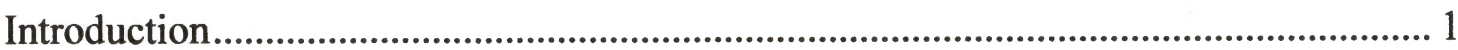

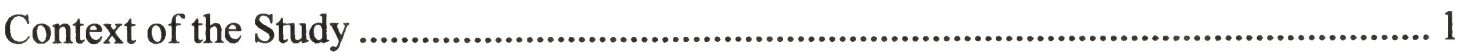

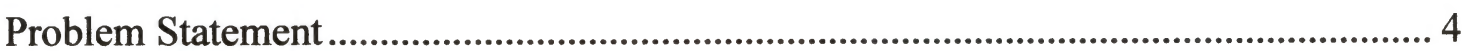

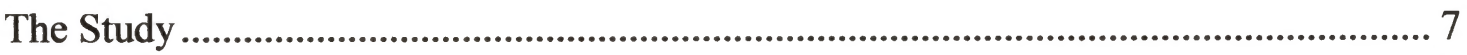

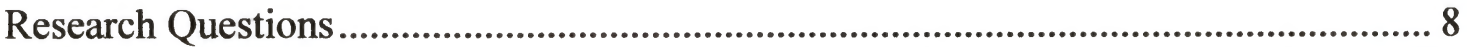

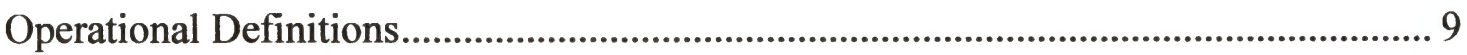

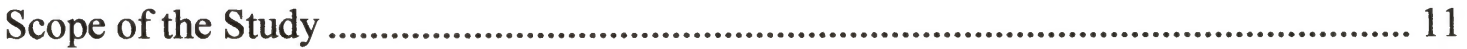

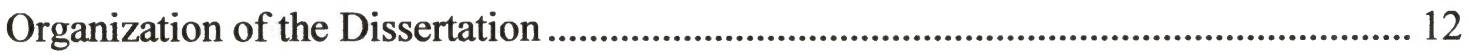

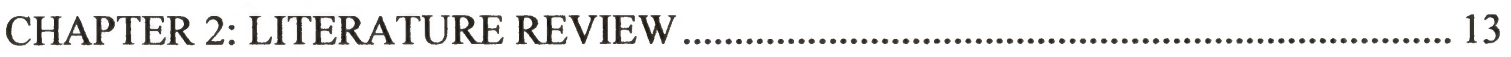

Scope of the Literature Review................................................................................ 13

Structure of the Literature Review..................................................................... 13

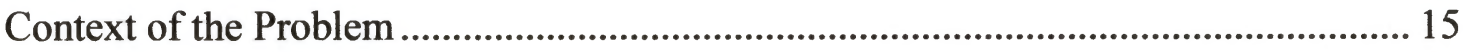

A History of Quality Assurance in Higher Education ................................................ 17

The Trusted Professoriate ................................................................................. 18

Increases to External Accountability ..................................................................... 18

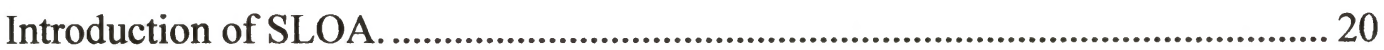


Introduction of SLOA.

Introduction of disaggregated outcomes data.

New California state reporting requirements align with federal and accreditor

reporting requirements.

Professional development programs for faculty support desired changes 25

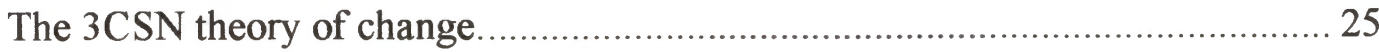

Solutions for Improving Results at Community Colleges ....................................... 26

SLOA as a Solution that Impacts the "Black Box" of Instruction ......................... 28

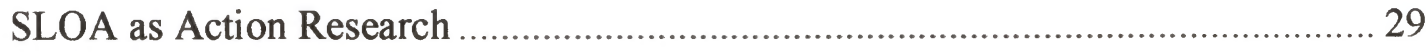

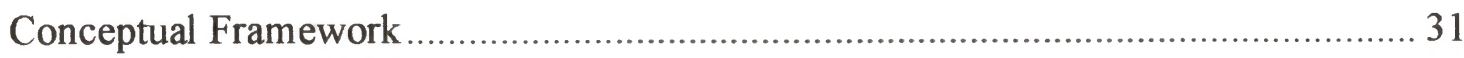

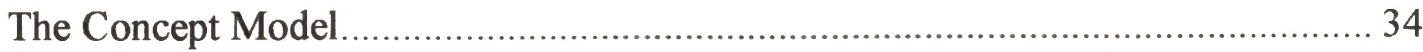

Theories Supporting the Conceptual Framework ............................................ 37

Rogers' Theory of Diffusion of Innovations. ..................................................... 37

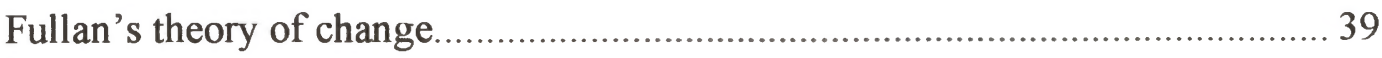

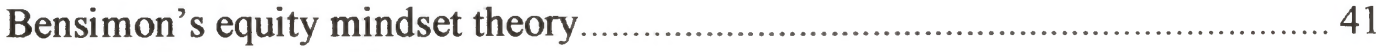

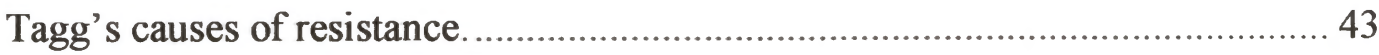

Challenges to Increased Faculty Participation in SLOA ….................................... 44

A Lack of Evidence that SLOA Improves Student Learning .............................. 45

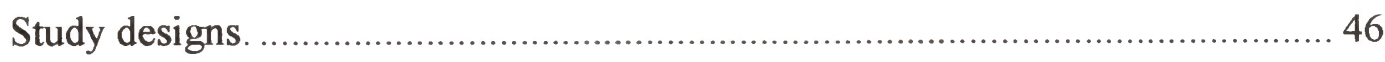

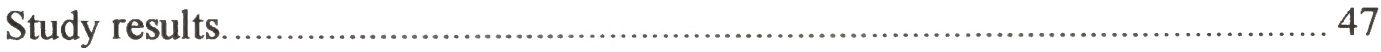

viii 
Resistance to SLOA

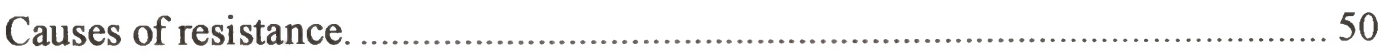

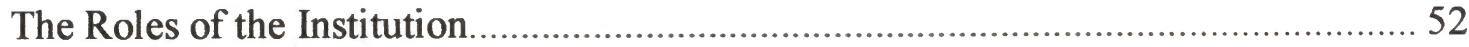

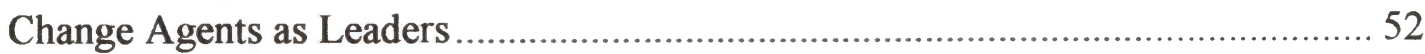

SLO coordinators as peer change agents. ............................................. 54

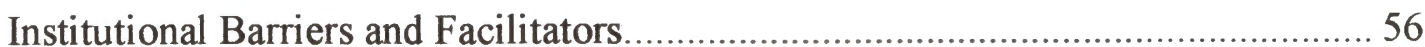

Alignment of Conceptual Framework with Educational and Social Reform Efforts ... 58

New Disaggregated SLOA Requirements Might Also Face Initial Resistance....... 60

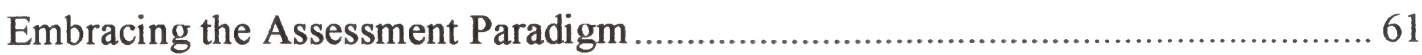

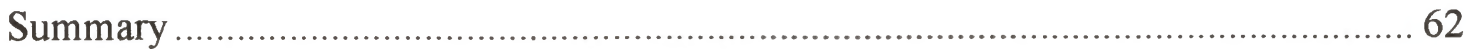

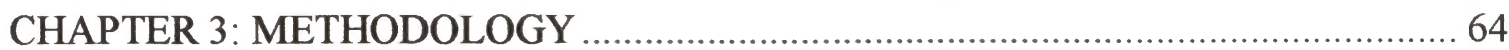

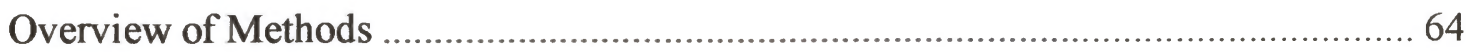

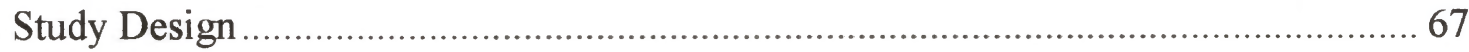

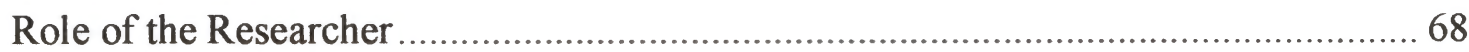

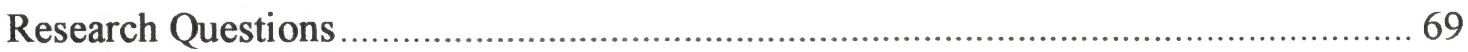

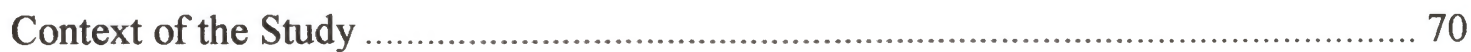

Participant Inclusion Criteria and Selection ................................................. 75

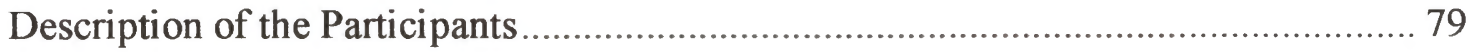

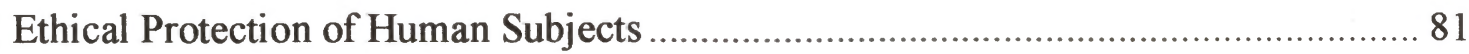

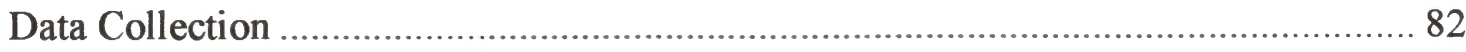

ix 


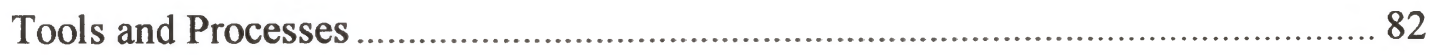

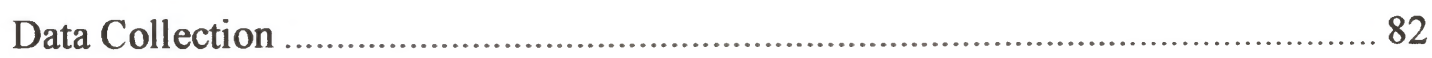

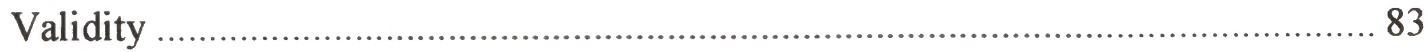

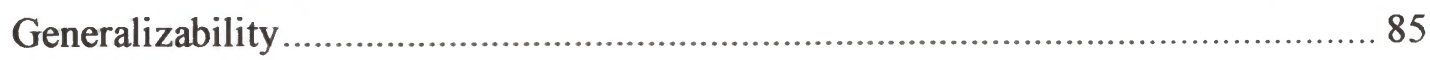

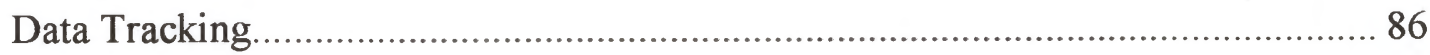

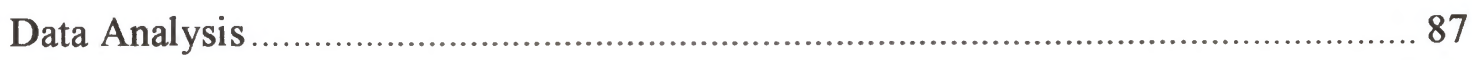

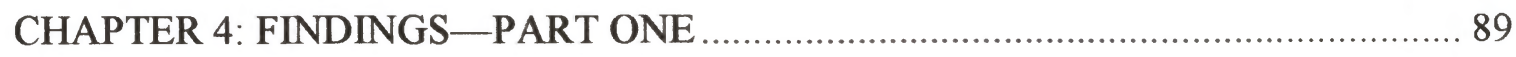

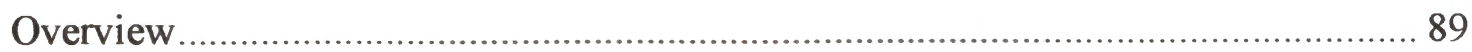

Factors That Influence Engagement in Student Learning Outcomes ....................... 90

SLOA and the Values of the Participants .......................................................... 91

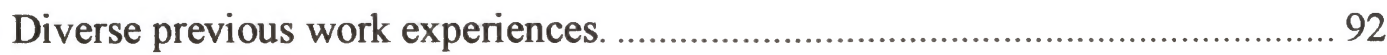

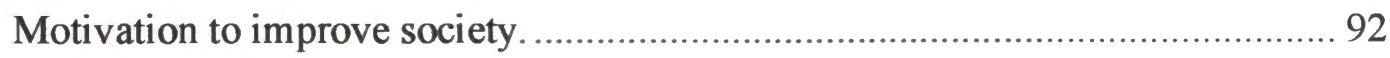

Pre-Existing Motives, Practices, and Using SLOs to Improve Society .................. 94

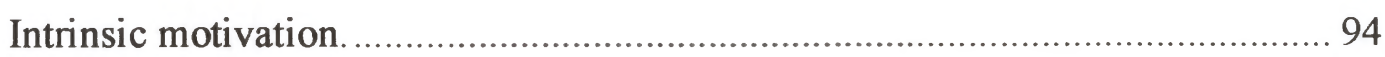

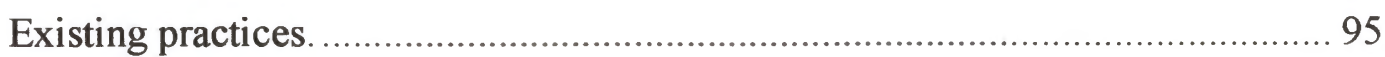

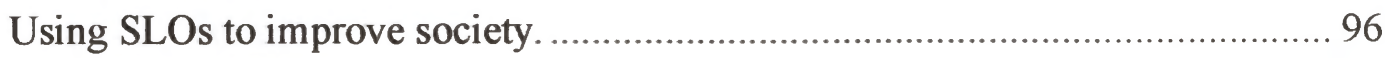

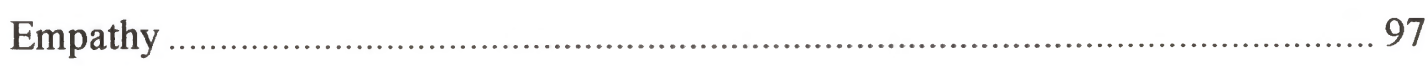

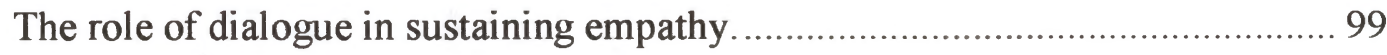

Dialogue Changed the Conversations About SLOA …................................ 100

Findings Validated by Coordinator Interview Data ...................................... 102 
Important Actions and Behaviors of the Engaged Practitioner

Aligning course content and activities with learning outcomes.

Promoting intra- and interdisciplinary alignment.

Making the learning process more transparent to students.

Focusing on critical thinking.

Restructuring time

Making Resources Available to Students

Encouraging the use of faculty time and institutional resources.

Findings Validated by Coordinator Interview Data.

Summary

Faculty Beliefs and Attitudes

Faculty Did Not Accept the Public Criticism of Teachers

Faculty Perceptions of SLOA

Alignment.

Student-centered learning that provides quality assurance.

Balance of Responsibility Between Faculty and Students 128

Responsibility for learning environment.

Responsibility for making expectations and content clear 
Taking it personally when students did not achieve

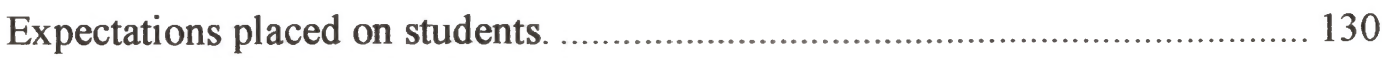

Change in Faculty Role ......................................................................... 131

A more scientific role ....................................................................... 132

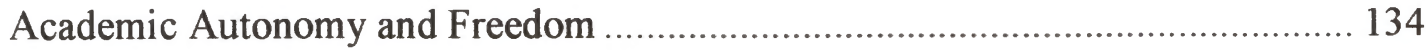

Restrictions to academic freedom as a red herring. ................................. 135

Faculty Believed SLOA Worked to Improve Teaching ............................... 136

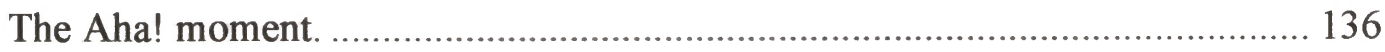

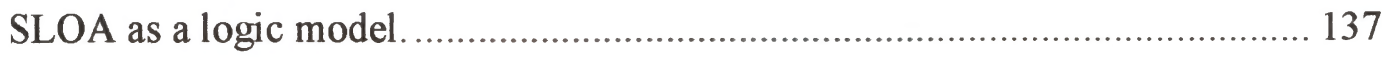

Faculty believed SLOA improved their own teaching practice...................... 138

Reluctance to Credit SLOA With Improvements to Student Learning ................ 140

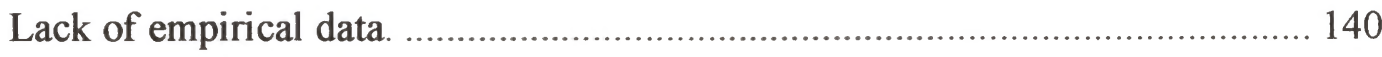

Reluctance to assume full responsibility for student outcomes..................... 141

SLOA identifies gaps in student knowledge and skills that need more time..... 141

Other valued outcomes were lost in the SLOA process. ............................... 142

Too many factors outside faculty control. .............................................. 143

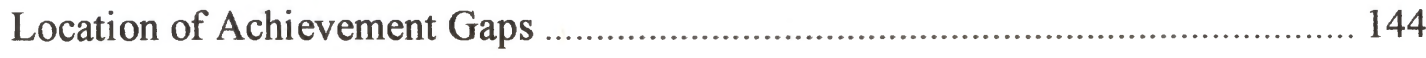

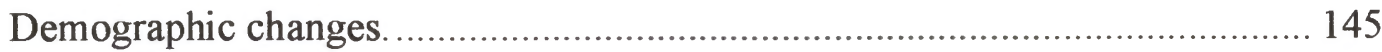

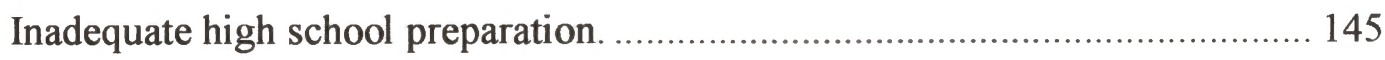

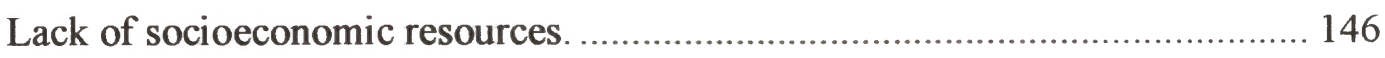


Disaggregating SLOA Data

More Faculty Engagement

A Call for Institutional Leadership

Findings Partially Validated by Coordinator Interview Data

Summary

CHAPTER 6: FINDINGS-PART THREE

The Roles of the Institution.

The Power of the Leadership 164

Faculty Senate and Union Leadership Attitudes Toward SLOA Are Important .... 165

Faculty Leadership Within Departments Was Critical to Success ..................... 167

Administrators Set an Institutional Tone ................................................... 168

Administrative Support for Faculty Leadership and Engagement..................... 172

SLOA Provided Opportunities for Faculty Leaders to Emerge .......................... 172

Faculty Participants Validated These Findings.................................................. 174

The Roles of Coordinators in Promoting Strategically-integrated Dialogue .......... 177

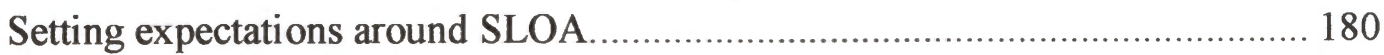

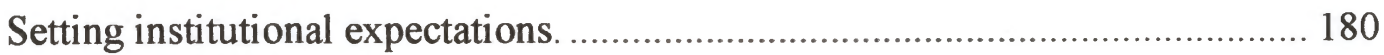

SLO coordinators acted on newly acquired perspectives........................... 182

Using processes to create engagement and design. .................................... 183

Focusing attention on teaching and learning. ......................................... 186 
Faculty Interview Data Validated Coordinator Interview Data ......................... 190

Coordinators Managed Faculty Resistance ............................................... 193

Helping faculty gain insights. .......................................................... 193

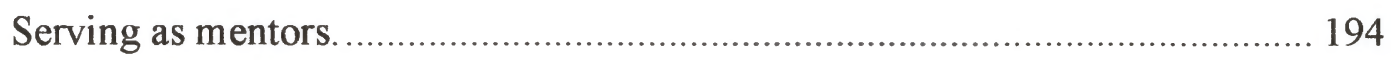

Witnessing a lessening of resistance ..................................................... 196

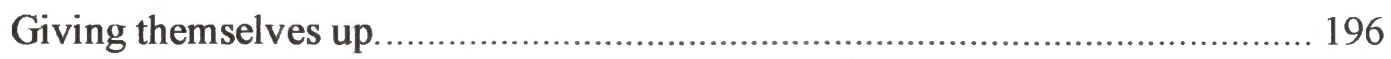

Faculty Participants' Data Partially Validated These Findings ............................... 198

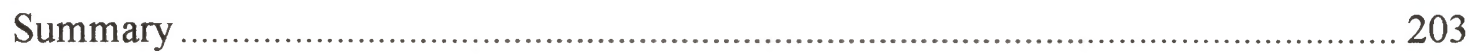

CHAPTER 7: DISCUSSIONS AND RECOMMENDATIONS ............................. 206

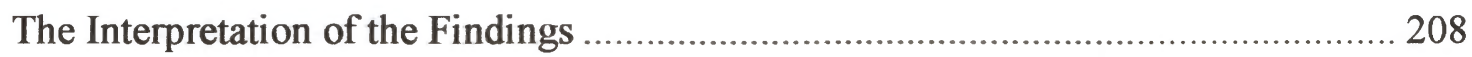

SLOA Works as a Change Process ................................................................. 209

Faculty believed SLOA improved teaching practice by changing the role of

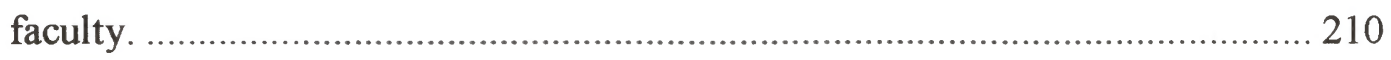

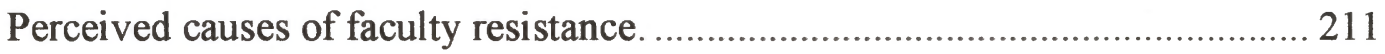

Faculty Did Not Perceive Learning Improvements as a Result of SLOA ............ 212

Faculty Responses to Using Disaggregated SLOA Data to Close Achievement Gaps

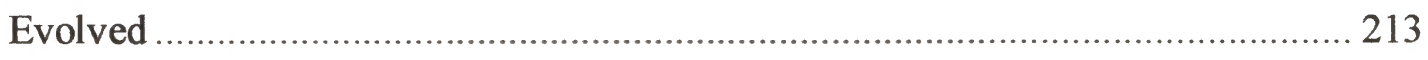

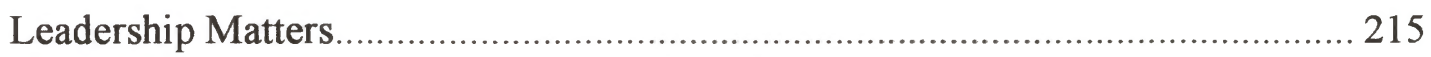

The SLO Coordinator Guiding Strategically-integrated Dialogue Created Change 
Equity Implications

Leadership Implications

Recommendations for Improving Teaching and Learning and Closing Achievement

Gaps 226

Limitations of the Study. 234

Recommendations for Further Study 234

Reflections on the Research Process. 235

Conclusion 237

REFERENCES 240

APPENDIX A 258

APPENDIX B 260

APPENDIX C 261 


\section{LIST OF FIGURES}

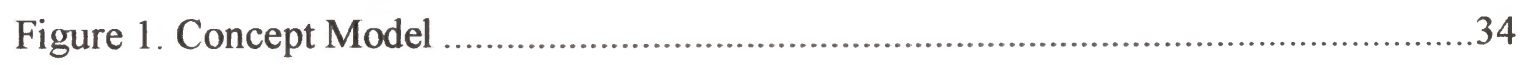




\section{LIST OF APPENDICES}

A. Interview Questions for Faculty Participants................................................258

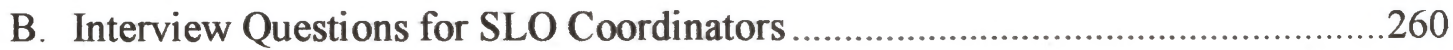

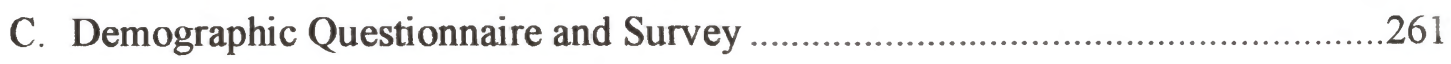




\section{CHAPTER 1: PURPOSE OF THE STUDY}

\section{Introduction}

This study explored the experiences of engaged student learning outcomes assessment (SLOA) practitioners at California community colleges. The goals of this study were to explore the reasons why some faculty members engaged with SLOA, how they engaged, and the impact of that engagement on their beliefs and perceptions about learning and teaching. In addition, this study explored faculty and coordinator participants' perceived effectiveness of SLOA to improve teaching and learning, including the use of SLOA to close achievement gaps between student demographic groups. The role of the institution in facilitating faculty engagement in SLOA was also considered.

The phenomenon of SLOA is an iterative process that includes identifying specific learning outcomes for courses and programs, designing assessments to measure student achievement of the outcomes, reflecting on the assessment results, designing changes to practice to improve student achievement of outcomes, then assessing the effect of implemented changes.

\section{Context of the Study}

The California Community College (CCC) system is the largest system of higher education in the United States. In 2016, 2.35 million students attended community college in California (California Community College Chancellor's Office [CCCCO], 
2017b). California students represent a large percentage of community college students in the nation, 24\% in 2011 (Community College League of California [CCLC], 2011). Most students enroll in community college intending to achieve an Associate's degree, earn a work certificate, or transfer to a 4-year university. California is relying on increasing numbers of students to attend community colleges, earn work certificates or degrees, and become effective members of the workforce (Committee for Economic Development [CED], 2013).

Another purpose of the California community college system is to provide access to higher education for all students regardless of prior academic experience (CED, 2013). The community college system accepts all students regardless of academic skill level or college preparedness. In addition, a disproportionate number of underrepresented students enroll in community college, creating a student population that more closely matches the demographics of California as a whole than student populations at the more selective California State University (CSU) and University of California (UC) systems. Academically underrepresented groups are population groups, typically Blacks, Latinos, and Native Americans, that have historically experienced fewer educational achievements than Whites and Asians. In the academic year 2015-2016, Latino, Black, Asian, and White students represented $46.2 \%, 6.4 \%, 11.5 \%$, and $27.3 \%$ of the statewide community college student population respectively (CCCCO, 2017b). These statistics generally correspond to the proportion of these demographic groups in the state, with Latino 
students attending community colleges in proportions larger than their share of the total population and White students attending community college in smaller proportions (CED, 2013).

There are over 60,000 faculty members teaching at community colleges in California, representing a highly educated group of professional instructors (CCCCO, 2017a). Most faculty members are required to have earned a Master's degree in the discipline they teach, and many hold Doctorates - the highest level of educational achievement. However, faculty members usually receive little to no training in teaching, learning, or assessment, and are expected to acquire these skills on the job, in the classroom. While many faculty members, almost 19,000, are full-time and benefit from tenure, twice as many, or almost 43,000 , are adjunct faculty who teach part-time with fewer benefits and no expectation of tenure (CCCCO, 2017a).

The faculty teaching California's community college student population represent a different demographic make-up than the students themselves. Like the college students, there are slightly more female faculty members than male. However, unlike the student population, in 2016 the faculty members were predominately White $(60.5 \%)$, with only 15.3\% Latino, 9.3\% Asian, and 5.8\% Black instructors. Non-tenured faculty divided into similar proportions (CCCCO, 2017a). These differences in the demographics of the faculty members and the student population become a topic of concern when efforts to close achievement gaps impacting predominantly Black, Latino, and Native American 
students require that a predominantly White faculty examine their assumptions about teaching and learning.

\section{Problem Statement}

For SLOA to effectively improve teaching and learning in California's community colleges, faculty need to fully engage in the process. However, educational reformers have identified a lack of faculty engagement as one potential underlying reason for the continued lack of evidence that SLOA improves student learning and success (Kuh et al., 2015). The lack of faculty engagement in best practices for teaching and learning is not a new problem, nor is it exclusive to California.

In 2005, after a 40-year career at UCLA teaching and researching on community colleges, publishing multiple editions of a widely accepted textbook on community colleges, and editing Community College Review, Arthur M. Cohen (2005) summed up the contradictions found in the research on the state of affairs in America's community colleges. There does seem to be room for improvement. Cohen found that community colleges vary widely in student populations and success rates. Some colleges create success rates for underrepresented students that exceed the overall success rates for all students at other colleges. However, the faculty, staff, and administrators have little control over the demographics or needs of their students. Cohen (2005) also captured the essential dilemma faced by community colleges with the tension between the following three statements. First, Cohen claimed that research since the 1960s and 70s had 
continued to demonstrate the power of clear student learning outcomes to positively affect student performance; second, colleges have not acted on this widely available information; and third, "practitioners understandably take a dim view of their being accused of discrimination, staff biases, and unresponsive pedagogy" (p. 55). It is this state of affairs in community colleges that allows reformers to promote SLOA as a logic model, which claims that student learning outcomes, practiced by some for decades, can work, if only faculty would engage.

However, the connection between SLOA and learning improvements has not been broadly and convincingly established. Using the evidence from SLOA and creating a culture of evidence in decision-making was expected to create effective innovations that would lead to improvements in learning (Baker \& Sax, 2012). A recent review of literature from the Community College Research Center showed no correlation between a culture of evidence at a college and improved student learning statistics (Bailey, Jaggars, \& Jenkins, 2015). Leaders like Pat Hutchings, from the learning improvement movement, and Peter Ewell and George Kuh, strong advocates for SLOA as an accountability measure for quality assurance in higher education, have each come to the recent conclusion that faculty engagement with SLOA is not sufficient to achieve the desired goals of improving learning and closing achievement gaps (Ewell, 2009; Hutchings, 2010; Kuh et al., 2015). In addition, the past 25 years of encouragement across the nation to use SLOA to improve student learning has led to only an "embarrassingly modest 
impact" on student learning (Kuh et al., 2015, p. 1). Kezar's (2013) review of empirical research on SLOA found little reference to evidence of improved student learning. In addition, the impact of faculty engagement in SLOA is not sufficiently understood to rely on this strategy for either improving learning or closing achievement gaps across the state (Baker \& Sax, 2012; Kezar, 2013).

For some SLOA experts, the reason for this lack of evidence of improved learning is because compliance measures, such as accreditation requirements, have derailed efforts by faculty to use SLOA to engage in authentic discoveries about how adults learn and to use that knowledge to improve the delivery of instruction and services (CCCCO, 2015). When accreditation requirements and avoidance of the punitive consequences of not meeting an accreditation standard become the rationale for putting SLOA into practice, too many faculty and administrators become so focused on directing resources and ensuring that all processes are in place, that there is little effort left for authentic engagement and dialogue about best practices for improving learning (CCCCO, 2015). It is possible for faculty and administrators to go through the motions of meeting the accreditation requirements without making real changes to what happens in the classroom. Of concern to many reformers, is how to change the "black box" of instruction so that learning improves (Elmore, 2004; Fullan, 2008). The solution still seems to be to encourage a larger portion of faculty to engage authentically with SLOA (Kuh et al., 2015). This study explores the experiences of faculty engaged with SLOA 
with the intention of using SLOA to improve their teaching practice, course design, and program development.

\section{The Study}

This is a collective case study of the phenomenon of faculty engagement with SLOA. Collective case studies are those in which a researcher considers multiple separate cases, such as individual interviews, at the same time (Fraenkel, Wallen, \& Hyun, 2012). This study is important and timely. Student learning outcomes assessment has been identified as a possible means of improving the quality of education and narrowing achievement gaps in California community colleges. The strong evidence of effectiveness in improving learning that could persuade more faculty members that SLOA works is missing (Kuh et al. 2015). For outcomes assessment to be effective, faculty members need to engage in assessment practices with the intent of improving their teaching practice, courses, and programs. Hutchings (2010) claimed that faculty engagement is the "gold standard" for effective SLOA that improves student learning in higher education. Yet Ewell (2009) claimed that faculty engagement levels remain too low to achieve the goals of educational reform in community college classrooms. Engaged practitioners are those faculty members who go beyond the minimally required SLOA reporting and intentionally use SLOA to improve their teaching, courses, or programs.

Engaged SLOA practitioners negotiate an array of potentially conflicting messages and feedback about how best to improve student success. These messages and 
feedback include professional training experiences, expressed values of institutional leadership and colleagues, student feedback, and SLO data. Engaged SLOA practitioners then make choices about how to respond. The process of negotiating this feedback, with the intention of making changes to improve learning, potentially changes the beliefs, actions, and perceived role of engaged SLOA practitioners. By exploring the experiences of engaged practitioners, including their shared characteristics, beliefs, and identified barriers and facilitators to engagement, suggestions for institutional practice were gleaned that might promote increased faculty engagement in SLOA.

\section{Research Questions}

Within this context of using SLOA to improve student learning, collective case study methods were used to explore qualitatively the following questions:

1. Why do faculty members become engaged SLOA practitioners?

2. What are the important behaviors, attitudes, and actions of the engaged practitioner that occur when engaged in SLOA?

3. What do engaged faculty believe about SLOA, teaching, learning, and achievement gaps?

4. What are the important behaviors, attitudes, processes, or structures at an institution that influence engagement in SLOA?

Grounded theory methods were used to evaluate interview data provided by SLO coordinators and engaged SLOA practitioners. Data analysis involved open coding for 
thematic analysis related to the following topics: faculty engagement, the role of leadership, institutional support for engagement in assessment, improvement strategies, faculty mindsets, changing faculty roles, and the perceived potential impact of assessment on both learning and achievement gaps.

\section{Operational Definitions}

\section{Student Learning Outcomes Assessment}

Student learning outcomes assessment (SLOA) is a phenomenon community college faculty engage in with the goal of improving student learning outcomes. In a collaborative process, faculty agree on common learning outcomes for each course and program and design assignments to assess whether or not students achieved them. Scores are recorded for student performance on specific learning outcomes (SLO). Faculty reflect on assessment data with the intent of making changes to their practice in order to improve outcomes. Those changes are then assessed for effectiveness. Ideally, this process, engaged in by multiple faculty across multiple institutions, can help identify best practices for teaching and learning.

\section{Disaggregated Student Learning Outcomes Assessment}

Disaggregated student learning outcomes assessment data is SLOA data broken down by student demographic groups. By reflecting on differences in performance, faculty might devise strategies to address achievement gaps between demographic groups. 


\section{Action Research}

Action research is described by (Fraenkel et al., 2012) as research aimed at solving a problem or informing local practice. Individuals involved in the local practice are included in the research process.

\section{Theory of Change}

Fullan (2006a, 2006b, 2008) identified an effective theory of change for educational institutions that included peer-facilitated, collaborative reflection on local data by local practitioners.

\section{Early Adopter}

Rogers (2003) described early adopters as those individuals willing to engage in innovation prior to others. Early adopters share characteristics including an openness to change and risk and an appreciation for science. They also express self-efficacy and empathy. In addition, individuals are more likely to be early adopters when the innovations align with their pre-existing values and experiences.

\section{Engaged Student Learning Outcomes Assessment Practitioner}

The engaged SLOA practitioner is a faculty member who actively participates in the process of SLOA with the intention of using the process to improve teaching practice, course design, or program development.

\section{Student Learning Outcomes Coordinator}


The SLO coordinator is an individual, usually a faculty member, responsible for coordinating SLOA activities at the institution (Academic Senate for California Community Colleges [ASCCC], 2007).

\section{Strategically-integrated Dialogue}

The term strategically-integrated dialogue describes the system of communication and reflective dialogue created by SLO coordinators to facilitate SLOA, as revealed by this study. This system of dialogue moves horizontally across departments and divisions at the college. Strategically-integrated dialogue also moves vertically, using data produced at the classroom level to inform institutional planning decisions and using accreditation standards for the use of SLOA to inform dialogue at the course and program levels.

\section{Scope of the Study}

While based on a limited number of participant interviews, the scope of this study is substantial. The selection of SLOA as a research topic was due to the high level of reliance on SLOA to improve student learning to drive social change. At the same time, whereas the logic model supports SLOA as an effective tool for improvement, the lack of evidence to justify such a reliance created a desire to learn more. The research questions lead to explorations of almost every aspect of faculty participation in SLOA. Faculty willingness to participate in SLOA, as a phenomenon, is influenced by many factors, including educational and work experience, intrinsic motivation for improvement, and 
personal values. The actions taken by faculty when responding to SLOA data have the potential to improve the quality of community colleges across California. Understanding how engagement with SLOA affects faculty beliefs about students and learning is crucial to better facilitate such engagement. The inclusion of institutional facilitators and barriers as part of this study is a logical outgrowth of previous lines of inquiry and furthers the opportunity to identify promising institutional practices that increase faculty engagement. The use of semi-structured, in-depth interviews allowed for the participants to describe their experiences and insights into the SLOA phenomenon.

\section{Organization of the Dissertation}

This study is organized as a standard dissertation. Chapter 2 provides a review of the relevant literature, including a history of the circumstances leading up to the implementation of SLOA in California's community colleges. Chapter 3 provides an explanation of the methods used to conduct the study. Chapters 4,5 , and 6 each present a portion of study findings organized by both research question and source of primary information. Chapter 7 discusses the findings as a whole in conjunction with the conceptual framework and supporting theories and makes recommendations for action at community colleges. 


\section{CHAPTER 2: LITERATURE REVIEW}

Reform efforts in higher education is a broad topic, narrowed in this literature review by focusing on the problem of insufficient faculty engagement in SLOA along with facilitators and barriers to the implementation of SLOA in California Community Colleges.

\section{Scope of the Literature Review}

This literature review is based on articles published by assessment experts working with the National Institute for Learning Outcomes Assessment (NILOA), primary sources from the regional accreditor for California and the $\mathrm{CCCCO}$, and peerreviewed empirical studies primarily produced within the last 15 years. Search terms focused on community college learning outcomes assessment, academic freedom, action research, early adopters, faculty beliefs, equity, achievement gaps, and SLO coordinators. In addition, the reference lists of peer-reviewed articles led to additional key sources on assessment, student learning, and models for successful change.

\section{Structure of the Literature Review}

Concerns about the quality of higher education in the United States focus on the roles and responsibilities of faculty to better meet the learning needs of an increasingly diverse student population. Cohen (2005) identified the tensions that resulted as faculty responded to perceived accusations of bias and ineffectiveness. Those tensions remain present on community college campuses today and are part of the context within which 
SLOA takes place. As a result, a history of the changing means to measure quality in higher education, including potential changes to faculty roles, begins this literature review. The development of SLOA as a solution to improve the quality of teaching and learning is also described. The conceptual framework that shapes this study includes a concept model identifying the components necessary for using SLOA to engage in change. Included in the explanation of the concept model are supporting theories that potentially explain distinct portions of the SLOA phenomenon. The supporting theories for creating and sustaining change focus on five key aspects of the SLOA phenomenon: initial individual engagement in SLOA, individual actions taken, beliefs about SLOA, causes of resistance, and the institutional context within which SLOA takes place. First, why and how faculty engage in SLOA is potentially explained by Rogers' (2003) theory of diffusion of innovations, Fullan's (2006a 2008b, 2008) theory of change, Bensimon's (2005) theory of equity mindsets, and Tagg's (2012) causes of resistance. Each theoretical explanation is followed by a brief summary of related empirical studies. Second, a review of the empirical articles on SLOA highlights the challenges to individual faculty engagement, especially the lack of evidence supporting SLOA and causes of faculty resistance. Third, faculty engage or resist participation in SLOA within an institutional context, culture, and structure. The roles of the institution in providing leadership, structure, resources, and encouragement or discouragement for engagement, 
are important facilitators or inhibitors. Finally, the alignment of reform efforts with the conceptual framework is discussed.

\section{Context of the Problem}

This study explores student learning outcomes assessment, or SLOA, the proposed solution to a widespread concern that the learning experiences of community college students need improvement. The phenomenon of SLOA explored in this study takes place within a complex array of circumstances. Education has long been viewed as an avenue for social change, both on the individual and the group level. California's Master Plan for Higher Education takes this into account (CED, 2013). Students demonstrating better academic preparedness are accepted to the 4-year CSU and UC systems. The community colleges provide an avenue of open access to all students. At the same time, discrepancies in academic achievement between demographic groups reflect and parallel historic patterns of discrimination and limited social, economic, and political opportunities for certain groups, particularly Blacks and Latinos. Community colleges in California, while held up as an exemplar of success for creating opportunities for all students to achieve in higher education, struggle to overcome the same deeply embedded inequities present in the larger society.

For example, students desirous of a baccalaureate degree who begin their higher education career in community colleges are less likely to achieve that degree than their comparable peers who enroll directly into 4-year universities (Long \& Kurleander, 2009). 
Although the educational goals of community college students are more varied than the goals of students at 4-year universities, community colleges across the nation have a graduation rate of only $39 \%$ (Juszkiewicz, 2015 , p. 3). In part, this is due to a need to provide additional remediation of academic skills. In $2009,68 \%$ of entering community college students across the nation needed basic skills remediation in either English, math, or both (Community College Research Center [CCRC], n.d.). This means community colleges must focus a substantial portion of their resources helping students meet college level academic readiness as well as providing college level coursework applicable to either a degree or transfer.

Students arriving at community college underprepared for college level coursework were less likely to achieve their goals. In California, students who arrived on campus ready for degree-level coursework were almost twice as likely as their underprepared peers to have achieved a certificate, degree, or transfer (CCCCO, 2016b). This effect is larger for underrepresented groups, particularly Blacks and Latinos, than for traditionally more successful students, which perpetuates unequal outcomes for historically underrepresented students (Geiser \& Atkinson, 2010). In California, these differences in academic success rates lead to disparities in overall academic achievement (CED, 2013). These concerns have driven changes to the measures used to assure quality in higher education. 


\section{A History of Quality Assurance in Higher Education}

The high level of national concern about the quality of higher education provided by community colleges, the expectation for access to higher education to serve as a palliative for deeply embedded social inequities, and the focus on faculty as the solution to educational improvement, as well as faculty resistance to perceived accusations of bias and ineffectiveness, warrants the provision of a substantial background on quality assurance in higher education. This history reveals a shift in the expectations placed on community college faculty from being content experts in a specified field of study to being experts in assessment and curriculum development. Changes in federal, accreditation, and state requirements have increased the reliance on outcomes assessment to demonstrate institutional quality. In response, professional development efforts increasingly recognize the need to support faculty engagement.

To assure the quality of postsecondary education, several levers are applied. The first lever relies on a trusted professoriate, protected by academic freedom and expert in their field (Tagg, 2012; Whicker, Kronenfeld, \& Strickland, 1993). The second lever is an external accountability enforced through accreditation standards that each institution must meet (Ewell, 2009; Hutchings, 2010). As of 2002, these accreditation standards include the use of SLOA. In California, the combined new state reporting requirements that rely on SLOA to demonstrate effective learning improvements and improved student 
outcomes are the third lever. These state reports are tied to funding, making engagement in SLOA critical to demonstrating institution effectiveness.

\section{The Trusted Professoriate}

Since higher education was first offered in the United States, faculty members have been responsible for designing courses, shaping curriculum, and developing pedagogical strategies to impart to students the insights and values relevant to their particular area of expertise. The establishment of expertise in a particular field is conducted through a sequence of coursework, degree granting, and peer review that ideally leads to a granting of tenure (Whicker et al., 1993). These faculty experts design instruction and materials to instill in students the values, knowledge, and beliefs of their specialized areas of knowledge. Such trust in faculty expertise is expressed in the granting of faculty tenure in response to discipline specific research and publication success. With tenure, faculty also expect a level of academic freedom that allows for a great deal of autonomy in the highly individualized professional experiences of faculty members (Tagg, 2012).

\section{Increases to External Accountability}

However, since 1965, as the federal government's share of the cost of higher education has increased, the federal government has also taken an interest in improving the quality of community college educational outcomes (Ewell, 2009; Hutchings, 2010). The federal Department of Education uses institutional accreditation standards to 
mandate changes (Eaton, 2015). Standards have increased over the past several decades, with each set of revised standards adding to the reporting requirements necessary to be identified as an accredited institution. The changes in accreditation standards represent an attempt to improve the quality of higher education in the United States (Ewell, 2011). Two-year California community colleges are overseen by the Accrediting Commission for Community and Junior Colleges (ACCJC), which creates a set of published accreditation standards used to measure the quality of community colleges (ACCJC, 2017). The accreditation standards cover all aspects of an institution's educational services, including the proportion of full time faculty with the appropriate degrees (Umbach \& Wawrzynski, 2005), sufficient technological tools to manage the services provided to students and to maintain student records, adequate financial planning for institutional stability, and processes for measuring student success (Eaton, 2015).

For California community colleges, the evolution of accreditation standards can be viewed as transitioning from a measurement of quality inputs to the current measurement of quality outputs. Prior to 2002, accreditation expectations required community colleges to ensure that they had a sufficient number of current library books on hand in a wide variety of subjects and that courses were taught by faculty in possession of the correct degree to teach the courses offered (Umbach \& Wawrzynski, 2005). Discipline level program quality was ensured through a program review process that documented the varied advanced degrees and discipline specific publication 
successes of the faculty, the wide variety of course offerings in the subjects of interest to students, and the quality of the courses demonstrated by the number of students enrolled each semester and the grades distributed (Ewell, 2009). These accreditation criteria were based on an assumption that provided with the right resources, students would be successful.

Introduction of SLOA. After 2002, in response to greater calls for accountability in higher education, evidence of student achievement at an institutional level-for example, the number of certificates granted or number of students transferring to a 4-year school — was added to the accreditation standards for all community colleges (ACCJC, 2004). Community colleges were also asked to put in place processes for measuring student learning outcomes to demonstrate institutional effectiveness. At the program or discipline level, faculty members were asked to identify specific learning outcomes for each course offered, to define measurements for each learning outcome, and then to report, in a program review document, how many students met the learning outcomes (ACCJC, 2004). Whereas student achievement is measured by the number of courses passed or degrees earned, learning outcomes are measured by the attainment and demonstration of specific knowledge or skills. For example, faculty in a particular department might determine that students demonstrated the outcome of logical reasoning and analysis in a course by sufficiently analyzing course content and incorporating their findings into an essay. A rubric designed to measure student essays for analytical depth 
or critical thinking could be used to assess student learning outcomes (Cabrillo College, n.d.-b). Faculty could then share assessment results with colleagues and discuss methods to improve student performance (Cabrillo College, n.d.-a). This information from various educational programs could be combined and added to an overall assessment of the college's institutional effectiveness (Bontenbal, Buechner, Mcginnis, \& Wulff, 2014). The 2002 ACCJC accreditation standards assessed effectiveness by evaluating the sufficiency of SLOA processes the institution had in place.

Introduction of disaggregated outcomes data. Over the past 10 years, education policy groups then led a national movement advocating the use of SLOA as a tool to address achievement gaps between gender and ethnic groups. Groups such as NILOA, and research centers such as the CCRC at Teacher's College Columbia University (Completion By Design, n.d.), published reports supporting such use of learning assessments (Ewell, 2009). In addition, in 2006 the federal Department of Education published a report on issues facing the nation's community colleges (Spellings, 2006). This report, A Test of Leadership, summarized reports prepared by the Department of Labor, the Department of Education, the Stanford Institute for Higher Education Research, the Chronicle of Higher Education, and the College Board, among others. The report also relied on United States census data and testimony presented to the commission charged with producing the report. Often referred to as the "Spellings Report," the summary of research concluded with calls for a heightened level of data- 
driven accountability for student learning, institutional efficiency, and closure of academic achievement gaps. To address what was described as a national crisis, the Spellings Report recommended that closing the achievement gap across community college student populations be a primary goal of accreditation agencies (Spellings, 2006).

As a result, in 2014, revised accreditation standards in California intentionally shifted from an assessment of sufficient SLO processes to an evaluation of the resulting outcomes themselves to gain a reaffirmation of institutional accreditation. These assessments required more in-depth, equity-focused outcomes reporting by faculty and were added to the measurements of institutional quality (ACCJC, 2014). Institutional self-evaluation guidelines produced by ACCJC make this new emphasis clear (ACCJC, 2017). New reporting mandates require faculty members to not only identify and assess specific learning outcomes for each course, but, if the outcomes assessment results are unsatisfactory, to design improvements to the program design, course curriculum, or teaching methods to improve student performance. In addition, faculty are asked to break down learning outcomes performance results by racial and ethnic group at the program and course level (ACCJC, 2014; Beno, 2013). If performance differences are found between different racial and ethnic groups, faculty members are asked to analyze their causes, design pedagogical changes to address such differences, and then assess the changes made to determine if they were effective (ACCJC, 2014; Bontenbal et al., 2014). 
The SLOA assessment findings, evaluations, and improvement strategies are to be written into program review documentation and linked to institutional funding decisions.

For example, if Latina students were significantly underperforming, an instructor might include more Hispanic American readings to make the course more relevant and engaging for Latina students (Aspen Institute, 2013). A funding request for supporting learning materials might be included in program review. Then, during the next program review, student performance data would be examined to see if such pedagogical changes improved student learning outcomes and improved the performance of Latina students. The same could be done for Black or Native American students, as all three groups tend to disproportionally underperform in California's system of higher education (CED, 2013).

Overall, in response to lower performance on the part of any group, faculty might revise curriculum to include content of greater interest to particular students, replace course content with academic skill building exercises, or engage more directly in the lives of students by paying close attention to attendance and calling students at home to encourage them to return to class (Wang \& Hurley, 2012). In short, ACCJC requires that faculty frame their instructional decisions in ways that can be expected to increase equity across student populations (ACCJC, 2014). It also requires the institution as a whole to focus its resources toward improving student learning and making documented decisions that fund the most effective strategies. These assessment changes-from measuring 
inputs to requiring evidence of processes that prompt dialogue about student learning, and to requiring evidence of learning outcomes resulting from those strategies - also change the role of faculty (Tagg, 2012).

New California state reporting requirements align with federal and accreditor reporting requirements. Actions taken by the $\mathrm{CCCCO}$ further encourage the use of SLOA as an accountability measure. For example, the CCCCO recently renewed the requirement that all community colleges write a student equity plan. These measures urge transformational change based on locally implemented plans to close achievement gaps. Each community college must use student achievement and SLOA data to evaluate five key indicators: access, basic skills completion (math, English, and English as a Second Language), course completion, certificate completion, and degree achievement (CCCCO, 2016a). Using student achievement and learning outcomes data, colleges are required to identify access or achievement gaps for student groups in each of these five areas, devise plans to close those gaps, then assess their success. Ideally, the disaggregation of student achievement and success is analyzed within each department's program review process, which also includes plans to address achievement gaps and overall student success (CCCCO, 2016a). Such requirements place a substantial amount of responsibility on faculty to ensure that plans are implemented and assessed and that goals are met to continue to receive funding. 
Professional development programs for faculty support desired changes. The CCCCO is also providing support, in the form of professional development, for faculty to gain the capacity necessary to achieve these goals. The California Community College Success Network (3CSN, 2014a) is an initiative of the California Community College Chancellor's Office. The goal of $3 \mathrm{CSN}$ is to promote professional development among community college faculty focused specifically on teaching practices that improve student achievement. In its stated goal to increase the capacity of community colleges to serve underrepresented students, $3 \mathrm{CSN}$ is intended to be transformational (3CSN, 2014a), changing community colleges from places where many students desirous of higher education face too many barriers to succeed, into a place where students are transformed into agents of success. The key to achieving this goal is transformation of faculty. The 3CSN initiative aims to increase capacity by creating networks of faculty working together to improve their own teaching practice. As such, $3 \mathrm{CSN}$ is itself a network-a dialogue community - of initiatives that serve as $3 \mathrm{CSN}$ components.

The $3 \mathrm{CSN}$ theory of change. The $3 \mathrm{CSN}$ initiative explicitly claims to operate on the following theory of change:

If we provide training on networking and we use action research methodologies, community college professionals will transform their environments and identities to create communities of practice that will 
produce powerful learning and working across campuses. This will lead to greater student success. (3CSN, 2017, par. 1)

The theory of change provided by $3 \mathrm{CSN}$ reflects expert understandings and advocacy to create successful change of and within the entire California Community College (CCC) system. The mission of the CCC system is provide access to higher education for all students who desire it. These changes aim to address historic disproportionate achievement rates in CCCs that run counter to their mission. As such, the penumbra of changes to the assessment of the quality of community colleges align with a goal to use accountability measures to create overall social change in California.

\section{Solutions for Improving Results at Community Colleges}

Not everyone agrees that increased accountability measures in community colleges will lead to improved learning and closing achievement gaps. A substantial body of research describes challenges faced by historically underrepresented students in higher education. Looking beyond higher education institutions at poverty, lack of parental education, and inadequate K-12 preparation, some research explains causes of achievement gaps (Ginwright, 2004; Wilson, 2009) that are largely outside of community college faculty control. These studies explain the underachievement of underrepresented students based on the assumption that past experiences have ill prepared students for college success and that such students lack the resources and skills that would help them be successful in higher education. Bennett and Brady (2012) claim that SLOA is a 
distraction from the real causes of achievement gaps, such as conditions that correspond with economic challenges. Reardon's (2011) economic study supports this claim, finding that achievement gaps between richer and poorer students were 10 times larger than the achievement gaps between Black and White students. For these researchers, addressing large-scale disparities in socioeconomic conditions will address educational achievement gaps.

For others, the key to improved student learning and achievement resides within the institutions and classroom themselves (Bensimon, 2005; Elmore, 2004; Fullan, 2008; Hutchings, 2010). Looking inside the community college institution, new questions focus on how institutions can better meet the needs of students. For example, instead of offering a potentially confusing array of coursework to choose from, community colleges can intentionally organize themselves into larger contextualized pathways with support services embedded at each transition point (Bailey et al., 2015). Colleges can also focus on needed skill building for academically underprepared students. The 3CSN professional development services (sponsored by the $\mathrm{CCCO}$ ) assist faculty in teaching reading, accelerating basic skills completion, and instilling growth mindset in students (3CSN, 2014b, 2014c, 2014d).

These improvement methods are dependent upon evaluating student achievement and student learning outcomes data to determine the most effective learning improvement strategies. Student achievement outcomes and student learning outcomes differ. Student 
achievement outcomes represent concrete accomplishments, such as passing a class or achieving a degree. Improvements to student achievement are evaluated by analyzing trends in student course completions, transfer rates, and degree or certificate completion rates. Grades are also different from learning outcomes. Grades represent the cumulative score of all assignments and demonstrations of skill in a course. Grades include final combined scores of all extra credit assignments, participation, quizzes, and essays. As a combined score, grades represent measures of student achievement, the analysis of which does not necessarily impact teaching practice.

\section{SLOA as a Solution that Impacts the "Black Box" of Instruction}

Student learning outcomes assessment has the potential to change what happens in the classroom to improve student leaming (Hutchings, 2010; Kuh, Jankowski, Ikenberry, \& Kinzie, 2014). The 2006 A Test of Leadership report from the Department of Education (Spellings, 2006) connected the goals of improving educational achievement, especially among traditionally underrepresented students, with the use of SLOA as an accountability measure. SLO assessment scores, when used to determine if students overall are satisfactorily meeting the learning goals of the course or program, can effectively change teaching practice: Faculty members explore possible reasons for lower than satisfactory outcomes on discrete skills and devise improvements to teaching practice, course curriculum, or program design. Reassessing the outcome provides an opportunity to see which improvement strategies were most effective. Over time, this 
iterative cycle of assessment and improvement is expected to improve student learning and the quality of community colleges in the United States. To support faculty in these efforts, community colleges have hired SLO coordinators to assist faculty with assessments, provide professional development opportunities to interpret results and plan improvements, and assist with institutional reports on assessment progress and improvements.

\section{SLOA as Action Research}

Outcomes assessment is a form of action research. Action research is recognized as a standard methodology for solving local problems. Fraenkel et al. (2012) define action research as research conducted by participants engaged in the process being studied. The goal of action research is "to change conditions in a particular situation in which they are personally involved" (Fraenkel et al., 2012, p. 14). Action research is well suited for teaching and educational professionals desirous of solving an identified problem within the local context. Fraenkel et al.'s (2012) example of an action research question works well for driving classroom based research using disaggregated SLOA data, asking, "How can content, teaching strategies, and learning activities be varied to help students of differing ages, gender, ethnicity, and ability learn more effectively?" (p. 589). Whereas single incidents of local action research are difficult to generalize into the larger field of education, engaging in similar research across institutions can help identify effective best practices. 
Participation and reporting requirements of SLOA fit this action research definition and purpose. In addition, Fraenkel et al. (2012) identify action research as appropriate when attempting "to empower participants or bring about social change" ( $\mathrm{p}$. 611) and SLOA is also aimed at empowering participants (ASCCC, 2010) and bringing about social changes (Spellings, 2006). Further, the identified threats to the validity of action research, "data collector bias, implementation, and attitudinal threats" (Fraenkel at al., 2012, p. 612), were all identified by this study's participants as challenges faced when attempting to effectively conduct SLOA (See Chapter 6).

While engaged in SLOA, faculty members are serving as researchers in their own classrooms and producing data that can be used to drive strategic improvements at the course, program, and institutional levels. Faculty keep track of student scores on specific assessments and if scores are recorded individually, similar to the record keeping practices of individual student grades, assessment results can be disaggregated by student group. This means that the data generated can explore whether or not there are differences in performance by age, ethnic identity, income, race, gender, and more. If differences exist, improvement strategies can be tailored to meet the needs of specific student groups - and potentially close achievement gaps. The intent is to produce a quantity and quality of knowledge and understanding about the teaching and learning process conducive to improvements in the overall learning experiences for students (Bensimon \& Malcom, 2012; Hutchings, 2010, Kuh et al., 2015). If all faculty members 
are actively engaged in pursuing the best methods of teaching and course delivery, especially if they pay attention to differences in learning outcomes by group, entire institutions can move toward more equitable learning outcomes for all students (Bensimon \& Malcom, 2012).

\section{Conceptual Framework}

The conceptual framework for this study derives from combining a selection of theories on change that each potentially explain distinct portions of the SLOA phenomenon. Together these theories help explain the experiences of engaged SLOA practitioners. The development of this conceptual framework is the result of my personal desire to understand why SLOA was such a controversial education reform combined with a reading of the literature aimed at trying to discover if SLOA worked to improve teaching and learning, and if not, why.

The decision to intentionally engage in SLOA can be personal, as it was for me. I have always wanted to teach. I recognized the value in education from a very early age. I come from a family that is blended in several ways. My mother was a single 16-year old high school dropout when I was born. A few months later she married my dad, a Vietnam veteran. He used the GI Bill to become the first in his family to graduate from college and then the first Spanish-speaking Latino to join the Orange County Police Department in California. I became increasingly aware of the challenges she faced due to a lack of education, and that he faced being a minority in law enforcement. In addition, my own 
path through college was non-traditional. Instead of going straight to college after high school, I worked and took care of my mother. Community colleges offered me the opportunity to attend classes, sometimes at night while working full time, then later after my husband came home and assumed care for our son. I attended three community colleges and two universities before accumulating enough units to earn a Bachelor's, the first woman in my family to do so. But I wanted more. My goal was to teach at a community college and to help other non-traditional students achieve their own goals.

These insights informed both my undergraduate and graduate research in history where I focused on the experiences of women, African Americans, and Latinos. I graduated with my Master's, my third child on the way. Securing a tenure-track history position in a community college, where I could use my insights and energies to improve lives, was the next logical step. And while I did secure a tenured position, I also found out that there is more to successfully helping students achieve their goals than being an engaging and understanding instructor.

I decided to pursue a doctorate in education to better understand the difficult position I found myself in as a newly tenured social sciences faculty member attempting to negotiate educational reform politics within my own department. Just weeks before my tenured status was to become official, the institution was put on "show-cause" by the regional accrediting agency, the lowest status possible before losing accreditation. One of the main reasons was because we did not comply with the state regulation to implement 
SLOA. It was possible to be an active, engaged, dedicated faculty member at my institution and be completely unaware of SLOs. My department leadership was committed to resisting them. The SLOs were not even part of the discussions taking place. The show-cause decision changed that. We needed SLOs and we needed them fast. Once explained, SLOs made immediate sense to me. I recognized in SLOA a logic model that could be a tool for solving challenges faced by my department. Newly empowered, I volunteered for a leadership role to implement SLOs in my discipline - and ran straight into a wall of resistance that quickly became personal. Colleagues whom I recognized as smart, dedicated, and engaged questioned my motives and my judgment. They assured me that SLOs were just another educational fad, wrapped up in accusations of professional incompetence and even racism—and I was falling for it. The experience was painful.

I needed to reconcile the logic model of SLOA that made instant sense to me as a reform tool with the feedback I was receiving from my respected colleagues. My informal preliminary study focused on faculty members in the social sciences who openly and ardently resisted SLOA. I explored their values, their ideas about what students need to learn and why. They were insightful, cared about student development, and wanted students to become the best human beings they could. I observed their teaching. They were engaged: They engaged the students. I asked them about their lives. They were actively committed to social justice beyond the classroom. But they believed SLOs to be 
yet another misguided attempt to de-professionalize the academy and undermine social progress. These resistors made a persuasive case and left me unsure of what I believed.

\section{The Concept Model}

That lack of surety led me to keep reading, but now with a more critical lens. My goal was to answer the umbrella question, "Does SLOA work?" This questioning led to a concept model that might help explain how SLOA, as an ongoing change phenomenon, could work. The concept model that emerged identifies three key components necessary for change: cognitive framework, change processes, and institutional context. Figure 1 is a diagram of this concept model.

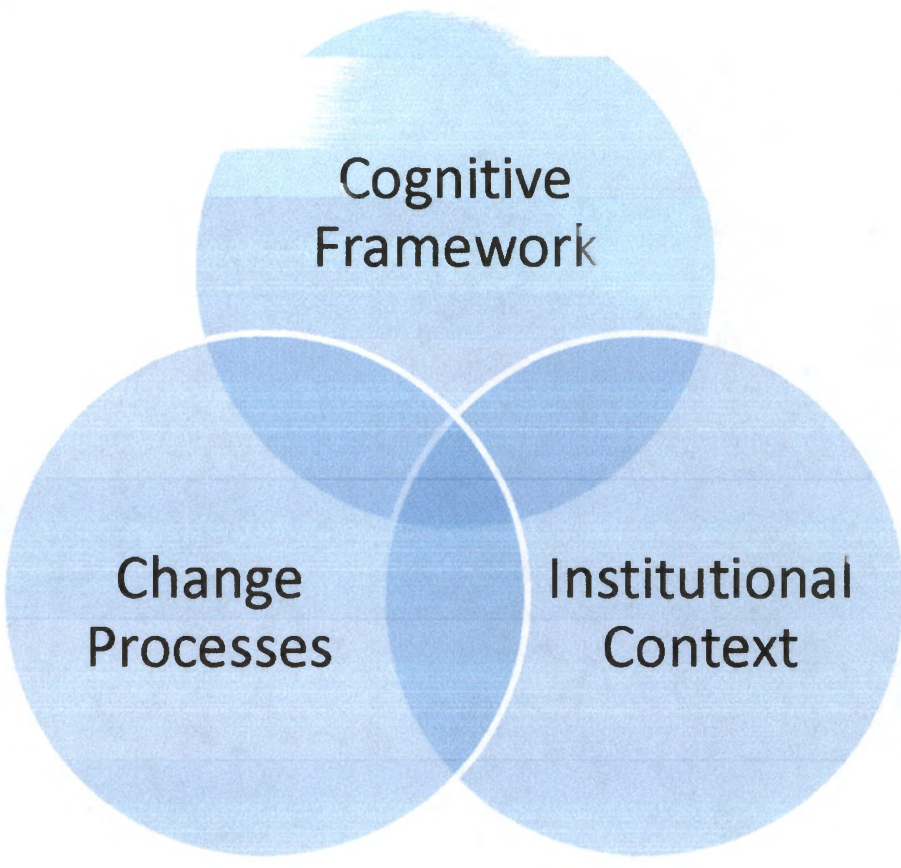

Figure 1. Concept Model. 
One's cognitive framework is an important factor in whether or not an individual engages in a reform activity. Rogers' (2003) diffusion of innovation identifies those who first take on innovative activities as early adopters. Early adopters share common personal characteristics and their values tend to align with goals of the proposed change. Rogers also proposes that individuals with more empathy are more likely to attempt innovation. Bensimon (2005) further theorized that faculty members' beliefs about student learning affect their responses to assessment data, specifically as regards gaps in the performance of different student groups. Faculty with a deficit or diversity framework will assume that differences in the disaggregated performance of different student populations result from conditions outside of their classrooms, conditions over which they have no control. These faculty members might be less likely to make changes to their teaching practice when they find achievement gaps among the student groups enrolled in their classes. Faculty members with an equity mindset assume that achievement gaps are a result of student learning conditions in the classroom, conditions over which the faculty member does have control. These equity-minded faculty use the results of learning outcomes assessment to make changes to their teaching practice, courses, and programs (Bensimon, 2005). Tagg (2012) identified circumstances when faculty might resist change, for example, when the change presents a threat to what they perceive as valuable in their role within the organization. 
A successful change process also has key elements. Fullan (2008) identified the understanding of the "black box of instructional practice" (p. 5) as a missing component from educational reform. He identified the most promising reforms as those that focus on aspects of successful change, such as results and reflection within the context of the faculty member's teaching environment. This focus increased faculty capacity to change the underlying assumptions preventing learning in the current system. Faculty members do this by focusing on assessment data from their own classrooms. Thus, SLOA fits Fullan's (2008) definition of a promising reform that might impact instructional practice.

Finally, the institutional context in which a change activity takes place impacts participant responses. If it was assumed that most colleagues were resistant to the change, individuals were less likely to participate willingly. Leadership within the organization also plays an important role. Both Rogers (2003) and Fullan and Knight (2011) identify specific leadership roles as resources that promote dialogue about feedback, support for individual change activities, and connections between the needs of the individual participants and the needs of the larger organization. In addition to supportive leadership, dialogue with peers also influences change (Fullan and Knight, 2011; Rogers, 2003). When an institution provides resources in the form of time to engage in dialogue, an infrastructure that facilitates dialogue and promotes the use of the results of dialogue (Willard, Dearing, and Belair, 2004), and demonstrates that the institution values the activities and its results, more individuals are likely to participate (Wang \& Hurley, 
2012). When more individuals participate, the results are more likely to be effective (Hutchings, 2010; Kuh et al., 2015).

\section{Theories Supporting the Conceptual Framework}

Overall, the combination of increased external quality assurance measures and requirements that faculty engage in equity-minded, improvement-focused, action research situates SLOA as a key tool for using educational improvements in community colleges to drive social change. Social change is a complex phenomenon. Faculty engaged in SLOA have the potential to transform institutions into drivers of social change. In doing so, engaged faculty must negotiate multiple sources of information and feedback, including responses and reactions from faculty peers, college leadership, students, as well as data, and their own ideas about teaching and learning. The phenomenon of SLOA engagement is an iterative cycle with multiple opportunities for faculty responses, including the distinct decisions to participate, to engage with peers, to attempt innovation and change, to face critical feedback, to reflect on the process, and to continue engaging. Several theories explain who is most likely to engage in new practices, what kinds of experiences are most effective in building engagement and creating change, the impact of those experiences on faculty, and the types of leadership and institutional support needed to sustain those changes.

Rogers' Theory of Diffusion of Innovations. By identifying the spread of an innovation as a social change process and dividing social groups into categories based on 
the likelihood of an individual adopting an innovation, Rogers' (2003) diffusion of innovations theory provides a framework directly addressing the concern that not enough faculty engage in SLOA. Aspects that influence adoption of an innovation include the alignment of the innovation with the social group's established values, the perceived advantage of the innovation over established practice, the ability to experiment with the innovation, and the ability to make the results easily available to others. The process of diffusion is based on communication and explanation of the ideas between peers. Rogers' theory proposes that the first adopters of an innovation share characteristics that differ from later adopters. These characteristics include a favorable attitude toward change, a willingness to take risks, a positive attitude toward science, greater self-efficacy, and greater empathy. Individuals are more likely to adopt an innovation when it aligns with their "values, beliefs, and past experiences" (p. 22). Rogers also presents innovations that create social change as a collaborative process involving many members of the community. In addition, Rogers identifies leadership that motivates others to engage in the innovation process as essential for success. In Rogers' theory, the change agent is a leader who mediates between the agency desirous of the change and those who need to change their practice. In community colleges in California, teaching practices are identified by the California state legislature as within the purview of the faculty per California Assembly Bill 1725 (1988). Participation in SLOA is required by both state legislation and the ACCJC through its accreditation standards (ACCJC, 2014). College 
administrators are not necessarily viewed as the agency desirous of faculty engagement in SLOA. As a result, working within Rogers' theory, the key role of institutional leadership is to promote relationships among faculty members that support SLOA engagement. Rogers' definition of communication as a sharing of information between participants includes the goal of creating mutual understandings about new ways to do things. This creation of mutual understanding is central to the goal of altering how the system functions. However, Rogers also points out that when an innovation becomes mandatory, the process of diffusion and adoption is interrupted.

A review of peer-reviewed articles on community colleges that used the theory of diffusion of innovation supported Rogers' theory. Faculty were more likely to be early adopters when the innovation was similar to methods they were already engaged in (Sahin \& Thompson, 2006; Van Horne \& Murniati, 2016). Faculty were more likely to adopt an innovation when it aligned with their values or they had a positive perception of it (Sahin \& Thompson, 2006). And collaboration was a key feature in creating sustainable change (Sun, Chen, Tseng, \& Tsai, 2011).

Fullan's theory of change. Fullan (2006a, 2006b, 2008) provides a framework for effective change that addresses a common critique of education reform: Too often the change, while well intentioned, never makes it into the classroom in an effective manner. Fullan (2008) identified the understanding of the "black box of instructional practice" (p. 5) as a key missing component from educational reform. The most promising reforms 
focus on key aspects of successful change, including a focus on results (data) and reflection within the context of the faculty member's teaching environment. This use of data and reflection increased faculty capacity to change the underlying assumptions that prevented both student learning and organizational learning in the current system. Fullan (2002) recognized the many layers and roles of leadership within an institution and their importance. Effective leadership demonstrates a sense of purpose, supports strategies that encourage problem solving, is accountable, and motivates others. Effective leaders build capacity throughout the institution that will sustain change beyond the term of a particular individual (Fullan, 2006b). Fullan (2006a) emphasized the necessity of maintaining a "permeable connectivity" (p. 11) between different areas of the system to maintain the changes that have taken place. Fullan defined permeable connectivity as "pursuing strategies that promote mutual interaction and influence within and across" (2006a, p. 11) the various levels of a social system.

Peer-reviewed studies on SLOA implementation support Fullan's theory of change. Faculty engaged in collaborative activities (Gallagher, 2008) that improved understandings of how students learn, realigned course curriculum with program outcomes (Cameron, Stavenhagen-Helgren, Walsh, \& Kobritz, 2002; Jennings, Rienzi, \& Lyda, 2006), and used data to assist in pedagogical decision making (Baker \& Sax, 2012) that faculty believed improved teaching. Studies on effective college level teaching strategies highlight specifc best practices such as increasing time spent in active learning 
in the classroom and small group discussions (Hunzicker \& Lukowick, 2012). Guiding students through practical applications and deeper learning of concepts (Coggshall, 2012), along with a focus on critical thinking (Coggshall, 2012; Hunzicker \& Lukowick, 2012; Yoo, 2013) are all identified as best practices for improved learning.

Bensimon's equity mindset theory. Whereas both Rogers (2003) and Fullan (2006a) emphasize a reliance on local data to effect sustainable change, Bensimon (2005) further theorized that faculty members' beliefs about student learning affect their responses to assessment data, specifically as relates to gaps in the performance of different student groups. Bensimon differentiates faculty beliefs into cognitive frameworks or mindsets. Faculty with a deficit or diversity framework will assume that differences in the performance of different student populations result from conditions outside of their classrooms, conditions over which the faculty member has no control. These faculty members might be less likely to make changes to their teaching practice when they find achievement gaps among the student groups enrolled in their classes. Faculty members with an equity mindset assume that achievement gaps are a result of student learning conditions in the classroom, conditions that the faculty member does have control over. These equity-minded faculty will use the results of learning outcomes assessment to make changes to their teaching practice, courses, and programs. The role of peers to guide inquiry was identified as important to the process, and essential to effective transformation (Felix, Bensimon, Hanson, Gray, \& Klingsmith, 2015). 
Bensimon is the key author behind the Equity Scorecard, identified as a "theory based strategy that assists community colleges in embedding equity into their institutional norms, practices, and policies" (Felix et al., 2015, p. 25). Bensimon and others recognized the difficulties involved in effectuating an "equity minded" (Felix et al., 2015, p. 38) culture on college campuses. One of the key difficulties is that the use of SLOA to address equity requires a predominantly White faculty to look closely at their own ideas of race. However, the description of the Equity Scorecard as a "theory-based strategy" should be noted. Bensimon acknowledged early on that one of the key pieces missing from the understanding of how to best implement equity minded changes was an understanding of the faculty themselves, their "knowledge, beliefs, experiences, education, sense of self-efficacy" (Bensimon, 2007, p. 444).

While Bensimon and Malcom (2012) included examples of changes to faculty insight and practice in their book expanding on the explanation, purpose, and implementation of the Equity Scorecard, this lack of understanding of the faculty experience continues. A search of databases, including ProQuest and ERIC, for peerreviewed articles that included outcomes assessment, equity and/or achievement gap, and education produced only three results related to the community college experience. A search for peer-reviewed articles on faculty, beliefs and/or attitudes, and equity was more fruitful, yielding 12 results after removing articles unrelated to community colleges. However, a review of these articles for discussions about creating equity in student 
outcomes resulted in one article that referenced Bensimon's work as a potentially useful framework for engaging in further discussions (Turner, 2015) and another that indirectly addressed equity through discussions on diverse learners (Rodesiler \& McGuire, 2015). An additional search on SLOA and faculty, or equity, or gap yielded another 16 potentially useful peer-reviewed articles. A search of these articles for discussions on promoting equity in student learning resulted in one article referencing the desire to use SLOA to promote equity (McClellan, 2016). A direct search for peer-reviewed articles on the Equity Scorecard netted three related results, two of which were authored (Bensimon, 2007) or co-authored by Bensimon (Felix et al., 2015). This lack of peer-reviewed research reveals a gap in the literature on the use of SLOA to close achievement gaps.

Tagg's causes of resistance. Further challenges to SLOA implementation are the changes to faculty roles that result. Tagg (2012) applies Richard Thaler's (1980) endowment effect to faculty in higher education. The endowment effect is the tendency of faculty to value what they already have, such as tenure and autonomy in the classroom, and the anticipated rewards of being recognized as an expert in a particular field of study. However, SLOA asks faculty to be curriculum, teaching, and assessment experts. As long as faculty members perceive engagement in collaborative curriculum development and teaching expertise as a move away from what is valued and rewarded by the institution and by higher education overall, faculty will be less likely to invest their time and energy. In addition, while the decentralization of higher education creates an ideal situation for 
faculty driven change (May, Susskind, \& Shapiro, 2013), it can also thwart reform efforts. Without a source of external accountability, it is difficult to get faculty to invest large amounts of time in activities that offer little immediate reward (Tagg, 2012).

Several empirical articles supported Tagg's position. In the STEM fields at research institutions, faculty were rewarded for obtaining research grants (May et al., 2013). For faculty in community colleges, the impulse to be identified as an institute of higher education, instead of aligned with the K-12 system, may motivate faculty to seek rewards parallel with more elite institutions, and to resist activities that would move them closer to teaching practices associated with lower levels of education (Bennett \& Brady, 2012; Wang \& Hurley, 2012).

\section{Challenges to Increased Faculty Participation in SLOA}

Two key challenges stand in the way of addressing Kuh et al.'s (2015) concerns that not enough faculty are engaged in SLOA to make it meaningful and effective: a lack of evidence that SLOA works to improve learning, and the substantial level of existing resistance among faculty. Faculty resistance was found to be the single largest barrier to SLOA implementation. Fullan (2006b) emphasizes the importance of listening to resistors to both ensure that critical information or ideas have not been missed and to negotiate the politics of implementation. As Baker and Sax (2012) declared in their study of culture change, the depth of the change being asked of faculty when they engage in SLOA "goes to the core of who we are, what we do, and how we do it" (p. 48). 
Considering the level of commitment faculty have already invested in their education and career, asking them to change the "core of who we are" logically leads to some resistance. A Lack of Evidence that SLOA Improves Student Learning

The challenges to increasing faculty engagement in SLOA become more relevant as reviews of empirical studies of implementation of SLOA fail to provide convincing evidence that SLOA works. Faculty members, by virtue of their achievements in higher education and receipt of advanced degrees, have access to studies on SLOA. Several participants in this study were aware of the lack of evidence that SLOA improves student learning. An Achieving the Dream (AtD) survey found the impact of SLOA "remains to be seen" (Jenkins \& Kerrigan, 2008, p. 25). Another AtD article noted a follow-up study of a prized reform program revealed no actual increases in student success (Parcell, 2012). More recently, NILOA conducted a large survey-based, multi-institutional assessment of the use of SLOA in driving program and institutional decisions.

Researchers found that after the accrediting agencies included assessment activities in their accreditation standards, more institutions were reporting using more methods to conduct more assessments (Kuh et al., 2014). Positive changes were reported. However, these changes were all focused on course, program, and policy alignment with learning outcomes. Alignment takes place when changes are made by departments or institutions to align practices to facilitate SLOA. These alignments are not related to student acquisition of higher order critical thinking (e.g., Bloom's taxonomy). The report did not 
provide data that students increased their actual knowledge or that access to programs and courses increased.

The NILOA survey followed Kezar's (2013) review of empirical studies focusing on the institutionalization of SLOA. Kezar found that clear concepts of leadership, culture, and organization were insufficiently developed to facilitate the study of SLOA. Evidence that the large investment effort expended on SLOA actually improved student learning was lacking. Too many studies were descriptive single case studies that relied on self-reporting instead of data analysis. Even in these case studies, not enough evidence was presented that assessment can be done well and consistently enough, nor was there enough empirical evidence to make the claim that SLOA positively impacts student learning. Kezar's findings were reinforced by national assessment leaders who also found little evidence for the practice of SLOA to improve student outcomes (Kuh et al., 2015).

Study designs. A review of case studies of individual colleges and multiinstitutional analyses of SLOA implementation, with an emphasis on 2-year colleges, was conducted for this study. Few examples were found of researchers attempting to connect program or institutional assessment with corresponding improvements in student learning. Several studies conducted qualitative document analyses of program review and course SLOA reporting forms in search of common best practices for improving programs (Baker \& Sax, 2012; Bresciani, 2009; McNeice-Stallard \& Stallard, 2011; Rodgers, Grays, Fulcher \& Jurich, 2013). Smaller, single department ethnographic 
studies examined how analysis of embedded written assessments led to changes in program structure (Cameron et al. 2002; Jennings \& Rienzi, 2006). A qualitative study of survey responses at one college was used to discover the perceptions of faculty toward assessment and student learning (Wang \& Hurley, 2012). Quantitative studies used surveys of chief instructional officers, administrators, and department chairs to assess the level of support for SLOA and connections between SLOA results and program resources (Gallagher, 2008; Peterson \& Einarson, 2001; Spalter-Roth, Kisielewski, \& Van Vooren, 2013). Only one study — and it involved K-12 institutions, not a college - compared survey results regarding faculty perceptions of school effectiveness across 75 schools using quantitative data on student success and found little correlation between faculty perceptions and the resulting success data (Scott, Parsley, \& Fanz, 2014).

Study results. Further, institutional studies conducted on SLOA failed to report findings that SLOA led to changes in andragogy to improve student learning, but did identify collaboration among faculty as a benefit of SLOA. Two multi-institutional studies surveyed administrators and others responsible for student assessment at all levels of higher education (Gallagher, 2008; Peterson \& Einarson, 2001). This research had the potential to provide a set of findings for evidence that assessment matters, yet researchers found low rates of assessment information being used by the institution or the faculty members. These findings suggest that colleges are not using the data. One study of 13 institutions used grounded theory program review document analysis to examine best 
practices in assessment, the criteria institutions used to measure whether or not student learning improved, and whether assessment practices could be sustained (Bresciani, 2009). While these researchers did not explore empirical evidence of improved student learning, and determined that a longer longitudinal study was required to measure assessment sustainability, the findings identified collaboration among faculty as supportive of effective practices - a finding supported by other researchers who found that faculty report collaboration as one benefit of SLOA engagement (Peterson \& Einarson, 2001). Of all the practices suggested in the multi-institutional survey of colleges, only one focused on helping students learn a particular skill: including more research and more writing across the curriculum (Gallagher, 2008).

Case studies of individual colleges or departments were more likely to report positive impacts of SLOA. There was general agreement that the most important qualities of SLOA were relevance to the program under study (Gallagher, 2008; McNeice-Stallard \& Stallard, 2011; Rodgers et al., 2013), student-centeredness (Gallagher, 2008; Rodgers et al., 2013) and measurability (Baker \& Sax, 2012; Rodgers et al., 2013). In the individual case studies of specific programs, assessing embedded writing assignments provided evidence of the most direct program and curricular changes. After students were directly assessed on their ability to write an essay that applied social theory, faculty engaged in dialogue about the disappointing results and created an "agenda for change" that included allowing students more space to write, including more theory in prerequisite 
courses, and clarifying learning outcomes on course syllabi (Jennings \& Rienzi, 2006, p. 288).

\section{Resistance to SLOA}

Faculty resistance to SLOA takes many forms. Several empirical studies found that faculty forced to engage in SLOA tended to take the path of least resistance, using less informative assessments and reporting what accreditors wanted to hear without making authentic changes to their practice or program. For example, in studies on SLOA implementation, significantly more faculty were willing to use the less time-consuming survey assessments than the more useful portfolios (Peterson \& Einarson, 2001; SpalterRoth et al., 2013). Even when faculty claimed intentions to make pedagogical changes, $90 \%$ of the document analyses did not prove this out. Instead, faculty were reporting standardized and repetitive responses (McNeice-Stallard \& Stallard, 2011). A study of thirteen institutions' best practices document analyses found that faculty tended to use standardized tests since they were quick, easy to assess, and doubled as a student grade (Bresciani, 2009). Due to the accreditors' expectation that assessment will have a positive impact, even this reporting was suspected of inflation. Whereas only $20 \%$ of institutions reported positive impacts as a result of SLOA for research purposes, approximately $40 \%$ of institutions claimed that student assessment had a positive impact when filling out required accreditation forms (Peterson \& Einarson, 2001). Baker and Sax's (2012) article on the creation of a culture of evidence suggested that faculty might be reporting a more 
positive impact of SLOA in official communications such as work email and organized focus groups. However, faculty might be revealing less positive, and potentially more accurate, impacts of SLOA through unofficial channels such as private emails.

Causes of resistance. Causes of resistance to SLOA include increased workload, de-professionalization, and misalignment of SLOA with faculty understandings of causes of social change: For some SLOA is a tool to reproduce social inequality.

The most frequent theme that detracted from SLOA implementation was workload. In empirical studies reviewed for this study faculty reported that they did not have time to engage in authentic assessment activities and meet all the other, often more rewarding, demands of their career (Jennings et al., 2006; Rodgers et al., 2013). One study found that if faculty were compensated they were more likely to engage in assessment activities (Gallagher, 2008). Many faculty are adjuncts with very little available time and no extra compensation to engage in assessment (Kezar, 2013; McNeice-Stallard \& Stallard, 2011). Nor was assessment considered a valuable activity with direct links to andragogy (Baker \& Sax, 2012; Bennett \& Brady, 2012; Jennings \& Rienzi, 2006; McNeice-Stallard \& Stallard, 2011; Spalter-Roth et al., 2013; Wang \& Hurley, 2012).

De-professionalization was also a concern (Baker \& Sax, 2012; Bennett \& Brady, 2012; Spalter-Roth et al., 2013). One study found the biggest barrier to faculty engagement was the perception that assessment was not a scholarly activity (Wang \& 
Hurley, 2012). This suggested that a significant barrier to SLOA implementation was a "lack of motivation" (p. 9) on the part of faculty, or that picking up the phone and calling students who had stopped showing up was a "powerful technique" (p. 56). Informal preliminary research suggested that many faculty members might find such claims themselves, in fact, evidence of de-professionalization (Marrujo-Duck, 2014). Faculty expressed concern with their professional and academic freedom being threatened by standardization (Baker \& Sax, 2012; Jennings \& Rienzi, 2006; McNeice-Stallard \& Stallard, 2011; Rodgers et al., 2013) and, in fact, faced with reporting requirements, some institutions did turn to standardized exams (Bennett \& Brady, 2012; Jennings et al., 2006). Whereas several authors noted that the trust of the faculty was key to successful implementation (Baker \& Sax, 2012; Bennett \& Brady, 2012; Jennings \& Rienzi, 2006) others noted feeling coerced (Baker \& Sax, 2012; McNeice-Stallard \& Stallard, 2011) and were concerned that assessment results would affect professional evaluations (Baker \& Sax, 2012; Rodgers et al., 2013).

Finally, the most vociferous resistance to SLOA is made on moral grounds: that SLOA, as mandated, reproduces social inequalities in U.S. society (Bennett \& Brady, 2012). The most immediate means to raise scores is to require prerequisites. For example, introductory level social and behavioral sciences courses have traditionally been open to students regardless of English placement scores. However, informal research revealed that some faculty assume that less well-prepared students have lower course retention 
rates (Marrujo-Duck, 2014). Changing course requirements to include eligibility in transfer level English would both reduce challenges faced by instructors and increase reportable student success rates, but, because Black and Latino students are disproportionately under-enrolled in transfer level English (CCCCO, 2017c) it might also disproportionately impact underrepresented groups. Participation in SLOA is required of less prestigious institutions that serve disproportionately underrepresented populations and will misdirect financial resources away from the kinds of real support necessary for struggling students (Bennett \& Brady, 2012). This concern is reinforced when one of the proposed claims of evidence of institutional commitment to SLOA is the amount of resources and personnel dedicated to assessment. In addition, SLOA distracts from the larger social issues that underlie the academic achievement gap, broader social and economic inequality (Bennett \& Brady, 2012; Reardon, 2011).

The Roles of the Institution

Faculty engage with SLOA within a larger institutional context, including the roles played by leaders and the support of leadership for SLOA resources.

\section{Change Agents as Leaders}

The individual who arranges key meetings, coordinates professional development activities, and coaches peer participants through the change process plays one of the central leadership roles in facilitating change. At the core of these activities is dialogue. Rogers (2003) and Fullan (2006a, 2006b, 2008), in their innovation and change theory 
development and analysis, identify various forms of dialogue between participants as a necessary element of any successful change process. Further, the role of a peer dialogue facilitator is critical to encouraging additional participants to engage constructively in changes taking place (Fullan \& Knight, 2011).

Change agents facilitate communication and dialogue. Rogers (2003) describes change agents as those leaders, in a middle position between the agency desiring the changes and the clients needing to change to improve the system, whose role is to influence others. Change agents connect, via communication, the resources of the agency with the needs of the clients. This facilitation of information is the change agent's main role and success correlates to the amount of effort spent on communications. Fullan and Knight (2011) identify an important change agent in educational reform as the coaches who work directly with teachers to improve learning. Like Rogers' change agents, Fullan and Knight's coaches fill a role in between the district - the change agency with resources — and the clients - the faculty — connecting them effectively to create and sustain change. Coaches are experts in their subject matter. They arrange and facilitate meetings, work directly with faculty, and provide information about district goals to the faculty and advocate for their needs to the district. In addition, because change agents and coaches are peers, often engaged in face-to-face communication, they are able to manage resistance more effectively. They create means for sharing information, remind participants of the moral purpose of the change, demonstrate care for and understanding 
of the difficulties experienced by those attempting to engage in the process, and remove barriers to engagement (Fullan \& Knight, 2011).

SLO coordinators as peer change agents. The roles fulfilled by the change agents, or coaches, substantially align with the roles of the SLO coordinator at many California community colleges. At many institutions, the creation of an SLO coordinator position resulted from accreditation standards that mandated increased participation in and reporting on student learning outcomes. Resistance was immediate and widespread. The ASCCC (2004) published a position paper opposing SLOA. However, by 2007 the ASCCC recognized the emergence of a new faculty leadership role in the SLOA coordinator (ASCCC, 2007). The ASCCC identified the coordinator as a change agent and assigned the coordinator with responsibilities paralleling the change agent roles identified by Rogers (2003) and Fullan and Knight (2011). The SLO coordinator was responsible for implementing institutional assessment plans, training faculty, organizing assessment data for accreditation reports, mediating between the needs of administration and faculty, and dealing with resistance. Facilitating dialogue, focused on teaching and learning, at the faculty, department, and institutional level, was a primary responsibility for coordinators. By 2010, the ASCCC changed its position on assessment, describing SLOA as a means of facilitating dialogue, focusing on teaching and learning, and even empowering faculty roles in institutional planning and decision-making (ASCCC, 2010). 
The SLO coordinator position is also referred to as an assessment coordinator by authors exploring the role of these emerging peer leaders in promoting assessment at both 4-year universities and community colleges. Researchers found that the SLO coordinators are faculty members who facilitate dialogue between the institutional leaders and the faculty, explaining the needs and goals of the institution and connecting those goals to the values of faculty. The SLO coordinators kept the dialogue focused on teaching and learning. They both faced and managed resistance, over time helping change the conversation to create a culture that could sustain outcomes assessment (ASCCC, 2007). For example, Wildey, Vanek, and Trevisan (2003), in their study of the characteristics of and institutional support for coordinators at 4-year universities, found that colleges use professionals in this position, mostly faculty peers, to facilitate change. Coordinators helped create assessment guidelines, monitored assessment results, facilitated assessment committees, and also managed resistance. Ten years later, Livingston and Zerulik (2013) reviewed literature on the role of coordinators in the student affairs divisions and found similar roles and responsibilities. The coordinators managed teams that worked on assessment, used their institutional knowledge to promote assessment projects, communicated the needs of the division to institutional leaders, provided professional development opportunities, engaged with faculty and staff in interpreting data, and managed resistance. In addition, Livingston and Zerulik (2013) noted that dealing with resistance can be exhausting for the coordinator. 
However, the efforts of coordinators appear to be effective. Marsh, Bertrand, and Huguet (2015), in their study on the use of data to drive instructional change, found that coaches were integral to success. When changes were made to instructional delivery, a coach or learning community helped facilitate the change in over two-thirds of the cases. Facilitating dialogue about both the student data and teaching practices was the most important. Monroe Community College created an "assessment liaison system" that included an assessment committee for each department and program as support, using faculty peers as liaisons for departments and programs (Willard et al., 2004). Faculty liaisons received training, support from the assessment and research offices, and remuneration for training activities. With the expertise they gained, they met with their assessment committees and shared information. The faculty committee representatives then fanned out into their departments to train individual faculty, conduct assessments, and bring the results back to the committee and the liaison. One important aspect of this system was the facilitation of sharing information about the purpose of assessment. It also kept the focus on teaching and learning. Both liaisons and faculty representatives facilitated difficult conversations and managed resistance.

\section{Institutional Barriers and Facilitators}

Institutions can take steps to promote SLOA. A common theme in the literature on SLOA implementation is the support of administration, collaboration, and adequate provision of resources by the institution to both promote and sustain the desired changes. 
Reid (2014) conducted a review of the literature on barriers to faculty adoption of instructional technologies that inform community colleges' struggle to promote broader and deeper use of SLOA to improve learning. These barriers included a lack of resources even beyond the availability of technology. A lack of resources included a lack of training and time to implement new practices, such as when faculty members attempting to engage with the innovation found themselves faced with extra tasks. Other barriers were inadequate organizational structure to support the changes and a lack of administrative and peer support for the change. A lack of professional development to better understand and use the innovation also created barriers to adoption and sustained use of desired changes to practice. Additional barriers included faculty beliefs about the benefits or lack of benefit the change provided and their overall willingness to engage in new practices.

At least one additional empirical study supported Reid's (2014) findings. Access to technology, administrative support, professional development, and collaboration assisted in promoting innovative change. Faculty who needed specifically designed classrooms to promote collaborative learning were limited by the number of appropriate classrooms available during any particular teaching hour. And department chairs were not well informed about either the changes faculty were making or the needs of faculty who were engaged in change (Van Horne \& Murniati, 2016). 


\section{Alignment of Conceptual Framework with Educational and Social Reform Efforts}

While the literature on the implementation of SLOA reveals challenges to increasing faculty engagement, very little research is available on the use of SLOA to close achievement gaps in community colleges. The conceptual framework for this study provides a path for understanding the change phenomenon being engaged in, and provides good reason to suspect that resistance to SLOA as a tool to close achievement gaps will also surface. As a tool for social change, the SLOA phenomenon is complex and the responses to it reflect that complexity. However, changes to higher education are a fait accompli and paths to improvement may need to embrace both the changes and the goals.

Rogers' (2003) theory of diffusion of innovation and Fullan's (2006a, 2006b, 2008) theory of change include the same components as the $3 \mathrm{CSN}$ professional development program: groups of engaged practitioners collaborating to reflect upon and dialogue about local circumstances and sharing findings across broader networks. Also included is provision of peer leadership to provide training, promote new ways of looking at information that stir innovation, and motivate further engagement. These same elements are included in the practice of SLOA. Further, both Rogers and Fullan provide their theories of change within a context of making necessary improvements. Rogers (2003) explicitly places his theory of diffusion of innovations within a context of creating positive change to social systems. Fullan (2001) also identifies the combination of "moral 
purpose, good ideas, focusing on results, and obtaining the views of dissenters" (p. 8) as evidence of actions aligned with positive change. These alignments support the conclusion that SLOA is a potential force for sustained change to improve higher education, with these improvements leading to creation of positive change to the larger society. Emphasizing the similarities between both Rogers' and Fullan's constructs for successful change, and aligning those constructs with the best practices in SLOA, highlights the promise of SLOA as a change system intended to drive improvements. However, even though both Rogers (2003) and Fullan (2001) identify a moral purpose as key to effective lasting change, measuring the ability of these changes to address the mission of California's community colleges requires further theorizing. Bensimon (2005) takes Rogers' (2003) and Fullan's (2006a, 2006b, 2008) constructs further and adds the transformation of college professionals themselves to the process promoted by 3 CSN's theory of change and SLOA. Bensimon theorized that faculty confronted with the reality of the achievement gaps revealed within their own local data would be moved by that data to transform their practice and their own mindset toward students and learning. But the issue is more complex than assuming that SLOA, if engaged in effectively, is a positive moral force. Tagg's (2012) identification of potential sources of resistance includes a resistance to changes that threaten the values of practitioners. Faculty may resist any changes based on assumptions that their current practices are inadequate for all students and potentially harmful to underrepresented 
students. In addition, without evidence that SLOA works, the resources dedicated to SLOA could detract from potentially more effective change efforts (Bennett \& Brady, 2010).

New Disaggregated SLOA Requirements Might Also Face Initial Resistance

Continued resistance to engagement in SLOA leads to some questions about the likelihood that SLOA can be further used to close achievement gaps, a key goal for social reform. The logic behind the use of SLOA to close achievement gaps is based on an assumption that current teaching practice is based on biases held by a largely White faculty. These White faculty presumably are engaged in education to serve the public good, not reinforce social dispariaties. The inherent accusation of bias in mandating SLOA to close achievement gaps may lead to resistance by faculty based on a the same tensions present in reform efforts described by Cohen (2005): That reform efforts include inherent accusations of bias and ineffectiveness. If Rogers (2003), Fullan (2006a, 2006b, 2008), Bensimon (2005), and Tagg (2012) are providing theories about change that can be collectively applied to faculty to address Kuh et al.'s (2015) concern that not enough faculty are engaged in assessment to make it effective and meaningful, a substantial transformation of faculty attitudes and beliefs is necessary. Prior research also suggests that faculty members perceived an emphasis on SLOA as an intrusion on traditional academic freedom (Bennett \& Brady, 2012) and an autonomy highly valued by faculty (Tagg, 2012). Faculty values change slowly. For example, Graves (1995) used survey 
results to reveal that faculty values and priorities had not changed substantially in 29 years. In addition, non-disaggregated SLOA faced initial resistance. Some faculty members perceived mandated assessments as coming from an assumption that current teaching practices are faulty (Cohen, 2005; Hutchings, 2010; Tagg, 2012). These faculty members defend their professionalism and prefer a learning process where students are engaged in the classroom through a traditional faculty demonstration of expertise in the field, the presentation of materials relevant to the field, and the making of that material relevant to the students' interests (Prince, Felder, \& Brent, 2007; Tagg, 2012). Mandating that faculty respond to disaggregated SLOA data rasies further assumptions of bias and discrimination. Informal interviews with faculty revealed an assumption that achievement gaps are the result of social and economic inequalities, not community college classroom andragogy. They insisted that faculty, trusted experts in their field, should be relied upon to ensure program quality, not be forced to participate in meaningless assessment (Marrujo-Duck, 2014).

\section{Embracing the Assessment Paradigm}

Still, educational reforms such as Kuh et al. (2015) and Hutchings (2010) continue to advocate that SLOA will be playing a key role in the future of community colleges. Ewell's (2011) New “Ecology" for Higher Education makes the claim that new methods for teaching and learning represent a new "paradigm" for higher education ( $\mathrm{p}$. 2). This new paradigm shifts from a "faculty-centered" teaching and evaluation system 
based on lectures and exams to a student-centered "mastery-based" system where students complete work and demonstrate learning outcome mastery at their own pace (pp. 1-2). Some faculty members have embraced SLOA as a constructive tool for creating a student-centered learning environment. A review of Cabrillo College's (n.d-a.) outcomes assessment manual reveals promises that some students' learning will deepen if faculty engage in SLOA. In addition, the ASCCC revised its initial resistance to SLOA and now declares SLOA to be "beneficial and productive" providing "concrete evidence" to improve student learning (ASCCC, 2010, p. 1). The ASCCC further advocated that participation in SLOA "can empower faculty voice in planning and budgeting discussions" (2010, p. 1). While Hutchings (2010) claims the "gold standard" (p. 3) for effective assessment that improves learning is faculty involvement, achieving this gold standard level of faculty involvement requires an understanding of how engaged SLOA practitioners are negotiating this changing and challenging landscape.

\section{Summary}

A review of the literature reveals that education reform efforts are relying on faculty in the classroom to engage in SLOA with the intent of using results to drive improvements in teaching practice, courses, and programs (Bensimon \& Malcom, 2012; Ewell, 2009; Hutchings, 2010; Kuh \& Ikenberry, 2009; Kuh et al., 2015). However, SLOA changes the role of faculty (Tagg, 2012) in a manner that both potentially improves learning (ASCCC, 2010; Huber \& Hutchings, 2005) and potentially creates 
resistance (Bennett \& Brady, 2012; Hutchings, 2010). In addition, there is a lack of direct empirical evidence of SLOA's effectiveness in producing the desired learning gains (Kezar, 2013; Kuh et al., 2015; Rodgers et al., 2013). Kezar's (2013) review of the literature on SLOA implementation at institutions of higher education revealed that both the concepts and theories surrounding these changes are underdeveloped.

However, there are always those individuals more willing to engage in innovation than others and this study focuses on them. In order for Hutchings' gold standard of large-scale faculty engagement in SLOA to be achieved, the ways in which these engaged faculty participants traverse potential changes to their role need to be better understood. This study of engaged SLOA practitioners addresses some of these shortcomings. If SLOA and disaggregated SLOA data stand a chance of closing achievement gaps, a better understanding of the experiences of engaged SLOA practitioners could point to qualities to look for when hiring new faculty, shape professional development activities, direct resources into curriculum development, inform assessment tools, and identify promising practices for a successful increase in faculty engagement. 


\section{CHAPTER 3: METHODOLOGY}

This chapter describes the methods used for this qualitative collective case study of the experiences of engaged SLO practitioners. An overview of the rationale for using qualitative interview data is given with a description of the theoretical framework being explored through these interviews. The research basis of the study design is provided with an explanation of my role as researcher and the questions I intended to explore. The context of the study offers a rationale for the selection process and inclusion criteria for the participants. Because anonymity was important to the research participants, an explanation of the steps taken for the protection of human subjects follows the anonymized description of study participants. To support the goals of this research, including efforts to discover findings upon which generalizable recommendations could be made with a level of confidence, the description of the data collection process is followed by a set of enumerated steps to ensure validity. The careful steps taken to track and analyze the data also support the validity and generalizability of the findings.

\section{Overview of Methods}

Creswell and Plano Clark (2011) identify qualitative research as appropriate to explore phenomena that are not well understood. The process and experiences of faculty as they engage in SLOA is a complex phenomenon that would benefit from research designed to increase that understanding. The impact of engagement with SLOA on faculty participants' beliefs about themselves, college students, the teaching and learning 
process, and perceptions of their role as faculty in higher education, is best evaluated through the descriptions that faculty themselves provide. Semi-structured, open-ended interviews were used to obtain these descriptions. Collective case study methods and grounded theory analytical methods were used to identify themes derived from the interviews that best capture both the insights of SLO coordinators and the experiences of faculty.

The theoretical framework explored in this study combined several established theories about change processes that might explain the potential influences upon and the results of change at key points in the SLO assessment process. Engaged SLOA practitioners negotiate an array of potentially conflicting information and feedback. These include professional training experiences, expressed values of leadership, student feedback, and SLO data. Faculty choose whether or not to engage in SLOA based on a common set of characteristics described by Rogers (2003). Faculty who do engage also make choices about how to negotiate the feedback they receive. The process of negotiating this feedback with the intention of making changes to teaching practice, course design, and program development to improve student learning (Fullan, 2006a) potentially challenges learning assumptions held by faculty and changes the beliefs of faculty about teaching and learning (Bensimon, 2005; Fullan, 2008). As a result of engaging in SLOA, faculty take actions designed to improve student learning: The result of those actions has the potential to change the perceived role of engaged SLOA 
practitioners and lead to resistance (Tagg, 2012). The research design is intended to explore this change phenomenon by asking participants to describe their experiences related to SLOA engagement. (A more thorough explanation of the theoretical framework is provided in Chapter 2.)

Other forms of data, in addition to interviews, were also considered for this study. Classroom observations, student coursework, course materials and handouts, and final SLOA reports were all considered for inclusion. However, while the data gleaned from observing classes or analyzing supportive written documents would support the exploration of whether or not participants actually put into practice the activities they were describing, the primary purpose of this study was to analyze the participants' perceived experiences to reveal beliefs and perceptions. Interviews are the best means available of accessing the participants' perceived lived experiences. In addition, because the theories being explored focus on the faculty members' self-described motivations for engaging in SLOA, perceived changes in their roles as instructors, or focus on an assessment of the faculty members' rationales for making changes as representative of, and assigned to particular categories of cognitive frames (mindsets) and the reasoning behind their decision-making, the only way to gain access to these experiences is through interviews. 


\section{Study Design}

This qualitative collective case study was based on in-depth, semi-structured interviews with five SLO coordinators and eight faculty. The phenomenon under investigation was faculty engagement in SLOA. Qualitative case studies are appropriate when the goals of discovery are a better understanding of how and why a phenomenon occurs and when the phenomenon is closely tied to the context within which it takes place (Baxter \& Jack, 2008).

Because I was unable to observe the participants over time, in-depth interviews were relied upon for an analysis of the phenomenon itself (Yin, 2011). Semi-structured, in-depth, individual interviews with participants were designed to explore faculty experiences with SLOA. Two sets of interview questions were created. Faculty participant interview questions (Appendix A) aimed to elicit responses revealing why faculty engaged with SLOA, how that engagement changed their teaching practice or beliefs about teaching and learning, and the institutional facilitators and barriers to their engagement. Coordinator participant interview questions (Appendix B) aimed to elicit responses describing engagement with SLOA from a broader, institutional perspective. Questions focused on areas including additional roles of leadership, institutional support for SLOA, and perceptions of factors that facilitated engagement in SLOA. Both sets of questions included queries about the overall effectiveness of SLOA in improving student learning and the potential of the disaggregation of SLOA data to close achievement gaps. 
This study's analysis follows the steps outlined in Yin's (2011) Qualitative Research from Start to Finish. These steps included the compiling of data through the interview and transcription process. Coding across the interview data, and the division of the interview data into multiple spreadsheets based on those codes, was used as a means of disassembling data. The creation of matrices arrayed the data in a format from which patterns were identified, analyzed, and developed into themes. Narrative descriptions of the data patterns that undergirded the identified themes provided the first level of interpretation. A second level of interpretation was provided when themes, such as social engagement, empathy, or strategic dialogue, emerged across several matrices. Finally, the discussion and recommendations in Chapter 6 provide the conclusions from the analysis.

\section{Role of the Researcher}

I designed the study, reached out to SLO coordinators for nomination of engaged SLOA practitioners who might participate, contacted and vetted potential participants for inclusion, conducted the interviews and surveys, transcribed a substantial portion of the interviews, and created the matrices of codes and themes. I also wrote data memos at regular intervals in the research process and included those data memos in the data analysis. These data memos included preliminary identification and analysis of emerging themes. These emerging themes were then explored as additional data were received. I also completed the Institutional Review Board (IRB) Collaborative Institutional Training Initiative (CITI) certificate prior to collecting data for this study. 
I was connected to one of the colleges included in this research. I was faculty in the social sciences and a self-identified engaged SLOA practitioner. I also had experience implementing SLOA in the social sciences department at a California community college I anticipated being able to establish a working relationship with interview participants based on these common experiences. However, specific steps were also taken to ensure that my identification as an engaged SLOA practitioner did not create bias in the findings.

\section{Research Questions}

The overall question guiding this research was "Does SLOA work?" Within this context of using SLOA to improve student learning, grounded theory methods were used to explore the following questions:

1. Why do faculty become engaged SLOA practitioners?

2. What are the important behaviors, attitudes, and actions of the engaged practitioner that occur when engaged in SLOA?

3. What do engaged faculty believed about SLOA, teaching, learning, and achievement gaps?

4. What are the important behaviors, attitudes, processes, or structures at an institution that influence engagement in SLOA? 


\section{Context of the Study}

This study focuses on California community college SLO coordinators and faculty in the social and behavioral sciences. The rationale for including institutional SLO coordinators was based on these faculty members' role in organizing and facilitating faculty engagement in SLOA across the entire institution. In the process of fulfilling their role, these coordinators ideally gain an understanding of the needs of the college as related to SLO, the strengths and weaknesses of different disciplines in SLOA assessment, and the institutional facilitators and barriers to SLOA. SLO coordinators also have insight into the roles of leadership as it relates to SLOA. SLO coordinators were asked to identify faculty who are engaged SLOA practitioners. These SLO coordinators were aware of, through the course of their job activities, who was engaged in assessment. For example, at many community colleges, SLO coordinators design and facilitate professional development activities related to assessment, read and evaluate faculty produced SLO reports, chair campus-wide SLO committees, and field questions from faculty about SLO assessment. As a result, these coordinators were able to identify individual faculty engaged as SLOA practitioners.

The rationale behind limiting participants to those teaching in the social and behavioral sciences is multifaceted. First, other disciplines were considered, such as career and technical education (CTE), math, and English. Because CTE courses have long-standing relationships with separate program-level accreditors were left out of the 
study. This means that most faculty in CTE could be assumed to be more familiar with and more accepting of SLOA requirements. Interviewing CTE faculty might not provide the insight on gaining buy-in that is necessary for college-wide effective engagement with SLOA. Also, CTE faculty are assumed to not be struggling with these concepts or challenges to their roles as faculty.

Math was left out of the study for two reasons. The first is because math courses are sequential. Having sequential courses in a program facilitates alignment of course outcomes across different levels by faculty. This alignment is furthered by outside acceptance of the concepts that belong in each level and category of math. Thus, most math faculty will not be struggling with defining what students need to know. Second, math assessments have concrete answers. This means there is less room for subjectivity on the part of the instructor when it comes to evaluating the students' success in achieving the outcome. This study is partially about the mindsets of faculty. While teaching practice in math is not uniform, math assessments, by their nature, are not as subjective to mindset as in other types of courses.

English was also left out of this study due to the sequential nature of English courses. Because students need to progress from one level of English to the next, English faculty have more experience in and assumed acceptance of common outcomes for each level. In addition, the sequential nature of English courses means that students need to 
place into a particular level of English, narrowing the breadth of skill level that students bring to each class.

The social and behavioral sciences are ideal for this study for a multitude of reasons. Most social and behavioral sciences have no prerequisites. This means students can sign up for these classes and begin to complete some general education requirements even while enrolled in ESL, remedial English, or remedial math. Other students in the same class may possess the skills to enroll directly into college-level coursework or be on the verge of transferring into the CSU or UC systems, creating a wider breadth of skill levels across the class for faculty to negotiate.

Because most social and behavioral sciences courses are not prerequisites for other courses, the outcomes for any particular course are not determined by the needs of the next course in the sequence. The core outcomes for courses in the social and behavioral sciences are also broader. For example, in history, a core outcome is to demonstrate the ability to interpret primary and secondary sources and use them, as appropriate, to formulate an analytical argument. Unlike math or English, where a student often identifies a specific concept (e.g., the use of a specific equation to solve a specific type of problem), the interpretation of primary sources in history does not identify which primary sources are to be interpreted. This leaves much more room for instructors to modify the content of the course and their teaching practice while still achieving the outcomes. 
Such variability is also found in assessments for the social and behavioral sciences. The ideal form of assessment relies on writing analysis, but the content, form, scaffolding, and final assessment of the written product as having achieved the outcomes are highly subjective. For example, some faculty may choose to conduct a formative assessment to gauge where students are in the development of an outcome. Then, faculty can scaffold the key skills and provide step-by-step opportunities for students to develop the conceptual skills necessary to achieve the outcome over the duration of the course. A summative assessment lets the faculty know how much students have improved. Each step in the process is subject to the judgment of faculty about how to best teach and how students best learn. Each step is subject to faculty judgment, providing fertile opportunity to study the impact of faculty mindset on their practices.

Finally, the social and behavioral sciences have a reputation for social criticism. The academic freedom traditionally granted to faculty with tenure in all fields has traditionally provided the freedom to explore new social theories and question accepted social norms. These fields have also been identified as potentially resistant to SLOA because they see SLOA as a threat to these freedoms. If this study can identify, through conversation with faculty in the social and behavioral sciences who have embraced SLOA and found it beneficial to their practice, some means of facilitating broader engagement or a deeper understanding of what assessment means to them, these findings may be of use to the community college system as a whole. 
The inclusion of part-time, or adjunct, faculty in this study broadens the type of data gathered about SLOA. The adjunct perspective is particularly important due to the growing proportion of courses that adjunct faculty teach. Kezar, Maxey, and Eaton (2014) found that at community colleges, adjunct faculty taught on average over $50 \%$ of the courses. Over $37 \%$ of faculty in the social sciences were part-time. Adjunct faculty face particular challenges, including less time to prepare for courses; lowered access to professional development, curriculum design, or departmental decision-making; and limited office space and other instructional supports. As a result, students who take courses from part-timers experience less success than students who take courses from full-time tenured faculty (Kezar et al., 2014). This means that the experiences of those part-time faculty who have managed to negotiate these challenges and engage in SLOA are highly relevant to this study.

However, adjunct faculty may have additional motives for doing SLOA well. Adjunct faculty already employed by a college may not have the freedom to opt out of SLOA or even to participate only minimally. They do not have the protections of tenure. In some cases, they can simply not be called back to teach the next semester. On the other hand, the increasing state of attention to SLOs means that adjunct faculty can highlight their successes with SLOA when applying for full-time jobs. In addition, adjunct faculty might be younger, more recently in graduate school, and possibly more familiar with a 
broader range of teaching styles, practices, and adult learning theories or methodologies. As a result, they might be more open to SLOA.

Part-time faculty may reveal both key barriers and key motivations to faculty participation in SLOA. Because part-time faculty face increased challenges to accessing professional development and institutional support, those part-time faculty who have managed to overcome these challenges may reveal paths toward assisting other parttimers to engage in assessment. At the same time, many part-time faculty do not have the protection of tenure, similar to adjuncts. This may create a sense that they must engage in SLOA to protect their employment. In addition, many part-time faculty are seeking fulltime employment. They might believe that one of the best ways to gain an edge in the job application process is to demonstrate engagement and facility with SLOA as it is intended to improve teaching, courses, and programs.

\section{Participant Inclusion Criteria and Selection}

This study included as participants five SLO coordinators and eight faculty teaching general education courses in the social or behavioral sciences from a crosssection of California community colleges. At the start of this study, an assumption was made that the controversial discourse around and resistance to SLOA might limit the number of willing participants. As a result, I used established connections to identify the first two SLO coordinator participants. Upon the realization that gaining sufficient 
participants was likely, participant access was gained by intentionally reaching out to SLO coordinators who represented a breadth of community colleges within the state.

California has a total of 113 community colleges. The Chancellor's office divides California community colleges into peer groups. Colleges in each peer group share enough qualities, such as size and service area demographics, income distribution, and proportion of service area population that already holds a baccalaureate degree, to allow for a level of useful comparison of college performance in specific areas of student success. By selecting colleges from multiple peer groups, a wider cross-section of California community colleges was included. In the study, SLO coordinators from five different California community colleges representing four identified peer groups recognized in the Focus on Results report (CCCCO, 2012) were included.

In addition to representing a cross-section of community colleges, the sample for the SLO coordinators was also intentionally selected to represent a broad spectrum of experiences with SLOA. Coordinators were chosen first by identifying those who worked at community colleges already practicing the disaggregation of SLO data. Attendance at several ASCCC conferences, specifically the sessions where the new 2014 accreditation standards were discussed, assisted with the identification of these colleges and individuals. This provided the study with SLO coordinators from community colleges already engaged in disaggregation of SLO data, a community college that had attempted to meet the 2014 accreditation standard on disaggregated data, a community college that 
was engaged in SLOA prior to the 2002 accreditation standards, and a community college sanctioned by ACCJC for not meeting 2002 SLOA requirements and currently experiencing rapid changes to come into compliance with the 2014 standards. These four colleges represented three different peer groups identified by the ARCC.

The ACCJC evaluates colleges every six years with a portion of the 113 California community colleges being evaluated each semester. The first set of colleges to be evaluated using the new 2014 accreditation standards were evaluated in spring and fall 2016. The disaggregation of SLOA data is a new requirement in the accreditation standards by which all California community colleges are measured. Colleges are expected to meet the new accreditation requirements on a staggered timeline, as each college comes due for a comprehensive self-evaluation every seven years after the requirement is implemented. The first colleges to be evaluated using the new accreditation standards did not complete their self-evaluations until spring 2016. However, colleges were notified in advance of the upcoming requirements for disaggregating data. Several colleges have been taking steps to meet this requirement in advance. The SLO coordinators at those colleges were contacted first. These colleges were the first group of colleges to write institutional self-evaluation reports that address the new emphasis on SLOA outcomes instead of the SLOA process. In addition, these were the first colleges addressing the disaggregation of SLOA data. Attempting to gain access to SLO coordinators and faculty at colleges already practicing the disaggregation 
of SLOA data assisted in being able to not only gather data both on the process and effects of engaging in SLOA, but also on the potential of the disaggregation of data to narrow achievement gaps. Engaged SLOA practitioners and SLO coordinators from four of these colleges have been included in this study.

Additional colleges were identified by using the peer groupings listed in the ARCC to identify institutions that represent the variety present in community colleges across the state. Online resources were used to identify the current SLO coordinator at these colleges. These SLO coordinators were contacted and invited to participate in the study. Some of the SLO coordinators were willing to be interviewed. Following the interview, these SLO coordinators identified faculty who they recognized as being engaged SLOA practitioners. Other SLO coordinators engaged in a short phone conversation about the study and then identified faculty who they recognized as being engaged SLOA practitioners.

The sample for the faculty was also purposive: Participants were nominated by SLO coordinators as engaged in SLOA and, when contacted by me, they self-identified as engaged SLOA practitioners. This process provided the advantage of including two filters that assisted with the identification of faculty intentionally using SLOA to improve their teaching practice, course design, and program development. This two-step process also limited the ability to ensure a demographically diverse set of faculty participants. This limitation was based on the criteria provided to the SLO coordinators. Coordinators 
were asked to select faculty in the social and behavioral sciences who were actively engaged in SLOA. Coordinators were not asked to identify faculty of specific demographic groups. In addition, at the beginning of the study, there were concerns that the controversial nature of SLOA might place limits on the willingness of faculty to participate; however, most of the individuals contacted - both coordinators and facultywere willing to participate. I interviewed each of the individuals who expressed a willingness to participate and who, upon receipt of the study parameters, followed through with an interview.

\section{Description of the Participants}

The final set of participants included five SLO coordinators and eight faculty participants. As described above, the California State Chancellor's Office divides community colleges into similar peer groupings for comparison purposes. The SLO coordinators represented five community colleges in four of the seven California community college peer groups. The coordinators were experienced faculty. Their mean age was 49 . They averaged 4.4 years of part-time teaching experience and 18.2 years of full-time teaching experience. They were more ethnically diverse than the faculty participants with two White, one Hispanic, one Asian, and one Jewish participant. Four of the coordinators were female and one was male. Four of the coordinators held master's degrees and one held a Ph.D. 
The eight faculty participants represented social and behavioral sciences departments from six colleges. The faculty in this study represented colleges from five peer groups plus one college that had not yet been assigned a peer group. Overall, six of the seven community college peer groups were represented in this study. Faculty participants were slightly younger than the coordinators, with a mean age of 44 . Faculty participants averaged 6.5 years of part-time teaching experience and 9.25 years of fulltime teaching experience. One faculty participant remained a part-timer. Another faculty member was in her first year of a full-time tenure track position. Faculty participants were less ethnically diverse than the coordinator participants, with seven identifying as White and one identifying as African American. Five of the faculty participants were female and three were male. The faculty participants were highly educated. Five of the eight faculty participants held a Ph.D. The faculty participants represented five of the disciplines assigned to the social and behavioral sciences, including psychology, history, economics, sociology, and anthropology.

Altogether, the study participants represented 10 of the 113 California community colleges from six of the seven peer groups, plus an additional college not yet assigned to a peer group. Participants were highly educated with many years of teaching experience at the community college level and represented key disciplines within the social and behavioral sciences. While seven of the eight faculty participants were White, as a whole, the group represented four major ethnic groups in California and represented a mix of 
males and females. This broad representation allows for generalizability of the study's findings.

\section{Ethical Protection of Human Subjects}

There remained sufficient resistance to SLOA at some community colleges to create a potential level of discomfort for participants if their views on SLOA became public. In addition, the connection of individual faculty members' mindset to SLOs, if evaluated in a less than positive light, could harm their reputation. Bensimon's (2005) definitions of deficit mindset, diversity mindset, and equity mindset could be perceived as placing value judgments on the assumed mindsets of individual participants. These mindsets categorize faculty beliefs about students' capacity for learning and tie these faculty beliefs to racial and ethnic stereotypical explanations prominent in U.S. society. The assignment of a negatively perceived mindset to a particular individual could be perceived as labeling that individual as racist and stands a high chance of having negative repercussions should that information become public. Therefore, assurance of confidentiality was important.

All participants received an explanation of the procedures taken to guarantee confidentiality. Participants were informed of the option to skip any questions they were not comfortable answering. All data were stored on a password-protected laptop and all paper copies of data were kept in a private, offsite office. All interviews were transcribed and anonymized with actual names and locations were replaced by fictitious names so the 
identity of the individual and the institution would not be revealed. Once the transcripts were anonymized, the audio files and original transcriptions with authentic names listed were removed from the password-protected computer and stored in a separate locked safe in the offsite office. Still, it was possible that, due to concerns about one's professional reputation, participants were less than candid during the interviews.

\section{Data Collection}

\section{Tools and Processes}

The interview protocol for SLO coordinators consisted of 12 semi-structured, open-ended questions intended to elicit perceptions about faculty engagement in SLOA activities, the impact of professional development, institutional culture, expectations of students, and the potential for disaggregation of data to close achievement gaps. These interviews were audio recorded and transcribed for further data analysis. A short demographic survey (Appendix C) followed the interview. The demographic survey included questions about participants' educational background, work experience, participation in professional development, and demographic data on age, ethnicity, race, gender, and employment status.

\section{Data Collection}

All participants were encouraged to identify a space where they could speak candidly and without interruption. One participant chose to meet in a restaurant. One chose to meet in an unused professional development workspace. Eleven participants 
chose the privacy of their offices. Consistency in type of location and allowing participants to choose a place where they can speak candidly during interviews reduced the likelihood of "location threat" (Fraenkel et al., 2012).

\section{Validity}

To demonstrate validity of the inferences made about the data collected and to manage researcher bias in the findings of the study, several steps were taken. First, the structure of the participant sample contributed to the validity of the findings. By including participants from 10 different community colleges (CCCCO, 2012), plus an additional college not included in the peer groupings, the participants' interview data represented six of the seven community college peer groupings across California. Second, data analysis from faculty interviews was compared to data analysis from SLO coordinator interviews. The findings described in this study are those common to both groups, which strengthened the evidence. Third, since I also identified as an engaged SLOA practitioner, I took a number of specific steps to guard against researcher bias:

1. Two SLO experts evaluated the interview questions for both the SLO coordinators and the faculty participants to check for content-related validity (Fraenkel et al., 2012).

2. To support the validity of the constructs being evaluated (Fraenkel et al., 2012), five SLO coordinators were interviewed and the themes developed from an analysis of their interview data were compared to the themes 
developed from the analysis of faculty participant interviews. When themes were developed from the SLO coordinator interviews, the themes were validated with data from the faculty interviews.

3. A check of coding reliability ensured against researcher bias (Fraenkel et al., 2012). During the initial coding of the first interviews, a critical colleague reviewed the code selection and assignment.

4. For each of the themes developed, two evidence matrices were produced to compare the frequencies of incidents that supported the inferences being drawn (Fraenkel et al., 2012). One grid contained evidence of the theme derived from faculty interview data. The second grid contained evidence of the theme derived from coordinator interview data.

5. A critical colleague reviewed the first two sets of theme grids and compared the grids against the coded data spreadsheet.

6. Opportunities were provided for member-checking of emerging themes derived from the data (Fraenkel et al., 2012). Each participant received a copy of the transcript to check for inaccuracies. In addition, a summary of emerging themes associated with that transcript and an invitation to share thoughts on the emerging themes were provided. Several participants responded and their additional feedback was incorporated into the findings. 
Critical colleagues were selected from among the SLO experts at City College of San Francisco and individuals in the Ed.D. cohort whose research is also based on dialogue interpretation and grounded methods coding and theme development, or from peers at community colleges whose background or current work involves a substantial portion of dialogue interpretation in relation to SLOA.

\section{Generalizability}

In addition, this study is based on the self-reports of interview participants either selected by their institution to serve as the SLO coordinator or faculty nominated by the institutional SLO coordinator in recognition of their engagement in SLOA. In addition, all 13 participants self-identified as engaged SLOA practitioners. The results of this study are generalizable. The SLO coordinators were all faculty with knowledge of the practice of SLOA at their institution. The participants were all faculty teaching at California community colleges, thus they all met the minimum qualifications for their field of study. The faculty participants all taught general education courses in the social and behavioral sciences. These same general education courses are taught at the vast majority of the 113 California community colleges. These courses did not have prerequisites, allowing all students enrolled at the colleges to take the courses. My experiences in SLOA engagement provided an opportunity to create an interview environment conducive to candid responses and also provided the expertise necessary to interpret the data. 
The sample of participants represents multiple, varied community colleges as described by the Focus on Results report (CCCCO, 2012). In this report, to compare the performance of colleges on a set of seven indicators and compare that performance against target performance rates, certain features of the college's service area statistically correlated with overall student performance had to be identified. These features included overall population density, percentage of baccalaureate degree holders in the population, percentage of students enrolling with needs in remedial education, overall age of the students, and others. By combining colleges into peer groupings based on similarities, target rates for performance on each of the seven indicators could be set. If common themes were found in the interview data from participants who were working within widely varying institutional contexts from the perspective of the service area of the college, these themes could be arguably more valid than if all of the participants came from just one college or a group of colleges that were all very similar in the student population they served. For this study, including participants from colleges in at least four of the six peer groupings provided interview data from faculty who were working in a wide variety of institutions.

\section{Data Tracking}

Data and emerging understandings about the effects of engagement in SLOA on faculty were tracked in several ways. Data memos were created after each interview and after each coding session. These data memos also served as a reflective journal used to 
identify emerging themes. Data were tracked using Excel spreadsheets to create analytical matrices of content for each interview. These matrices identified the themes, type of codes, codes, direct quotes from participants, and location of quotes within the data sets.

Participants, identified as engaged in the assessment phenomenon, self-reported on their experiences. Themes that arose from this self-reporting were compared to Rogers' (2003) characteristics of early adopters, Fullan's (2006a) elements of successful change theory, Tagg's (2012) descriptions of causes of faculty resistance, and Bensimon's (2005) equity mindset theory. The demographic survey provided information about the individual participants, including gender, race, ethnicity, age, educational background, work background, years of teaching, employment status (i.e., tenured or adjunct), educational background, number of institutions taught at, number of different types of courses taught, number of publications in field of study, and number of publications in SLOA.

\section{Data Analysis}

Interviews and data memos were transcribed to produce verbatim transcripts and analysis began as they were collected beginning in July 2015. The methods used in this study were based on grounded theory qualitative analysis of documents similar to those Kezar (2013) recommended in her review of empirical studies of SLOA implementation at other institutions of higher education. Grounded theory methodology involves a study 
of documents - in this case interview transcripts - mining them for content, meaning, and process without a preconceived theoretical framework to guide the search.

The first coding cycle began with descriptive codes to gain an overall idea of the general content under review (Miles, Huberman, \& Saldaña, 2014). Subsequently, more refined codes identified themes common across the interview transcripts. To better see larger patterns across the data and to reveal the types of self-reflection that Fullan (2008) and Bensimon (2005) claim will lead to changes in mindset in the participants' descriptions of their experiences, a matrix was developed for each theme, similar to a data accounting sheet as Miles et al. (2014) demonstrated. In addition, cases were coded and themed individually before comparing cases to see if themes extended across cases. These cross-case themes were then compared to the literature (Rodgers et al., 2013)

Emergent findings were analyzed using the change models identified as relevant to this study. Educational researchers developed these change models, researchers in education have accepted them, and they have been further supported in peer-reviewed empirical literature. These models were organized into a framework that provided a plausible explanation for the themes that emerged from the data. The interview protocol was designed to probe these areas. 


\section{CHAPTER 4: FINDINGS-PART ONE}

\section{Overview}

The findings in this study are divided into Chapters 4, 5, and 6. Chapter 4

describes findings based on interviews that addressed why faculty engaged in SLOA and the actions faculty took as a result. The SLO coordinator interview data were also analyzed, with these data validating the themes revealed through the faculty interview analysis. Chapter 5 describes findings based on faculty interviews that explored faculty beliefs about teaching and learning. Again, SLO coordinator interview data were also analyzed, with these data validating the themes revealed through the faculty interview analysis. Chapter 6 reverses this structure and describes themes developed by analyzing the SLO coordinator interview data to explore the institutional facilitators and barriers to faculty engagement. This step — the use of coordinator data as a basis for Chapter 6-was employed in response to some of the unexpected themes that arose in the analysis of the coordinator data. Faculty interview data were also analyzed for these themes, and the faculty data were used to validate the themes discovered through the analysis of the SLO coordinator data.

Chapter 4 describes findings based on faculty interviews that address the first two research questions. The first section of Chapter 4 addresses the following research question: Why do faculty become engaged SLOA practitioners? Factors that influence faculty engagement in SLOA are explored, including previous work experiences and 
community service activities, intrinsic motivations for social engagement, and faculty participants' pre-existing social values. The second section of Chapter 4 addresses the following research question: What are the important behaviors, attitudes, and actions of the engaged practitioner that occur when engaged in SLOA? This section explores the actions taken by engaged faculty as they respond to outcomes assessment data. These actions include: (a) alignment of course content and assignments with outcomes, (b) increased focus on critical thinking, (c) greater clarity of learning goals for students, (d) restructured time and increased availability of resources, and (e) conversation with colleagues about the teaching and learning process. A summary of the findings for these first two research questions can be found at the end of the chapter.

\section{Factors That Influence Engagement in Student Learning Outcomes}

Faculty participants provided several suppositions as to why some faculty engaged in SLOA and some did not, including age and teaching experience. However, analysis of the interview data revealed other themes influencing faculty engagement. These themes included that engaged faculty shared diverse work experiences, viewed SLOA as aligned with their social values, expressed an intrinsic motivation to improve their teaching practice, perceived SLOA as a continuation of their values and practices, benefited from dialogue with colleagues, and demonstrated empathy with the students at their institutions. Engaged faculty also recognized the value of dialogue among themselves to facilitate these changes. 
Faculty participants described several propositions they suspected played a role in determining which faculty willingly engaged in SLOA and which faculty resisted. A common proposition divided faculty between new faculty and experienced teachers, with experienced teachers far more resistant to SLOA and new faculty using the SLOA process to learn how to teach. Michael acknowledged that early in his career, when SLOA was mandated and he was required to participate, he experienced an "Aha!" moment, realizing that SLOA could help him learn to teach better. This proposition was challenged by the participant data. When the participants' ages and number of years teaching were averaged, the SLO coordinators and faculty participants who identified as intentionally engaged in the SLOA process turned out to be veteran instructors. Coordinators averaged 4.4 years of part-time and 18.2 years of full-time teaching experience. Faculty averaged 6.5 years of part-time and 9.25 years of full-time teaching experience - together an average of over 22 years and almost 16 years, respectively. In addition, participants described motives for their own engagement in SLOA that focused on attempts to improve student learning.

\section{SLOA and the Values of the Participants}

An analysis of participants' demographic survey data and interview responses demonstrated that participants who engaged in SLOA shared some characteristics. Engaged faculty were open to change, as exhibited by the diversity of their work and educational experiences, and the goals of SLOA aligned with participants' purpose for 
teaching at a community college and with their goals to improve society. In addition, participants demonstrated empathy with students in their attitudes and actions.

Diverse previous work experiences. Participants were asked at the end of each interview to fill out a short demographic survey that captured prior work and educational experience along with descriptive information about their educational and teaching backgrounds. Overall, the work histories of the faculty participants reflected a diversity of experiences. Engaged practitioners reported a wide variety of work experiences outside of education. They worked in retail, for law firms and doctors' offices, and as stockbrokers, computer programmers, store managers, research analysts, receptionists, and chefs. One was a business owner. One was a political blogger.

Motivation to improve society. Faculty participants shared several additional characteristics that revealed an alignment with the values inherent in SLOA to improve society. These characteristics included a personal experience with community college or a family history in public education, a high level of social engagement, and a commitment to the mission of California community colleges.

Five of the faculty participants attended community college and were personally aware of the opportunities community college provided, or they had close family members who were public education teachers. For John, both he and his father attended a community college. Mary came from "a long line of public school teachers... [her] husband's a teacher. He comes from a long line of teachers." 
Faculty participants overwhelmingly described an intrinsic motivation to use their efforts and expertise to improve social conditions. Most all individuals - five of the eight faculty participants - were engaged in social reform work prior to assuming a faculty position at a community college. Summer tutored K-12 and adult basic skills students. Laura taught at an alternative high school, an experience she credits with providing an understanding of differential learning experiences that inform her current teaching practices. Mary volunteered to help provide guide dogs for the blind.

These same faculty also made a connection between the social engagement activities they experienced prior to accepting a teaching position and the mission of the community college system. Mary explained:

I was an old-fashioned social worker, a volunteer coordinator in nonprofits for a long time... I was a community organizer... neighborhood organizing and restorative justice campaigns and on and on and on... It was a moment where I realized... I could take my social work experience and my academic enthusiasm and put them together, and give people better access to the educational world.... From that point forward, I was like, “That's it. I definitely want to be a community college teacher."

Mary managed to capture all three of the primary experiences of SLO practitioners. She had family members who were public school teachers, she engaged in several social justice activities, and she connected teaching to a continuation of that social justice work. 
Three of the eight participants who were not previously engaged in social reform work expressed a strong commitment to the mission of California community colleges. Of the remaining two participants, one always intended to teach and one had attended community college himself and found the work rewarding once there. Starbuck was drawn to "the concept of community college." Laura recognized students as "the most dynamic population" with whom to work. John identified community college students as "on that edge" where a real difference can be made. For Toni, "it was a miracle [the students] made it this far." Overall, faculty expressed an acknowledgement that within the community college they could make a difference in students' lives.

\section{Pre-Existing Motives, Practices, and Using SLOs to Improve Society}

Faculty participants shared a set of common reasons to engage in SLOA directly related to their pre-existing motivations to teach at a community college. Faculty participants were intrinsically motivated to improve their teaching practice and, perhaps as a result, SLOA aligned with their existing teaching practices. Faculty also valued the cooperative and social work activity that SLOA represented. Faculty participants hoped that students would learn more than the stated outcomes for the course and would become better citizens as a result. Faculty participants also appreciated dialogue as a tool for achieving their goals.

Intrinsic motivation. The strongest finding fell again under the category of intrinsic motivation to improve experiences for students. Six of the eight faculty 
participants described a pre-existing desire to improve their teaching practice. Richard was "hypersensitive to new changes each semester" because he wanted to be effective at teaching. John strove "to be a better instructor and find better ways to teach." He claimed it was "always an internal thing." Laura wanted to make sure the SLOA work authentically reflected students' accomplishments. When she "looked at those scores... [and] didn't feel it was representative of what the students learned," she began to take ownership of the process. Starbuck summed up the most salient point: "Most of us... are interested in being good at what we do." Mary's experience highlighted the depth of intrinsic motivation. She described taking a community college course from an instructor with a reputation for excellent teaching:

I knew I wanted to teach at the college level. I actually set out to try to see good teachers teach.... I took her class... just to watch her teach... my notes for the class were about half content, and the other half were teaching reflections... I learned a lot about teaching from her... I didn't realize what a position of activism it was.

Existing practices. Faculty participants employed teaching improvement strategies prior to engagement with SLOA. Laura learned to teach to different student strengths in a previous job and described how her knowledge of learning styles informed her teaching. Richard described participating in teaching improvement efforts earlier in his career: "There's always been something, we keep changing the name." Summer 
explained how she was keeping track of student success even before SLOA became a mandate: "I knew the SLOs were happening in my class... [I] was keeping track in the most general way." John described a similar process of reflecting on student performance. When students underperformed, he changed tactics. Starbuck benefitted from an intense teaching training process early in her career. Her training as a graduate teaching assistant "was rigorous and interrogated itself." She saw the benefits of assessment early on, explaining, "That kind of evaluation has always been a part of my teaching... I already drank the Kool-Aid.”

Using SLOs to improve society. Faculty participants also expressed a desire for the SLOs in their courses to lead to positive social behaviors on the part of students. Faculty participants were invested in the long-term benefits of the class that included personal student development, job skills, and civic participation. College was recognized as a means of personal student development. More important than memorizing specific quantitative calculations, Michael stated, "It might be more impactful if your confidence has increased a little bit." Toni described her class as "planting seeds" and stated, "Even if I don't see them grow right now, I know that at some point... there is something that they are going to get out of what they are learning."

Faculty participants wanted students to get a good job. John recognized the employment benefits: "Employers are saying [to students], 'We need you to be stepping forward and take ownership' of job responsibilities." Direct connections were made 
between a lack of education and poor civic participation. Laura and Starbuck agreed that there is a problem "with students dropping out and not completing their degrees." Laura stated, "I mean, to be really cynical, the election of certain political parties [is] a really good indicator that students aren't following through." Mary wanted students "to be better members of a democracy." Good teaching could be a solution. Starbuck stated, "I always get to build civil society, that's what we're doing, that's always worked. Maybe it helps them critically evaluate political candidates more effectively and that means they make an informed decision.”

For SLOA to serve a positive social purpose, faculty participants needed to be intentional with designing their outcomes and their courses with student development in mind. Starbuck stated, "I do as much of that as possible, think of them, students, as human beings." Laura stated that she promotes "processes that will make them successful in [her] class and will also make them successful human beings."

\section{Empathy}

The faculty participants, by virtue of their backgrounds in social engagement, their expressed social values, their sense of personal responsibility, and their engagement with SLOA, demonstrated a high level of empathy. This empathy was sustained through dialogue with other engaged faculty.

Faculty participants were reflective about their actions, made time to learn about their students, and thought deeply about the students' broader needs. Mary recognized 
that veterans have difficulties: “They're coming back with heads full of who knows what" and might need specific resources directed toward them. Richard, after he discovered troubling student success statistics by participating in a program review process, described newfound knowledge as "affecting [him] when [he is] in the classroom." He stated, "I'm just as concerned about what's happening with them in other classes and the fact that there's a struggle." Toni recognized that, as a result of previous life experiences, sometimes students lacked confidence: "Students don't give themselves credit for what they are capable of [and] what they already know." Faculty were keenly aware of the outside demands students faced. Laura commented that students "have kids... work a full-time job... none of that is going to change."

Faculty participants recognized the potential impact their actions could have on students. Starbuck stated, "There are things we can do... being as aware as possible that all the stuff that happens outside comes in the room with them." All students need attention, and as Michael shared, "You never know what impact you're having and when you're having it... you could be giving that D student... something."

Concern for students shaped faculty teaching practices. Laura shared, "Now if a student starts doodling in my class, I go up to them and say, 'Does this help you?' and just talk and make sure they are paying attention." Mary listens to the Latino USA podcast to learn more about her students. Toni addresses student confidence and esteem by starting students off at the top. Toni shared: 
I give them 350 points, and I say to them, "It's up to you to maintain those points." Instead of working from the bottom and trying to reach something that most of them think is unattainable, I just tell them, "You're already there. You've arrived." ... It's not so much a trick, but I think it's validating something that's already there that they have yet to see in themselves.

The role of dialogue in sustaining empathy. For faculty participants, SLOA represented a continuation of the type of improvement-oriented, collaborative work that inspired their prior social engagement and volunteerism. These collaborations were dependent on communication and the sharing of ideas. John described himself and his engaged colleagues as "always talking within our departments about better ways to do things." Mary credited conversations about SLOA with inspiring her entire division: "We just get more and more excited the more we talk about it. We get ideas, and we try other people's ideas out." Richard recognized the importance of dialogue to the process and now looks upon his job "as more about communication and helping people be okay with it." These conversations extended beyond faculty teaching the same course or in the same department at the same college. For Summer, "all of the experiences" at another college "were informing what I was doing in my role as Chair and vice versa."

These dialogues served additional critical purposes for faculty who were interested in accountability and authentic improvements to student learning. For Toni, 
they were not only "talking about the strengths and weaknesses of the course" and then letting that dialogue evaporate into thin air, they were "having a dialogue that's documented because that's more honest" and can be followed up on to gauge the effectiveness of new strategies. Open, documented dialogue about SLOA al so led more faculty to participate. Laura described how these dialogues promoted increased faculty participation by "incorporating faculty in courses that were being left out." Soon enough, non-participating faculty became noticeable outliers, more faculty joined into the discussion about how to improve the lives of students.

\section{Dialogue Changed the Conversations About SLOA}

Dialogue was a critical component of SLOA. The agreements made about course outcomes and the insights gained in discussing results directed the changes faculty participants made to their classes. This dialogue was key to SLOA's effectiveness and was most valued by faculty participants. Dialogue was described as the key component that created synergy among groups of dedicated, well-educated, socially-engaged professionals doing action research focused on improving teaching and learning.

Faculty participants generally described talking in smaller groups that included representatives either from their department or division and from college committees specifically focused on SLOs. They valued hearing a variety of perspectives. Mary reflected on a division meeting she attended: "We're incredibly small. We're this dinky little college. There's so many one-person departments." Laura valued conversations on 
the learning outcomes committee because it brought diverse perspectives and experiences to the table. For Starbuck and Toni, some conversations involved getting off campus and having some food and drink. Toni stated, "We need to make it more of a social activity... [so that it's] something people look forward to."

These discussions impacted faculty participants in ways that furthered the goals of SLOA. It was in conversation with colleagues that faculty participants became part of a team, learned from others, gained assurance, and were inspired to continue their endeavors. At first, it was a place "to speak your frustration, to hear the frustration and then address it" (Richard) or "to get away from all this and just be[ing] able to be open and speak openly" (Toni). They shared ideas that were solution-focused. Summer explained, "I see what works for them, I see what doesn't." Then the groups began to bond; Laura shared, "It can make you realize, 'Oh well, it felt like this for me, maybe you feel that way too."' Mary stated:

It's just so interesting to hear what other people do. I have fantastic colleagues. They're true believers. They really believe in community college education, and teaching, and the magic of the classroom, and the guiding from the side, all the good stuff that keeps me coming back to the table.

Mary admitted that as time went on the engaged group began describing those who were less enthused by outcomes assessment as "not so awesome." 
It was through this dialogue that the conversations around SLOA began to change. It led to wider conversations. Mary asked, "How can I work with other groups on campus?" For Starbuck, it "led to a great dialogue with a whole bunch of folks from... different departments." Toni identified dialogue as key to re-invigorating the teaching experience:

Faculty are much more engaged with what they bring to the table. They hate it, but when they do it, they want me to look at it. They're excited to know what I think. They're just like, “Wow, yeah, I get it." It's one thing to just keep giving students tests and everything, but it's another thing to be reengaged on the intellectual level with your peers about how you teach... I think it helps them to feel validated... or realize, "You know what? I need to pick up the slack. I'm just here, and I've been doing the same thing for 50 years, and I've got to do better."

These dialogues changed over time from venting sessions to bonding experiences to a means to reinvigorate teaching.

\section{Findings Validated by Coordinator Interview Data}

An analysis of coordinator interview data validated the themes found in the faculty data. The diversity of work experience was also reflected in the experiences coordinators reported. They had worked as novelists, consultants, and bakers, in a doctor's office, in marketing, and in TV and journalism. One was also a business owner. 
Coordinators, as engaged SLOA practitioners themselves, also shared a commitment to social engagement. Louis held writing workshops for cancer patients. Naomi identified herself as a social justice organizer. Athena volunteered at a food bank and intentionally embedded social justice into her coursework when teaching at a 4-year university. Stephen worked toward ending homelessness.

Coordinator participants also connected their social engagement work with the mission of the community college system. They described their work as "a dream job" (Louisa) that "feels like home" (Athena). They "realized how [they] could make a difference" (Naomi) and "work with underserved, underrepresented... populations" (Stephen).

Coordinators, in their work with faculty from across their institution, also recognized that faculty who were intrinsically motivated to improve were more likely to engage in SLOA. Coordinators described engaged faculty as open to new ideas. Athena's description of disengaged versus engaged faculty characterized the differences expressed by all the participants. Engaged faculty

are probably the kind of people on the campus that are change makers... people who seem the most motivated and doing outcome work are those who say, "You know, let's change something and see if we can make it better," or "We're having a problem here and we need to change it." The people who are not that engaged seem to be pretty happy with the status 
quo... I have a lot of sympathy for faculty [who] have been doing their craft for a long time and feel like [the] state is mandating them to do it differently... I think that the people who are not put off by and are engaged in student learning outcomes see this as part and parcel of good teaching and they've reframed it as, "I want to internally create a great teaching product or outcome for my students." They do that through being thoughtful about what they're putting together for students.

CJ summed it up: "For all those individuals who have a true dedication and vocation to their teaching job, [SLOA] is fabulous."

Coordinators also acknowledged dialogue with others as a driving force for change. Athena described "doing SLOs" as "really enriching your experiences by sharing ideas and taking ideas from others and making [them] your own." For Naomi, these conversations about teaching are what draw faculty in. As a result, coordinators described their own roles as primarily creating and maintaining a system of strategically-integrated dialogue to facilitate broader and deeper faculty participation in SLOA.

Coordinators acknowledged as well the connections between SLOA and social improvement. CJ described the purpose of previous educational reform movements as efforts "to create a better citizen in the sense of a more educated individual." In addition, the coordinators' own experiences paralleled the experiences of faculty. The coordinators were motivated to do the work because it aligned with their pre-existing values and 
practices, they valued positive social outcomes, and by virtue of accepting a difficult leadership position necessary to broaden the practice of SLOA, they were also directly engaged in positive social work themselves. CJ described the goals of everyone involved in SLOA as "making that student a better citizen, more responsible citizen who will go out there with an AA degree or with the courses they just took to improve reading and writing, and that's going to be a better citizen."

Coordinators, reflecting on faculty at their institution who are engaged in SLOA, acknowledged the centrality of dialogue to the process. Faculty "love the talking about teaching" (Louisa) and "they love to talk about the results of their students' [work]" (Stephen). From their institutional perspective, coordinators watched as faculty gained insights from working with colleagues to "articulate what our SLOs are" (Stephen), and found out that not everyone agreed. Naomi also witnessed faculty grappling with consensus: "When we have norming sessions and people are realizing that they're interpreting even the rubric language differently, that can be really insightful." Faculty learned from each other. CJ stated: "It helped them understand... see what changes they needed to do in their teaching to engage students or... [to] move the needle for the success rate." Naomi spoke about how SLOA engaged the faculty: "It was great to have faculty who are typically checking their phones or grading homework during the meeting... [say], 'Wow, that was really valuable. That was really a worthwhile process." Athena described why this dialogue is essential: "The struggling departments on campus 
are [those] where people are... not talking to each other about how they can focus and direct students in a positive manner" and why SLOA is so effective. She further shared that the successful departments:

They're arguing together, they're creating together, but they're meeting... to discuss what's happening in their classrooms. When I talk to other SLO coordinators, ...it's that process that makes it difficult to leave a faculty member behind. When you leave a faculty member behind, think about the 90 and the 120 students that are left behind. Because you know a poor faculty member still has a load that they teach and generally contract rights. The impact on those students... you have to bring them along. That synergy of dedicated professional faculty focused on improving teaching and learning together became seen as a resource for engaging more faculty.

Coordinators, through their expressed values and actions, also demonstrated empathy. Coordinators expressed concern that students needed more support, and that "when they have a failure... nobody is helping them" (Louisa). They questioned core assumptions of "what it is that is at the foundation of our discipline" (Athena) that might present difficulties for various student groups, and they supported efforts even when "it's a lot of trouble." CJ stated: "It should allow you guys to see if you are reaching Latino, African American, Asian students.” 


\section{Important Actions and Behaviors of the Engaged Practitioner}

The changes faculty participants made to their teaching practice as a result of engaging in SLOA shared some characteristics. Further, an analysis of the actions faculty described taking demonstrated that SLOA works to change teaching practice. Faculty participants described creating closer alignments between the course outcomes and their own course content and assignments. These changes, and cross-disciplinary discussions about outcomes, promoted intra- and inter-disciplinary alignment. Faculty reevaluated assignments, clarified instructions and the learning process for students, and restructured class time to focus student energy on the development of critical thinking skills. They also made sure their own class materials were readily available to students in an electronic format.

\section{Engaged Practitioners Made Changes to Their Instructional Practice}

As a result of engaging in SLOA, faculty participants changed several aspects of their instruction. These changes fell into four categories: (a) aligning course content and activities of the course with the agreed upon course learning outcomes, (b) investing time and thought in making course materials and expectations clear to students and focused on critical thinking, (c) restructuring class time to increase active learning and dialogue, and (d) making resources - including their own time - more easily available to students.

Aligning course content and activities with learning outcomes. Faculty participants described reviewing their teaching process for effectiveness in a variety of 
ways prior to implementation of SLOA. However, SLOA heightened the level of intentionality with which faculty approached their teaching practice. Seven of the eight faculty participants described taking action, once SLOs were implemented, to align their course content and activities with the commonly agreed upon learning outcomes. Summer re-examined "the types of assignments [she gave her] students to determine whether or not they're applying the course concepts." Richard changed his lectures and assignment content to align with the outcomes: "What I talk about in class has changed dramatically." Michael described giving up a favorite lecture that he always believed was a source of inspiration to students: "As a concrete result of the SLO reconfiguration of my class, material got thrown out." John shared:

It was the balance of what topics do I cover more of and less of? I had to beef up whole sections of my class... I used to not teach it. Now, I'm having to teach it. I've had to drop some other stuff to fit it in. I even tell my class, "Okay. Now, we're going to cover the stuff I'm not a big fan of. It's good stuff. You're expected to know it. We're going to do it." That's the change.

For Toni, although she felt her class was fairly set prior to the implementation of SLOA, "it help[ed] [her] to clarify" the plans for each semester.

Promoting intra- and interdisciplinary alignment. For several faculty, the collaborative effort of colleagues to agree "to set very specific pedagogical goals for 
classes" (Starbuck) within their discipline led to changes. For some faculty, this was challenging. Michael lamented, "Oh, I see, we get to write our own student learning outcomes, but not really, they have to be aligned" with what other faculty are focusing on and assessing. Others found it to be a positive change: "I like to think that when students leave my class, that students who are leaving my friend's class are leaving with the same knowledge" (Summer). Some departments found ways to be flexible and "realized that creating rubrics for instructors might be a good way [for] them to still have their individualized assessment methods, but with a standardized rubric of what the expectations are for that SLO" (Laura).

The benefits of such alignments were recognized even as they crossed disciplines. Starbuck experienced "a great moment of synthesis with two of my colleagues" and described the moment further:

We realized we were all talking about this same method of inquiry in our discipline specific ways, but there was this synthesis across all of it [and] we have students who are in each of our classes... [all] getting the... scientific method.

They made this connection clear to the students as well. Starbuck explained:

I did mention it to [students]. I said, "You know, I was talking to one of my colleagues about this, and what we are doing right now... is what you are doing in political science... [and]... psychology." The colleague in 
political science mentioned that as well in his classes, like pointed it out... I was walking past and he had just mentioned it as I was walking by so I popped in and said, "Hi!" ... It was just so nice that we recognized that and then pointed it out to students.

Making the learning process more transparent to students. Faculty participants all found that for the learning outcomes to be achieved, the alignment of the outcomes with the course content and assignments needed to be made more transparent to the students. Faculty described making outlines and instructions clearer and "more explicit" (Laura) to help students. Michael described it as "a more regimented expectation on [his] end for [students] and on [their] end for [him]," like step-by-step instructions: "Get on the train and we are going to stop at this station and pick up some packages, stop at this station, and we are going to get off here."

These steps helped faculty move toward an increased focus on more difficult skill development. Starbuck explained what happened without such focus: "[Not] clearly articulating what you are doing and why you are doing it... can lead... to assignments that are not getting at those higher order skills developments." Summer acknowledged how SLOA helped focus her lecture and assignments:

Once I started to institute these, the first change I made was I added all of my learning objectives to the start of each presentation... I started announcing, "Here are the things that we're going to accomplish 
today."....Then I started doing more projects that aimed at meeting those outcomes.

Faculty participants also changed the instructions for their assignments. Mary used rubrics to make expectations for assignments clearer to students. Laura also had "a scoring sheet that pulls apart elements of the rubric so that they explicitly understand that this means you should include those things." Rubrics made things easier for instructors as well "because you don't have to explain." (Toni). Toni stated, "If I have to explain, I just show them an A paper [on the rubric].”

Creating greater transparency for students also meant working with content that was relevant and of interest to students because, as Summer stated, "If they' re not interested, they're not going to meet the objectives no matter what I do.” John had to learn what interested his students: "I quickly discovered a lot of people don't care about baseball... I've had to learn to talk about things like MAC cosmetics. I didn't know anything about MAC cosmetics, but now I do." For Toni, these tactics helped connect underrepresented students to the course content: "It's about inserting the student." For Summer, inserting the student was a literal effort:

I knew that the test scores themselves were not a reflection of what they were learning. I brought it back to the class. It was a summer session, so we were seeing each other two or three hours a day every single day. I felt like we had a really good rapport. I just came back and I said, "Guys, your 
test scores weren't great. I know you're getting this because you're talking to me. Tell me how you want me to assess you. Tell me what would be better for you as students." They actually decided to form a committee in the class... and we met after class in the coffee shop. They had their little student [laughter] representative for the committee. We all hashed out these different ideas. Their ideas were awesome. We put them together and came up with something that the whole class could agree on... involving the students [is] the most important thing I can do.

Focusing on critical thinking. When faculty participants described the changes to their course content and assignments, seven of the eight identified increasing attention to critical thinking skills as a driving force. Whether it was a student's ability to "use... theories to make predictions" (John) or identifying "what's the cause, effect, and can you find examples to support that" (Laura), the changes described focused on higher order skills. Critical thinking included more sophisticated reading skills such as "how to read a primary source [and using] primary sources for their own papers" (Mary). Overall, faculty participants described "a combination of integrating content with higher order learning outcomes... reading comprehension and argument analysis" (Starbuck) that benefited students beyond the specific learning outcomes for the specific course they were teaching. Toni aligned the increased use of critical thinking skills with overall 
student development: "Once they do that, that helps with the critical thinking process in terms of how they see and articulate just about everything."

Restructuring time. Faculty participants also restructured how time was used in class. While not all of the changes described were specific to changes made after SLOA implementation, faculty described a transition to a more dialogue- and activity-based classroom structure as they became more effective instructors. At first, John reduced lecture time and told students, "I'm going to let you work silently." Later, he transitioned to group-based work: "Now-it's a collective." Michael and Richard described a similar trajectory: "I've increased the activities in the class by 50\%" (Richard), and "I make sure you practice what I hope for you to do on an exam" (Michael).

Faculty also described increasing levels of complexity in the dialogue structures they created. Mary described how students learned to read primary sources in "teams of four." She stated, "They all have a folder with a document in it that are all related, but distinct from one another... I shepherd them through this." Students are "mixing it up... getting into groups and doing things or even [into] different groups and doing different things with different people" (Richard). Starbuck created a research project poster session: "We're going to set it up like a poster session at a conference," and small groups will provide feedback on each project. 


\section{Making Resources Available to Students}

Faculty made course materials, their own time, and institutional resources more readily available to students. While interview questions did not specifically address technology, faculty depended on it to cover course content without lecturing on every topic. Faculty participants relied on textbook readings outside of class and made use of technology to place course materials online for outside-of-class review. First, they put all of the class materials online. Starbuck shared, "Every single thing I do is on there... so all of it is accessible to them." Toni did the same thing: "That way the students can access it... you show it in class, that's it... but if they can access it online... they can watch it anytime and they can constantly stay engaged." Then they added features like online quizzes and links to current events. Online quizzes helped ensure that students arrived in class prepared, already "familiarize[d] with the big concepts... so that when [they'd] come into class, [it was] already familiar to [them]" (Mary). Links to current events made classes more relevant. Richard shared, "If something happened yesterday, it could have been in today's lecture" and online for future review and on a future test. Faculty also used technology to make sure students did their homework. John appreciated the accountability that technology allowed: "Not only will you do it in advance, but I have ways to check to make sure you've done it in advance." 
Students are helping to drive these changes. Richard explained that faculty need to respond to demands from students to have course materials easily accessible even in class:

Things have changed and [students have] these expectations. Students will say, "You know what forget it— because I'm used to this other thing [online access] and I will go somewhere else to get that." ... It's just like... the service learning thing. Instead of saying you have to go down to this room somewhere down there... all the links are on the website. Just print them out at your house and bring them back to me. I can guarantee there are students who would not be doing service learning had I not made those links available on the class website, cuz they'd be just like, "I'm not going to go down there, forget it. Because we just want things we're used to." Faculty need to meet the students where they are or [they're] going to lose students.

Richard further expressed, They bring their laptop and they go, 'We can't access your slides, there's no WiFi in this classroom." ... It's not just used for social media-we need it and they need it and it's a part of how they learn and do their work. 
Faculty expressed the same needs in reference to their own work. Richard admitted, "If I can't do Moodle whenever I want to, I'm not teaching online... if it's not easy and accessible to me immediately, especially at my home, I'm not going to do it."

Faculty demonstrated a commitment to meeting students' needs by making these efforts. It takes time to manage a website, to update it every semester, and to keep the information on it current. It is much easier to have the same textbook every semester and simply email students back if they have a question. The faculty participants are demonstrating engagement in the learning improvement process through their investment of time. Finding the reading articles to put online, searching the YouTube videos, posting current news articles - all of this involves a time commitment. Summer shared:

I am on all the time...I spend a lot of time on YouTube and Googling and watching things. Even if I'm only going to show a minute and a half, I'll spend an hour watching something to make sure that I've got the right minute and a half clip that I want to show in class.

One faculty participant is writing his own textbook so that it will be free to students.

Encouraging the use of faculty time and institutional resources. Students attending community college tend to be the least academically-prepared when compared to students enrolling directly into the CSU or UC systems (CCCCO, 2016b). Many need assistance in learning how to direct and achieve their own educational goals. Faculty participants were aware of this and made efforts to help students gain those skills, either 
by making their own time increasingly available to students or by directing students to support services on campus.

Faculty participants made themselves available to students. Richard provided unlimited feedback on student research papers up until the due date: "I didn't used to do that." For Summer, it is a larger commitment: "I give my students full access to me. They can email me anytime. They can basically text or call me anytime." Mary does personal outreach: "I say, 'I've noticed that you haven't turned in any assignments... and I'm wondering if I can help you.... It's not too late, let's meet this week."' She also embeds positive encouragement to seek assistance into her presentations, sharing with the class, "I saw three of you this last week. Thank you for coming to my office hours. It was good to talk with everybody."

Faculty participants were aware of support resources available to students. Even without a direct question on the use of student support services, half the faculty participants did include support services such as TRIO, Puente, Project Rebound, disabled student services, learning centers, writing centers, and tutoring services in their responses. Several faculty participants described referring students to resources. Laura requires that they find a tutor or visit the disability resources office "if they are having trouble with the reading" or "to see whether or not they need some kind of accommodation." Mary described a more structured approach: 
On every syllabus, I have what's due, and we're doing that day, and then also recommended, "This week I recommend that you go to the reading center and get assessed for different ways, strategies, that will help you read better in college level classes."

Sometimes faculty participants needed to take a more personal approach: "Sometimes it might mean walking them to that [student support] office" (Starbuck).

\section{Findings Validated by Coordinator Interview Data}

An analysis of the coordinator interview data supported these findings.

Coordinators found that it benefitted departments when course outcomes and content were aligned, when faculty "had to come to some agreement... on how the course outline was put together [and] what those competencies [were]" (Athena) and to identify "'here's the criteria I'm looking for' and then [be] able to arrive at a consensus as a department" (Naomi) about how these criteria will be measured.

Making course expectations and assessment clear was necessary. Some faculty “just assumed [students] were getting it, but when they [did] the assessments, they learn[ed] that they [didn't]" (Steven). Louisa examined her course materials for clarity and described her actions as paradigm shifting, rewriting everything "from a student perspective." Naomi's department "ended up coming out with [their] own rhetoric... so [they] have a common language around how [they] teach." She also found that students 
appreciated rubrics "because then the grading [didn't] seem so subjective anymore... it's [no longer], 'The teacher likes me or doesn't like me"' (Naomi).

Coordinators, in describing what engaged faculty do, described something akin to the restructuring of class time, but instead discussed restructuring faculty time. The activities of engaged faculty as they worked on their teaching paralleled the increased use of dialogue that they asked of students in their classes. Athena described their meetings:

[T]hey were discussing what they were teaching. People were bringing new ideas and content to the table. There was a problem-solving mode. They were willing to invest a lot of time in grading portfolios... they knew that [dialogue] got at the root of understanding what their students weren't getting and what their students were.

Engaged faculty used institutional resources themselves. They attended professional development activities. They learned new software and reached out to others to improve their teaching. When Mary recognized an area she needed improvement in, she reached out:

That might be a process of writing, of having colleagues come in and provide feedback to you about how you do what you do. I just asked a colleague the other day, "Could you come and watch me teach in this class? Because I'm not sure if I'm doing this in the best way I could, and I know you could help me." 


\section{Summary}

The faculty participants in this study all identified themselves as engaged SLOA practitioners, using SLOA with the intention to improve teaching and learning. The participants also shared some additional characteristics. Faculty shared a diversity in their previous work experiences. Through both their stated values and described actions, participants revealed values that aligned with the overall goal of improving society.

Faculty and coordinators both engaged in collaborative volunteerism aimed at addressing social needs. They identified a shared belief that access to and success in education was a means of improving society. As a result, they designed courses that promoted civic engagement in their students as well.

Faculty were intrinsically motivated to improve their teaching with the goal of helping students learn. As an educational reform effort, SLOA was perceived as a continuation of other similar teaching assessment and improvement methods with which faculty were already familiar, and they identified it as a method that promoted positive social values. They focused their outcomes and assignments so that the critical skills being developed aligned with skills needed for positive social participation. These included job skills, critical thinking and writing skills, effective communication skills, and the ability to take responsibility for their own work and advocate for their advancement. The attitudes expressed toward students and actions taken by the faculty participants demonstrated empathy. Faculty reflected on their own actions, took steps to 
learn about their students, and engaged in activities aimed at meeting students' needs. Faculty also recognized the importance of collaborative dialogue in facilitating SLOA. Faculty included a variety of types of conversations in their descriptions of collaborative dialogue promoting SLOA. Whether faculty were deciding on outcomes for courses at the department level, analyzing assessment results in a committee, or working on their teaching practice in a small group, dialogue was described as facilitating synergy within and across departments and disciplines. In addition, it was through conversations that attitudes toward SLOA changed.

The actions taken by faculty in response to SLOA revealed that it works to change teaching practices. Faculty aligned their course content and assignments with the course and program outcomes, restructured class time to allow for greater focus on critical thinking skills, took steps to clarify the learning process for students, and used technology to make course materials readily accessible. Faculty also took steps to encourage student use of institutional resources, including time with faculty. 


\section{CHAPTER 5: FINDINGS—PART TWO}

Changes in action often precede changes in beliefs. The faculty members in this study described making changes to their teaching practice as a result of participation in SLOA. While modifying their teaching practice, faculty beliefs about teaching and learning may have also changed. This chapter addresses the research question, "What do engaged faculty believe about SLOA, teaching, learning, and achievement gaps?"

\section{Faculty Beliefs and Attitudes}

Faculty participants in this study resisted the widespread criticism of public education. They described and revealed a set of beliefs about teaching and learning that aligned with their attitudes toward and reasons for engaging in SLOA and described SLOA within the context of desires for social improvement. They assumed responsibility for their teaching practice and its impact on students. Faculty participants did not claim that not enough other faculty members were engaged in SLOA for it to be fully effective. Instead, they resisted mandated participation. Faculty did feel their role as community college instructors changed as a result of SLOA, however, they did not feel that their academic freedom in the classroom was challenged. Faculty participants did recognize that engagement in SLOA improved their teaching practice, however, as a group, they were reluctant to claim that SLOA improved learning. Almost all of the participants identified the complex challenges faced by students as impacting students' ability to demonstrate the learning outcomes for their courses. Achievement gaps were identified as 
the result of differentials in the level of challenges faced by students outside the classroom. However, while at first disconcerted with the idea that their teaching practice might perpetuate achievement gaps, faculty members did consider SLOA, and further changes that they could make based on disaggregated assessment data, potentially useful for closing those gaps.

\section{Faculty Did Not Accept the Public Criticism of Teachers}

Faculty members at community colleges across the state of California are required to participate in SLOA (ACCJC, 2014). Policy papers from NILOA identify SLOA as a means of quality assurance, a result of genuine concerns that student success rates were lower than desired, especially considering the quantity of public funds invested in higher education. Most faculty participants acknowledged these concerns when asked why they were being required to participate in SLOA and recognized that concerns about teaching quality existed. However, even though faculty participants acknowledged the benefits of SLOA to their own teaching practice, they expressed skepticism about the validity of holding higher education as a whole, and teachers specifically, accountable for educational outcomes.

Several faculty participants acknowledged that SLOA might help solve some existing problems in the system of higher education. Starbuck recognized improvements in education as a path to social reform and wanted to believe her "pie in the sky answer... [that] economic inequality is the problem that we want to solve." John wanted 
to "believe that it's just really an honest effort to get better at education." Several faculty participants also acknowledged that students were not graduating with "the skills that they should when they leave a college education or even a high school education" (Summer).

Public investment in education was also acknowledged. Michael described the purpose of SLOA as to “convince taxpayers that they are getting their money's worth when they pay for colleges." Richard sympathized with public concerns that our education system is not producing skilled workers. "In the end, it really boils down to dollars and cents" (Toni).

However, faculty participants also questioned the level of responsibility for student success placed on teachers. John was "highly skeptical" that there was valid evidence that “American education isn't as good as it should be." These national claims that our educational system is in crisis was "because of a propaganda machine that says public education doesn't work" (Michael). Mary's response was sarcastic. Clearly the problem with student success was because, teachers don't do their jobs... clearly, it's the teachers, because it's always the teachers. The teachers suck. That's always the answer, from Sacramento or Washington... Whenever there is a problem with education in the United States...the first answer is, well, there must be something wrong with the teachers. 
Michael was more direct. The criticism of faculty, "it is bullshit, it is absolute... it [public education] works. It has a hard job and it does the job as effectively as any institution on this planet could." Michael challenged Google to create a better education system and pointed out that it is always easy for people to complain.

\section{Faculty Perceptions of SLOA}

What in Chapter 4 an analysis of the actions taken by faculty when engaged in SLOA demonstrated that SLOA worked to change teaching practice, faculty also believed that SLOA works to improve teaching. Faculty acknowledged SLOA as a means of aligning the learning outcomes for a course more directly with the content and assignments. Also, SLOA was a means of creating and supporting a student-centered learning environment. More importantly, SLOA was identified as a means of quality assurance that supported faculty in learning to teach, encouraged them to innovate, and helped identify and address gaps in student learning. Essentially, SLOA was described as a conscientious and reflective teaching method that focused on meeting students' needs in a way that provided a measure of quality assurance.

Alignment. Faculty participants described SLOA as a means of aligning course learning outcomes more explicitly with course content and assignments. However, it was not as simple as using the outline of the course content as a starting point and creating assessments that measured student learning. Outcomes assessment allowed for the course content to be used as a means to an end in pursuit of developing students' higher order 
thinking skills, which were valued by faculty. Starbuck provided the most succinct explanation of this purpose. She said that SLOA required faculty to "set very specific pedagogical goals for classes, a combination of integrating content with higher order learning outcomes that were focused on 'So how do we use the content of a course to help teach these other broader skills?"'

For Michael, the first step in SLOA engagement is to "organize your class based on the student learning objectives [outcomes]." This organization then informed the presentation of material. For Laura, "the outcomes themselves are to help ground the student and the instructor in the core objective of the class - which sounds obvious, but it is easy to lose sight of, for both parties." Instead of measuring content, Summer wants to know if students are "applying the course concepts appropriately," because the concept is the higher order thinking skill-or outcome-around which the course is organized.

\section{Student-centered learning that provides quality assurance. Faculty}

participants described the SLOA process as facilitating a more student-centered learning environment. For Mary, “SLO assessment helps to create an environment where you're student-centered... and [that] is serving your students." However, while being studentcentered was described as an ideal, it was not enough to guarantee that students met the desired outcomes for the course.

Faculty participants focused on SLOA as a means of quality assurance that helped faculty learn to teach, to continue innovating, and to identify and address gaps in student 
learning. For Richard, using SLOA to learn to teach was fraught with uncertainty, but ultimately successful, “I had no training, I didn't know what I was doing." Laura found a similar purpose for SLOA,

So I see it as an assessment for holding the college-level line of "this is what's expected of [students]" but at the same time helping teachers identify where they need to create better assessment methods and teaching in their own classroom.

Mary described SLOA's entire purpose as a means of assessing the give and take between faculty and students that results in learning:

People are not vessels. We're not containers. You can't just put the skill into the person... It's not just about the student. It's about how you set up that information to be taken up and used, how you set up that information to be discovered.

Richard insists that assessment works better than student evaluations, "I've been in to observe a part-timer where I'm sitting there going, 'This is a disaster.' I'll read the students' evaluations and they're like, 'This person is great."' Richard insists, student evaluations will not reveal the strengths and weaknesses of teaching practice, but SLOA, when you use these assessment techniques, it does come out... [and] We just want you to do something that's working... Who goes to their job and you can do something that's not working and they're going to keep paying 
you? What's nice is we get to do whatever we want but now they're just saying, "we'd like it to work."

\section{Balance of Responsibility Between Faculty and Students}

While faculty participants did not fully accept responsibility for overall rates of student success or identify inadequate teaching practice as a primary cause of perceived poor educational outcomes in the United States, they did assume responsibility for doing their jobs well. They assumed ownership of the creation of the learning environment, for making expectations clear to students, and making content accessible. Faculty participants often took it personally when students did not do as well as was hoped.

However, it was the students' responsibility to participate in the educational endeavor by showing up for class, doing all assignments, and asking for assistance when needed.

Responsibility for learning environment. Faculty participants assumed full responsibility for creating a learning environment that promoted positive student development. Toni sets the tone by giving all the students full credit for the course up front and saying that it was up to them to keep the points. Mary intentionally designs her classes so that "you can trip and fall and get back up again and not fail." She sees it as necessary to “encourage students to fail. You can't learn anything if you don't fail... I normalize that struggling as 'this means you're learning." For Starbuck, it means letting students know "why they are in that room... why it matters that they learn" and understanding that "you will only learn what you teach yourself." 
Responsibility for making expectations and content clear. Faculty described responding to SLOA by making their content and assignments "clearer" and more "transparent." This theme permeated expectations faculty placed on themselves to meet their responsibilities to the students. Faculty participants described clarity and transparency as the faculty responsibility, and "trying to present the material the best way I can" (John) and "to model, as frequently and best possible, the best practice with which to approach the ... assignment" (Laura). For Starbuck, "transparency is a huge part of it... all of my assignments are ridiculously long because of the instructions."

Taking it personally when students did not achieve. Faculty participants questioned their own roles and responsibilities for student outcomes, especially when students did not do well. When students struggled, Richard asked himself, "Is there something I can do?... I've never thought,... 'Oh, it's their fault."' Michael described engaging, over the course of several years, in conversations with others about the responsibility of faculty members for student success. In the end, he assumed responsibility for helping each student make educational gains, "always giving onehundred percent to every student because every student is struggling in some way at some level." For Summer, when my students are struggling, I have that tendency...I put it on myself first... I judge myself first, "Maybe I didn't do that very well" or "Maybe I shouldn't have said that one thing" ... I can be pretty hard on myself. 
Expectations placed on students. Faculty participants also placed clear expectations on students to show up for class, do assigned work, and participate in the planned activities. All described these expectations as what students needed to choose to do. The faculty create the learning environment; students have to get the work done, avoid procrastination, and participate in the group work. Laura insisted that learning is a student choice:

I'm hoping that they rise to meet the challenge ...I will often use a lot of that language of choice, advocacy, resources, to make it clear that ...they have to make those choices...that if they are having trouble with the reading that they find a tutor. If they don't understand the assignment, that they ask me questions in a timely manner... If they are struggling with the material that they meet with somebody in disability resources... It's their responsibility to seek it out and advocate [for themselves].

For Mary, students have to be willing to take risks, "which is so hard...it requires you to be confident, to speak to your peers, and maybe even speak into a big group...they have to be courageous, really courageous."

Sometimes the faculty's efforts do not pay off and these experiences are the ones that inform where faculty place responsibility for student success. Responsibility is shared between faculty and students. Laura described her experiences when reflecting on SLOA data: 
The reality might be that no matter how hard I work, no matter how passionate I am, a student might not get something. And that's the reality and there's nothing I can do about that... I get angry, I get pissed, I think of all the times I reminded them to do their assignments. And then I kind of take a deep breath and I remind myself that things are not personal, that circumstances are as they are and I need to figure out a way to go from there. Cuz there's just no point in wagging the finger and going "but I told you guys..." It's like, well, realistically, whatever the situation is, they didn't do it.

\section{Change in Faculty Role}

Tagg (2012) discussed several reasons why faculty members resist change. One reason was attributed to the "endowment effect," or the idea that faculty valued what they already had. According to Tagg, faculty members in higher education are respected for the level of expertise in a discipline that they bring to an institution. Faculty members express and build on this expertise through research publications, not through teaching acumen. Thus, SLOA was perceived as a means of focusing faculty members' energies and talents away from discipline expertise and toward teaching expertise. This change in role is assumed to play a role in faculty resistance to SLOA.

Faculty participants in this study did perceive SLOA as a change to their role as faculty. Newer faculty members recognized the mandate to participate was new. More 
experienced faculty recognized changes to the extent and nature of their job. The youngest of the faculty participants, with only three years of teaching experience, did perceive a change in her role as a faculty member, but the change was based on the mandated aspect of SLOA, not the change in the job expectations. The new part was the requirement that all faculty participate, with an assumption that veteran faculty members did assess student results because all faculty "naturally do it" (Laura). Summer, the next youngest participant, also perceived the change as SLOA being a mandate that might change "the way we teach and change the lessons" based on the assessment data collected. Both of these responses are based on an assumption that assessment records were already being kept by more experienced faculty. For Richard, because SLOA was a tool for learning how to assess and teach, it could "potentially change what you're doing in the classroom."

However, other faculty participants identified SLOA as a change in the role of faculty within the institution. This included bringing a more scientific interpretation to teaching and using faculty expertise to experiment with new methods and write reports about best practices in teaching on behalf of the institution. These changes integrate faculty further into the decision-making at the institution.

A more scientific role. John identified the change in faculty members' approach to teaching that was necessitated by SLOA, "We have to get every faculty member to be like a scientist... be skeptical." He shared how another faculty member used to gauge 
their success as an instructor by how energized they perceived students to be, perhaps after spending the day talking outside under a tree. If that faculty member was told that their new role included basing effectiveness on assessment data, they would say, 'Well, that's not what I do."”

Michael shared a sense of loss, saying SLOA “doesn't allow me to explore the art of teaching, it forces me in a style that may not be my style...there is an art to teaching that this squashes tremendously." Richard acknowledged the shift away from being a specialist in a discipline. He explained,

part of the problem [may be] with university and college professors is that we are just specialists with no training in education. With no appreciation for this assessment process and no knowledge how to do that... If we did have that foundation before we came in here it would be a different discussion instead of an argument.

The SLOA process in California community colleges includes regular reporting on assessments and student assessment results, as well as the use of these results to inform changes and follow up on their effectiveness in improving student learning. Toni identified these reports and follow-up as what changed the faculty role. Further, community colleges, in making institutional decisions, are expected to use SLOA reports to identify effective improvements, direct resources to the most effective practices, and 
then measure institution-wide success levels. Mary found that SLOA, "integrated faculty into the institution in a new way... you're less able to teach and leave."

\section{Academic Autonomy and Freedom}

Faculty in higher education have traditionally expected to work with a great deal of autonomy (Tagg, 2012). Faculty also traditionally expect academic freedom-the right to explore the full range of ideas relevant to their discipline without fear of retribution (American Association of University Professors [AAUP], 2006). The participants in this study referred to both this autonomy and freedom as academic freedom. A continuation of Tagg's (2012) exploration of reasons why faculty resist change is the idea that faculty value academic autonomy and do not wish to give it up. For many, SLOA is a challenge to academic autonomy fueling some of the resistance to engagement. Faculty participants in this study universally disagreed with concerns that SLOA restricted academic freedom. They felt free to discuss topics in their field with no restrictions, they felt free to design the assessments of their choice, and they identified the claims that SLOA restricted academic freedom as unfounded.

For John, SLOA had not "created any kind of chilling as to the topics I can talk about or how I address those topics." Mary intentionally designed outcomes that, will never impede the academic freedom of the part-time people that work for us because I want them to be able - if they want to teach students how 
to read and interpret primary sources in a completely different way than I do, go for it.

Starbuck felt the same sense of freedom, "You pick your assignment, you make it whatever you want." Toni agreed, "It doesn't mean you have to give a test... Whether it's a project or a discussion that can be assessed, just keep that statement [the outcome] in mind...It's not that difficult."

Restrictions to academic freedom as a red herring. Faculty participants described claims that SLOA restricted academic freedom as diversions from other concerns about the impact of mandated participation. John explained that some faculty members expanded the definition of academic freedom from his own understanding of, "a complete freedom to [discuss what I want]" and that as long as he meets his "responsibility to represent his field," this definition of academic freedom is not restricted by SLOA. Other faculty expanded this to, "I have the right to talk about whatever I want to talk about" even if it does not represent the discipline. This more expansive definition of academic freedom might be challenged by SLOA.

Laura also suspected that faculty members who complained about restrictions to academic freedom actually had other concerns on their mind: "When they gave me examples of where it violated academic freedom, they were giving me examples of where the assessment showed that their instruction was weak... To be very blunt." 


\section{Faculty Believed SLOA Worked to Improve Teaching}

Faculty participants in this study described changes to their teaching practice that when analyzed revealed a movement toward alignment with research-based best practices in education (see Chapter 4). Participants also believed that participation in SLOA led to improvements in their teaching practice.

The Aha! moment. Most of the faculty participants, when asked at what point they realized SLOA was an effective tool for informing teaching practice improvements, acknowledged having some of this insight prior to required participation. For Mary, "I was always like this...I'm a new generation, too. We just assume that this is how it works." However, three faculty participants, John, Michael, and Summer, described an "Aha! moment" that converted them from either skepticism or resistance to supporting SLOA as a means to improve the classroom experience. All three began using SLOA as part of a college-wide mandate. John, a skeptic at the beginning, recognized, "there ha[s] been some improvement in results [and] I think it has really helped to clarify among the different faculty what we expect to achieve." Michael, who feared SLOA was a prelude to standardized testing, acknowledged "a moment that I said, 'I'm going to go with this better organized class." Summer, a SLO committee member tasked with helping others adopt the process, found that,

It really dawned on me in ways that it hadn't before this is something that is necessary and useful in my classes. I had definitely a peripheral 
understanding of that before, but after I turned around and had to verbalize that for my faculty, it became more important to me. I felt more passionate about it.

SLOA as a logic model. Others engaged in SLOA from the beginning because it made sense to them. Faculty participants accepted that the model of identifying outcomes, designing and implementing appropriate assessments, and using the data from those assessments to improve teaching practice should logically improve key learning, something they desired to do. John anticipated appreciating evidence of effectiveness, "We're going know whether this is working, where we wouldn't have known before." Richard anticipated being able to apply the outcomes data:

When you have a variety of those things [outcomes] and hopefully these SLOs are being measured in a variety of different ways, then you could even see with your population which mode of delivery and assessment is working best for your students.

Collaboration with colleagues can help even out the student experience, a concern for Summer, "I'd hate to think that we're teaching so differently and with such different objectives that the ... student I produce is going to be different from someone else's ....in that regard, there's great potential." Mary recalled, as a new instructor, being told, if "you're going to be looking at how to be a better teacher anyway, why don't you just design your SLOs to be something that will help you." 
Faculty believed SLOA improved their own teaching practice. Faculty participants identified SLOA as an effective tool for informing changes to their own teaching practice. Overall, SLOA provided opportunities for faculty participants to reflect on their teaching practice and use data to focus their efforts to improve.

Reflection. Mary identified SLOA as providing for more reflection whereas Starbuck described SLOA as a "constant feedback loop" she uses to "consistently interrogate what I'm doing." Reflection was not always easy. Laura and Richard experienced some nerves, and Richard shared "to be honest, my first emotion was 'This is difficult'... It's harder to digest than I thought it would be." The discomfort became fruitful for Richard, "I just said to myself, 'I don't know what I'm doing and I need to take this information and use it to make myself a better teacher" rather than do what he sees the resisters to SLOA doing.

Focus with data. For John, SLOA provided focus. His department had three SLOs. On two of them students seemed to be achieving the outcome, but not the third. John provided specific examples of students not doing well on a particular portion of the exam and he addressed those areas. Michael found SLOA "hugely important" to the redesign of his online course. He used SLOA to design departures from his face-to-face courses due to the different needs of online students. Richard emphasized that "when you have a variety of [assessments]... you could even see with your population which mode of delivery and assessment is working best for your students." 
Data and other empirical evidence were desired. Faculty participants appreciated the use of data to inform classroom changes and credited the SLOA process with creating a stronger reliance on empirical data. John shared his disdain for the "history of bad science" that used anecdotal or flawed data collection methods. He expressed suspicion that faculty members who invested a great deal of effort into classroom changes might "experience a belief that students - that you, did a better job" without relying on empirical evidence that improvements occurred. He questioned his colleagues' practice of "measuring performance" by "observ[ing] students' energy" and engagement in the classroom and found it frustrating. John had empirical evidence that students in his department's classes were improving - the instructors gave a common exam and were tracking the scores every semester. Summer collected qualitative feedback from students at the end of each semester, finding evidence that the learning experience improved from students' perspectives. Michael had direct evidence that retention and performance improved substantially in his online courses.

Most faculty participants, however, did not have measurable results that the changes they made to their courses improved student learning. The perceptions were described as "just peripherally what I'm seeing, not necessarily anything statistically significant" (Summer) and not enough time had passed, "It's too early for me to say whether or not we've seen any numerical impact" (Toni). 


\section{Reluctance to Credit SLOA With Improvements to Student Learning}

Whereas faculty participants believed that their own teaching practice had improved, most participants were unwilling to claim that SLOA improved student learning. While three faculty participants, Richard, Mary, and Summer, did state that student learning had improved, the other five participants declared outright that SLOA did not improve learning. John hedged, “Testing isn't a very good way of measuring, but we don't have good alternatives." Michael insisted, "The answer is no, put that down."

Faculty participants identified the lack of empirical data that learning had improved as informing their reluctance. Faculty also expressed a reluctance to assume full responsibility for whether or not student learning improved. Engagement in SLOA helped identify gaps in student skills and knowledge that required more than one semester to overcome. Faculty participants also shared concerns about the types of valuable, but longer term, learning outcomes that were potentially lost in the SLOA process.

Lack of empirical data. The lack of empirical data demonstrating improvements to student learning was the most commonly identified factor that led to doubts that SLOA improved learning. Michael started out as a skeptic, then later realized that "the whole SLO pedagogy, the whole concept of teaching to a standardized objective... is great for online learning" and as a result he declared, "I am a true believer and I think this method can work." However, even though he perceived the work of his online students to be 
"many degrees better than it used to be," he also provided a caveat about any student achievement improvements: "my retention rate, my success rate, those might or might not be measurable." John too, appreciated the logical model, "Certainly if students and teachers aren't engaged, it's not going to be successful." But he was reluctant to declare improvements to student learning. John served on his college's assessment review committee that looked at all the SLO results and did not see evidence of improvements in student learning, "I don't think you could see the trend in that."

Reluctance to assume full responsibility for student outcomes. While faculty members demonstrated an acceptance of responsibility for improving their teaching practice, they were reluctant to assume full responsibility for whether or not students learned. Using SLOA did change the teaching and learning environment in ways that perhaps lost other valued qualities. The type of learning valued by the faculty participants, such as critical thinking, advocating for oneself, and gaining confidence, required more than one semester to develop. Also, SLOA tended to reveal a lack of student preparedness, something faculty had little control over. And other factors, outside of class, also influenced student learning. In addition, SLOA was too new for anyone to really know if it were going to work.

SLOA identifies gaps in student knowledge and skills that need more time. With regard to preparedness for college level coursework, SLOA tended to work well at identifying gaps in student knowledge. Laura struggled with the low level of academic 
preparedness of her students, "If students don't have those ... basic skills, they are not going to be able to meet any of those outcomes for my class." Summer shared similar sentiments,

I don't think I was successful for all students. I just don't think that every student coming into my classroom was starting out at the same place. A lot of them have deficiencies that could be traced all the way through their education. I can recognize that more because of my [previous experience]. Participants also expressed concern about institutional expectations that faculty could both remediate the academic skills of weaker students and teach to college level learning outcomes.

Other valued outcomes were lost in the SLOA process. There were some concerns about the types of learning lost when faculty focused too directly on specific outcomes. Many outcomes valued by faculty were not always measurable over the course of one semester. Michael expressed concerns that some students who are comfortable asking,

What's the question going to be on the test?... How do I practice it?" are going to do better. Those same students, provided clear but narrowly focused outcomes, missed out on the opportunity to formulate broader responses to more open-ended questions with less immediate direction. 
John wondered about students being provided very clear expectations on fewer outcomes: "Where there might be great value in students having to be very uncertain and therefore have to build on their own broad understandings of everything."

John also worried that colleges might be failing to allow students to develop their own advocacy skills. Students need "to be stepping forward" and taking "ownership" of their education. He cited a psychologist on campus who insisted, "all that brain activity is really important."

Student development and learning were seen as cumulative across courses and over time. Starbuck recognized this feature, "They'll get some skill development in my class, they'll get some skill development in somebody else's class... it has a payoff a little further down the line." Faculty also recognized that students took a wide, often unexpected, variety of lessons away from their courses. Participants encountered students years later and discovered, to their surprise, that they were impacted by aspects of the class the faculty member had not identified as important. And faculty hoped that students developed cumulative critical thinking skills over the course of their college experiences, "I always get to building civil society, that's what we're doing..." (Starbuck).

Too many factors outside faculty control. Too many other factors, outside of faculty participants' control, also influenced student learning. John recognized that students who came to class and did the assignments were successful, explaining "One semester I pulled up all my data. I found out if I looked at all the students who passed, all 
but one of them had been there for every single clicker review and test." When it comes to data, this proved for John that "the changes in our overall college rates are swamped by factors that have nothing to do with what faculty do." Mary shared a similar insight, although she perceived SLOA to work for the students who were engaged with learning, she recognized that too many students lacked resources to focus on academics. SLOA,

Doesn't serve students who can't concentrate cuz they didn't have breakfast. It just doesn't fix all the problems. I can be the best possible teacher ever, and still have poverty rule my classroom, which is the frustrating truth.

Faculty participants, all college professionals with advanced degrees in the social and behavioral sciences, suspected that SLOA may not be sufficient to overcome the challenges faced by students outside the classroom.

\section{Location of Achievement Gaps}

Faculty participants described teaching practice improvements that resulted from engagement in SLOA, yet were reluctant to claim that SLOA improved learning. An additional challenge was that not all students were equally successful in their classes. This resulted in achievement gaps between demographic groups on campus. Faculty participants were all familiar with information about achievement gaps in success rates. They universally placed the cause of achievement gaps outside their classrooms: "The changes in our overall college [success] rate are swamped by factors that have nothing to 
do with what faculty do" (John). Toni agreed, "It has to do with stuff outside of campus, life." Faculty participants identified demographic changes, inadequate high school preparation and socioeconomic status as the most likely causes of achievement gaps.

Demographic changes. Faculty participants identified changes to student demographics as contributing to achievement gaps, including a change in the socioeconomic status of students and an increase in first-generation students. Mary recognized "that the student body is so different than it was even six or seven years ago, eight years ago, that the faculty haven't shifted to serve the student body that's here." Richard pointed out, "part of being a community college instructor is that you recognize the fact that this is a different population."

Inadequate high school preparation. These different demographic groups also tended to be underprepared for college level work. At John's college only $10 \%$ of entering students were prepared for transfer level English and math. Summer's students also struggled with college level reading and writing. Michael identified a lack of adequate high school preparation as problematic. Starbuck, too, worried about the preparation provided by the high schools in her area. In addition, she identified the challenges of English Language Learners. Laura was open to looking at instructional practices but also struggled to remediate both instruction and materials and direct students to outside supports when necessary. Laura felt this was especially difficult in general education classes because, 
The college is sending the message that you don't have to have prerequisites and that coming in with college level reading and writing expectations is optional ... the last thing I want to do is tak[e] it out on students, that "you should have done this in high school" attitude that is not fair

What Laura really needed was for "student[s] to come in with a college level" in reading, writing, and critical thinking. When students did not have these college level skills, they are not going to be able to meet any of those outcomes for my class, if your outcomes are set at a college level...[because] if you can't read the textbook, you can't come in with the knowledge to begin with, then there's no discussion in class around it.

Lack of socioeconomic resources. The demands placed on students who lacked sufficient economic resources also created achievement gaps. For Mary it was simple, “It's poverty. It's transportation. It's the cost of childcare. It's nutrition. It's illness and ability to get health insurance... The eradication of poverty would close the achievement gap in California." Michael provided a similar explanation; his students, "all of them work at least 20 hours and probably half of them work 35 hours" a week. Michael's solution to achievement gaps, "the easiest way ... would be, someone walks on campus, they get a stipend to live, they don't have to work 40 hours and they get a place to live and they can focus $100 \%$ on their school." 
While Starbuck hoped that the basic skills scaffolding she provided in class helped, steps taken by the institution or by faculty participants that might narrow achievement gaps also existed outside the classroom. John's college had a new tutoring center. Laura relied on the campus learning center to accept student referrals. Mary pointed out that institutions could find ways to provide free textbooks, improve transportation, expand child care facilities, or even take the classes out into the communities where the students are. Toni summed up the faculty participants' overall tone,

They're placing too much burden on faculty to solve a lot of ills that are beyond our-I mean, the faculty here are so passionate, and we deal with so few resources... There's homelessness. There's health issues... It's just the problems are enormous.

\section{Disaggregating SLOA Data}

Interview data about demographically-based student achievement varied. While identifying both the causes and solutions for achievement gaps as located outside of their classrooms, most faculty participants also expressed ambivalence, strong doubts about, and even outright resistance to the idea that disaggregating SLO data could be used to narrow achievement gaps. However, participants' answers also evolved as they responded. A few did feel that disaggregation of SLOA data could be a useful tool, but only if the data were used appropriately and a sophisticated conversation about the data's 
meaning was engaged in - the type of conversation not yet happening at their institutions. For example, Toni at first replied no, but as the conversation continued, her answer evolved to,

[For] new, young faculty...this could be transformational...It can either bring them halfway to the transformation table, they either feel guilty, or they don't know what to do with the emotions, or they actually try to really learn from the students.

Several other participants responded in similar fashion. Michael's first response was graphically negative:

If I found out that there were demographic differences in achievements I would be abhorrently throwing up in the bathroom. I would not have done my job well...that's a very personal problem for me. I would have to really rethink who I am.

With additional consideration, Michael's response evolved, Well, maybe I'll take that back... I would just be very careful about the measurement system ... If we had this conversation over dinner for three hours I might end up saying, "You know if we find those kinds of things happening ... you have to pay attention to it."

Then later Michael reassured himself, "I just don't feel the negativity that the numbers say... when I go in my classroom I have students who are just great." Laura too felt 
uncomfortable and her "gut reaction was that it would not be helpful," but she also advocated for the investigation of "that kind of institutionalized discrimination and privilege" and provided clear examples of the types of questioning and responses on the part of the institution and individual faculty that disaggregated data could lead to. At her institution, they explored disaggregated enrollment data to guide conversations about potential changes. She provided a specific example of a curriculum change that could result. For example, in United States history courses, if "you are not talking about the agency of African Americans... or you are only talking about the victimization... then there are certain students who might tune out." Even she would have "questioned the credibility of this course."

For John, the types of classroom adjustments suggested by Laura have the potential to trivialize the causes of achievement gaps. If the solution is, "instead of talking ketchup, you talk salsa, thus appealing to the Latino students," the entrenched and complicated difficulties associated with poverty and systemic inadequate K-12 preparation are overlooked. He is willing to look at the data and make changes, but "It's going to be hard to move the gap that much."

However, several faculty participants perceived disaggregated SLOA data as potentially more useful. Mary had not yet looked at disaggregated data but instantly began considering changes she could effect to "make the materials speak to that group of people in a way that it hasn't" or to "engage leadership of that particular group to 
shepherd us through the curriculum." Richard found the disaggregated data in his department's program review very useful and already, "there's some things that I'm doing slightly differently." Summer agreed that she is willing to respond to the students and to the data. She also has "an expectation that students can come in and regardless of their strengths and weaknesses or their backgrounds, that they will engage... and do the things necessary to elevate themselves." Starbuck answered, "definitely" yes.

\section{More Faculty Engagement}

Several researchers, including Hutchings, and Ewell, and Kuh, have identified faculty participation as key to the success of SLOA in improving student learning. Hutchings (2010) identified faculty participation as the "gold standard" for SLOA success. Summer recognized the lack of faculty engagement as, "one of the major challenges in making SLOs meaningful." However, other faculty participants did not agree, especially since participation was required. Participants found that faculty would resist mandates, were overwhelmed with other responsibilities, and did not identify SLOA as the solution for improved student learning, however, it might work to improve learning if more faculty participated. "That's probably true, maybe" (Mary), adding that more faculty participation might help, but,

more faculty should get involved from the bottom, not just right now, but really do it...I also think that certain faculty aren't reflective like this, just 
in the same way that you have students that just aren't analytical. You have to teach them slowly, slowly, slowly, how to be analytical.

Faculty participants acknowledged that resistance itself made SLOA ineffective. John and Toni both mentioned that some faculty members were just going through the motions to meet the mandate requirements. John explained some faculty attitudes, saying they will respond, "'That's not the kinda thing I do. I will fake it.' There's no way that it will ever work or be successful." Toni was more direct, "No. See, I see it from the faculty perspective. Students are either going to benefit or they're not, and a lot of it is on them [students] to step up." Faculty "do the best we can."

\section{A Call for Institutional Leadership}

However, several participants also expressed concern that institutional leadership was not ensuring the necessary constructive conversations necessary to use SLOA data well. For John, expecting faculty to make classroom changes was not enough. Laura felt uncomfortable when conversations turned to student deficits, "Some instructors felt that it had more to do with the generation of students that were coming in... and there were instances of instructors using veiled language about students simply being lazy." For Richard, the data he discovered in his program review stayed with him, "I can still see these pictures in my head. That's pretty powerful." He wished it could "lead to a campuswide discussion. But that's just something that doesn't happen." Summer pointed out, "there's just so many layers of dysfunction that keep people from participating in the 
process of learning about outcomes assessments and achievement gaps and ways to be effective." She was interested in taking on a leadership role but has met with resistance, I've gone to the deans, and I've said, "Hey, I'd like to offer this workshop" or "Can I reach out to the faculty and check in?" A lot of times the responses I get are "Yeah, I don't think you should do that." There's just no embracing of the need for us to have these open conversations... Nobody wants to talk about it. Nobody wants to commit wholly to it. The difficulty in categorizing faculty responses to questions about disaggregated data was also revealed in a short survey with demographic and additional questions completed by both faculty and coordinator participants. One question asked participants to rate on a scale of 1 to 10 how successful the effort to use disaggregated SLOA data, or DSLOA, might be in closing achievement gaps. A score of 1 was associated with the phrase, "Not at all-achievement gaps are not related to the classroom experience." A score of 10 was associated with the phrase, "Absolutely-working with disaggregated SLO data will improve the classroom experience." Polarized answers about the potential of DSLOA as a useful tool to help close achievement gaps showed up in the ratings participants provided. Both faculty and coordinators provided mixed results. Three faculty and one coordinator participant rated the potential of DSLOA at a 1, highly unlikely to be a useful tool in closing achievement gaps. One coordinator did not respond to this question, but her verbal answer was "I'm not sure." Two faculty participants, both 
on the verge of assuming a coordinator position, one faculty participant who was a part timer, and one faculty participant who was also a coordinator, rated the potential of DSLOA to help close achievement gaps at a 10,9, or 7 respectively. Only one answer fell in the middle, at 5, and the mean of the responses was a 5.5. This score was the lowest mean rating of all five additional questions asked on the survey.

\section{Findings Partially Validated by Coordinator Interview Data}

Analysis of coordinator interview data supported the themes derived from the faculty interview data. Like faculty, coordinators described SLOA in the same terms as they described good teaching. Athena identified SLOA as connected to "the things that I loved to do, which was go to my discipline's national conference and go to the great ideas for teaching... where everyone shares their teaching strategies and shares what they're doing." Coordinators, with their more institutional level perspective, recognized that the SLOA process created alignment within and across courses. Alignments facilitate course "norming" - agreeing on the criteria and standards for the course - and evening out of student experiences. The SLOA process helped put students at the center of learning. Coordinators did witness faculty members improving their teaching practice within a quality assurance framework. Stephen stressed, "There is a true desire to know the students have learned something" that was not measured by grades. Gaps in student learning were identified, and provided "a sense of what we can be discussing during departmental meetings" and during professional development (Naomi). Overall, SLOA, 
as described by faculty participants and reinforced by coordinators, was a system of quality assurance for teaching and learning that encouraged faculty participants to identify problem areas, then create strategies to improve teaching and learning in those areas. The activities described were believed to parallel good teaching practices.

Coordinators, who by virtue of their roles and responsibilities interact with faculty who are both believers in and resisters to SLOA, also acknowledged the concerns with overall student success. However, coordinators revealed far less skepticism about the validity of placing responsibility on teachers and faculty, even going so far as to directly identify teaching practice as a problem. Athena identified concerns about teaching, "We weren't teaching in such a way that students actually reached the achievement goal... it goes back to the building blocks of, 'what's behind the achievement data? What's going on in the classroom space in the teaching?"' While they did not directly identify less than ideal teaching practices as the cause, Louisa and Stephen both agreed that the problem being solved was one of accountability, "We were graduating people who couldn't read, write, or do arithmetic. And so the public doesn't trust us" (Louisa).

Coordinators were not asked to describe the balance of responsibility between faculty and students for student success. However, Louisa did answer the question within her overall responses, identifying the responsibility of the faculty member to be clear and transparent. Louisa also identified the students' responsibility as choosing to participate. 
She explained, "I am responsible for being as clear as I can about what they need to do and then if they make choices not to do it then that's their choice..."

While it might have provided additional insight to have the coordinators' perspective on whether or not more faculty engagement in SLOA would help improve student learning, coordinators were not asked this question.

Coordinator participants, with a more intimate relationship with the reporting processes at each of their colleges, agreed with faculty participants that SLOA asked faculty to become researchers on behalf of the institution. Stephen insisted that "even faculty who embrace SLOA will tell you, 'I see value in it, I'm willing to do it, but it's not part of my job." He continued, yes, "Assessing is a responsibility. ... To provide bucket-loads of data for others? That's outside the scope." For Athena, the whole process has been conceived of as one that has to be well documented...It means that we're researchers alongside being teachers, and that's a big break in the wave... People have to have a working knowledge of how to read social science data... It's a real democratization of the research role.

Stephen expanded on how SLOA uses faculty members to serve the purpose of the institution and integrates their work into the decision-making process: "As soon as you take that concept of assessment and you then use it for something other than enhancing the relationship between teacher and student, then the act of assessment is serving a 
different master." That different master was the planning process and institutional accountability. "I've all the sudden become a project manager, and I'm an ad hoc administrator" (Stephen).

Coordinator interview data reinforced the faculty responses that SLOA did not challenge academic freedom. Stephen identified that the reporting feature, brushes up against academic freedom because that information is really for you as an instructor... The fact that I have to turn over here and tell Uncle Sam-that's impinging upon the time I have to do this and so therefore impinging upon academic freedom.

Athena linked SLOA to a new level of accountability:

When you agree to be a professor at a community college you are entering into a social contract about articulation agreements and teaching the course outlines of record and because the SLO process might reveal that you're a law breaker on that [not teaching to the course outline] ...ultimately the majority rules on that and the evaluation process puts that person, that outlier, in line.

Most coordinators also reported existing insights that made SLOA a natural fit to enhance their teaching practice. Stephen explained, "I don't think I was ever a skeptic...I never doubted because I understood the idea." However, Athena did experience an Aha! moment herself. Athena reported, "being kind of a punk" when first teaching at another 
institution. She watched as her discipline graduated far fewer students every year than a similar, and in her opinion, far less engaging discipline:

I couldn't figure it out. It made no sense to me why the students were going to [other discipline] when they had these engaging classes they could take.... and when I look back at it now, knowing where I am at now, it is because those professors got together and created a program that provided direction and focus for those students and we were all over the place.

Coordinators recognized that they did not yet have the empirical data necessary to prove that SLOA improved learning. Naomi's response captured the essence of the root of the doubts:

When you look at the success rates, right, and you're hoping to see the needle move. It hasn't moved that much. I don't think it has so far. That's what I'm concerned about, is that people say "SLOs and assessment, then show us how that's going to improve student learning," because we said this is a means to improve student learning, right? That has been the primary critique that has been present since this whole SLOs and assessment came into being in California... we're not seeing the needle shift. 
While Naomi, Louisa, and Stephen were reluctant to identify SLOA as a means to narrow achievement gaps, $\mathrm{CJ}$ and Athena were more willing to imagine that SLOA could help improve learning in that way. The cause of the achievement gap was not teaching practice, "SLOs don't get you to that" (Louisa). For Stephen, the cause of achievement gaps was outside the classroom, yet still partially within the power of the institution; "The key is shortening pathways without compromising rigor, providing both the financial support and the financial incentives to go to and get through college, and then making courses available, making everything available to everyone."

$\mathrm{CJ}$ and Athena described a connection between improvements in teaching practice and the potential to narrow achievement gaps. Athena also saw potential in the community colleges. And while she described "the pressure that teachers feel to solve for systemic poverty as ... a burden that I don't want to shoulder," She hasn't "lost faith in that CQI [continuous quality improvement] process being the major answer." For Athena, changes in curriculum could be made to challenge the "colonial roots" of much of our content so that "it is relevant to our diverse student body." These changes to individual classrooms and teaching practices are facilitated by conversations about achievement gaps. Recognizing that other faculty are experiencing the same challenges acknowledges a potential "systematic failure going on here that will never be solved by just my classroom, so I have to talk with my other colleagues as well." Athena also expressed confidence that faculty members could use disaggregated data to close achievement gaps. 
She acknowledged that the data at her institution was revealing that first-generation or socioeconomic status were not driving achievement gaps, instead, "Race is the difference." She was confident however, If there's any arena where people can unpack how weird and complicated it is that the most salient factor for whether or not a student achieves in the community college is race, it's here. It's in the academic setting that is trying to figure that out. I am not so naive that I think education is the answer to everything. But I just know that having been in academe all my life and in the classroom that if people are really engaging in rich discussions about that over and over again...I just have a faith that there will be some sort of breakthrough on this.

\section{Summary}

Faculty participants' beliefs and attitudes about teaching and learning revealed an understanding of their roles and responsibilities as a continuation of their social engagement. Faculty participants described SLOA as a tool for further social improvement. More than a means to align course outcomes with content, SLOA allowed faculty to focus on activities that furthered student development to promote positive social outcomes. Instead of organizing the course to teach the content, participants organized the content to teach "these other broader skills" (Starbuck) important to improving society. Also, SLOA was recognized as a quality assurance measure. Teaching 
practices became more student-centered and focused primarily on achieving the higher order thinking skills identified in the course outcomes.

While acknowledging the interests of the public in ensuring a quality education for all students, faculty participants did not accept the widespread criticism of the quality of education being provided in the United States. Instead, they questioned the level of responsibility that education reformers placed on faculty to solve long-standing social ills. Faculty did assume full responsibility for the creation of a positive, productive, effective learning environment. It was their job to teach well. But, faculty did not accept responsibility for student learning. Students were responsible for achieving the outcomes of the course. This was not a new expectation.

While the participants in this study all identified themselves as engaged SLOA practitioners, and may have wished that more faculty would engage authentically in the SLOA process, they did not feel that mandated participation was helpful. Instead, the mandate produced counter-productive behaviors by resistant faculty.

SLOA did change the role of faculty. Overall, they needed to approach their jobs in a more scientific fashion. Some saw SLOA as a form of ongoing action research in the classroom, conducted by the faculty themselves. This feature of SLOA-collection of data, formulation of improvement plans, then testing of improvements to teaching practice for effectiveness - was a new role. Faculty did not believe that this new role, or the alignment of course content and assignments with agreed upon learning outcomes, 
restricted their academic freedom. However, the time required to conduct the assessments and manage the reports and improvements detracted from time that could be spent on deepening discipline expertise.

Faculty did believe that their teaching practice had improved as a result of SLOA. Faculty who at first engaged as a result of the accreditation mandate experienced a moment of realization that SLOA improved their courses. Faculty who were already engaged in some form of assessment prior to SLOA described further changes to their courses and believed that those changes represented improvements. Faculty identified intentional reflection on the effectiveness of their teaching practice as valuable. Use of assessment data kept dialogue and reflection focused on teaching and learning.

However, whereas faculty did believe that their teaching practice had improved as a result of SLOA, they were not willing to claim it improved student learning. They wanted evidence, and it wasn't showing up in their assessment data. Although SLOA was effective at identifying gaps in student knowledge that faculty could then find ways to address, many of the gaps — such as low reading and writing skills — represented a lack of academic preparedness for college level work that could not be addressed within one course. In addition, many factors influencing student learning are non-academic: stable housing, food, healthcare, transportation, textbooks, childcare, and often mental health services. 
Faculty also recognized that not all student groups were equally successfully in their courses. Achievement gaps existed at all colleges. Faculty located the causes outside of the classroom. Demographic changes in California brought larger numbers of underprepared students to campus. High schools needed to do a better job. A general lack of socioeconomic resources contributed to differential outcomes.

Faculty were divided on SLOA's potential to close achievement gaps. At first some faculty members reacted strongly, insistent that their own current teaching practices were not contributing to gaps, or were uncomfortable with the idea. However, as interviews continued, their answers evolved, and most ended up willing to explore the idea. They did acknowledge it was a difficult subject and that institutional leadership would need to lead the way on productive campus-wide discussions. 


\section{CHAPTER 6: FINDINGS—PART THREE}

\section{The Roles of the Institution}

This chapter focuses on the roles of the institution. In this case, the institution includes leadership — both faculty leaders and administrators, culture and attitudes toward SLOA, and the resources provided by the institution to facilitate engagement in SLOA. The institution as a whole sets the tone and creates the cultural context within which faculty either authentically engage with SLOA or merely respond to the compliance requirements of accreditation. The fourth research question for this study was: What are the important behaviors, attitudes, processes, or structures at an institution that influence engagement in SLOA? This question was addressed by asking participants questions such as, "How do you perceive the institutional culture in regards to SLOA?" and "What more could your institution do to support faculty engagement in SLOA?" Follow-up questions allowed for further inquiry into topics the participants identified as important. Participant responses were analyzed for insights into their perceptions of circumstances that created barriers to or facilitated engagement in SLOA. Leadership is considered within the context of barriers and facilitators to faculty engagement in SLOA.

The SLO coordinators, as a byproduct of their role at the institution, shared a wider perspective on barriers and facilitators to SLOA. As a result, this chapter reverses the structure of Chapters 4 and 5 and focuses on findings resulting from an analysis of coordinator interview data. This analysis revealed that leadership plays an important role 
in shaping the campus climate toward, and thus engagement in, SLOA. The SLO coordinators themselves were key institutional leaders, facilitating a system of strategically-integrated dialogue that promoted engagement in SLOA. Finally, the structures and processes of the institution also play a role in creating either barriers or facilitators toward SLOA. Each section is then validated by an analysis of the faculty interview data.

\section{The Power of the Leadership}

Participants in this study repeatedly and consistently discussed the importance of leadership in setting the tone and influencing levels of engagement with and expectations around SLOA at the college. Participants themselves did not clearly define specific leadership roles in their responses. Except when discussing department chairs, participants tended to discuss leadership as a group, for example, referring to "administration" instead of to particular individuals or roles. Within this context, leadership was acknowledged by the participants as influential in SLOA implementation.

Faculty senate and union leadership also helped set an institution-wide tone. When coordinators described the union as not supportive of the SLO effort, the coordinators' perception of the college culture and productivity around SLOA was less positive. However, colleges are made up of a wide variety of programs and departments, each with its own experiences around SLOA. Almost all participants agreed that in each program or department "personalities matter." While other faculty leaders within a 
department could influence the SLOA process, in most cases, it was the department chair's personality that was described by the coordinator as most important. The chair's attitude toward SLOA was described as a determining factor in whether or not a department participated effectively in SLOA. Connections were also found between the coordinators' perceptions of administrative attitudes toward SLOA and the overall institutional culture toward SLOA. When administrators were both positive and encouraging of faculty ownership of the SLOA process, coordinators' descriptions of the SLOA process was positive overall. In addition, as the college engaged in SLOA, opportunities arose for faculty to assume additional leadership positions.

\section{Faculty Senate and Union Leadership Attitudes Toward SLOA Are Important}

Coordinators identified faculty senate and union leadership as playing a significant role in the college's overall climate around SLOA. Coordinators more frequently pointed out the effect of union resistance in creating a negative attitude. This influence varied even within different departments at a college. It was particularly difficult when both the union and the senate opposed SLOA. However, when the senate supported SLOA, the coordinator perceived a more positive institutional tone and attitude toward SLOA.

CJ explained how, because union representatives worked in the humanities, that the department was struggling with its SLOA reporting. In addition, the college had been on sanction from the accreditors. The last thing needed for accreditation was for the 
union to agree to include a section on participation in SLOA on future faculty evaluations. The union only agreed to meet the accreditation standard, and even then, only agreed to a very minimal statement of "I participate," a statement that leaves out any direct reference to using assessment results to improve teaching and learning. CJ predicted that her college would be sanctioned by the accreditors again during its next evaluation.

Stephen experienced increased difficulties when the academic senate president backed up the union in taking a minimalist stance on SLOA, telling faculty, "You only have to do one student learning outcome per course, and you don't have to measure it all the time, and you don't have to measure it per student. You don't have to do any of these things." The role of the union also affected his ability to positively promote SLOs.

Stephen stated:

The idea of SLOs as an academic and professional matter living with the Senate... that idea hasn't taken a hold... it's not there. And I will blame my Senate President for it in some regard because she took the union line. When the academic senate does support SLOA, coordinators perceived a more positive attitude toward SLOA. Louisa explained how the academic senate played a role in leading the efforts on SLOA, deciding on the methods to be used, and thus providing buy-in at the college. The senate also set the tone for transparency and connecting SLOA to teaching and learning. Louisa explained, "You are not done until you come to a 
department meeting and share" the results and talk about your next steps. Naomi's experience was similar. At her college, open conversations with the academic senate led not only to buy-in for SLOA but also to a guiding philosophy on the use of SLOs. This helped to implement and "lend some strength to it."

\section{Faculty Leadership Within Departments Was Critical to Success}

At the department level, the only difference that coordinators identified in whether or not a department was engaged in SLOs was the leadership within the department. For example, at Louisa's college, "the chair makes this huge difference. If they believe in it, the department does it. If the chair does not," they do not.

When the department chair or other faculty leaders did not support SLOA, faculty were less engaged in the process. Louisa described one of the chairs at her school as convinced that, since SLOA was not scientific, it was not worth the faculty's time; instead, he planned to just use the final grade for his SLOA report. According to Louisa, "He really sets the tone." At Naomi's college, one new department-level SLO lead, with an opinion different than the previous SLO lead on the use of rubrics, was "moving $[\mathrm{SLOA}]$ in a direction where it could have no meaning." After the faculty worked hard "to arrive at something that really worked for [them], now the [lead] want[ed] to... just define an essay as A, B, C, or No Pass."

When the department chair or other faculty leaders in the department supported SLOA, faculty were more engaged in the process. For example, at CJ's college, one area 
of career technical education had struggled with SLOA until a new person stepped into leadership and "that piece of the puzzle" fell into place. At Louisa's college, the chair of her department developed systematic processes that encouraged innovation and experimentation that influenced the quality of SLOA. Louisa explained, the department chair: "set this up purposely so that you do your assessment in your class, you use your major assignment, then shared the results." This created a process where "the dialogue was about teaching" (Louisa). In the economics department, the chair's enthusiasm led to the department assessing every single semester. Louisa shared that "he does this more scientifically... he graphs their results" and shares them with his department to guide the discussions. At Naomi's college, one key faculty member in a department took it upon himself to coordinate making the entire SLOA effort more authentic, and members did. Stephen described the same set of influences, explaining that "this [was] largely driven by personalities. People who've embraced it and who want to see their programs, number one, comply... [but also who] see some value in it... that's a big part of it." The most engaged departments have faculty leaders who "get it." Stephen shared: "They embrace it. They become proponents for it, and they're part of that cadre of people who walk in and say, 'Yeah, we're doing this, and we love it."'

\section{Administrators Set an Institutional Tone}

Coordinator participants described a wide variety of administrative attitudes toward SLOA. Administration played a role in setting the institutional tone and 
productivity by either taking a disciplinarian or distanced approach to SLOA or taking a more supportive approach to faculty efforts.

Coordinators perceived administrators' lack of understanding of SLOA or lack of recognition of the benefits of or work involved in SLOA as a barrier to faculty engagement. Administrators largely did not understand what SLOA was, how faculty engaged with SLOA, or how SLOA changed faculty members' roles within the institution. At Stephen's college, "the deans themselves [had] no role... and the VPs not really much either." The office directors were "clueless about what to do with outcomes" (Stephen). Instead, administrators were perceived as viewing SLOA as a part of faculty professional obligations, not taking it seriously when faculty insisted that it was an additional responsibility (Louisa). Coordinators described a perception that administrators viewed SLOA as an existing part of faculty responsibilities that faculty should just do without any encouragement or incentive. If pushed, administrators sent out emails to faculty reminding them to get the work done $(\mathrm{CJ})$. For $\mathrm{CJ}$, "there were very few instances" when an administrator talked directly to faculty about their work with SLOA. Instead, at Stephen's college, faculty were informed that their future department budgets were dependent on how well they complied with these new requirements.

What administrators missed was that to do the work, faculty needed to learn new software systems, enter data, and then run reports producing aggregated and disaggregated SLOA data. While those reports became the basis of conversations about 
student learning, data entry was not a professional obligation, nor was research-even inclass action research — an obligation for community college faculty. Faculty did not see using their expertise to write collaborative action-research reports on teaching practices, requiring those reports to be made public, and then basing an institutions' accreditation status on the thoroughness of those reports as part of their professional obligation. For Stephen, assuming this was part of the faculty members' job was a mistake on the part of administrators: "Even faculty who embrace SLOs will tell you, 'This isn't part of my job. I see value in it, I'm willing to do it, but it's not part of my job."'

Three of the five coordinators who described little interest on the part of administrative leadership also described lower faculty morale and a less positive attitude toward SLOA. For example, CJ described both a college with a history of accreditation difficulties with SLOA and a president who appeared unconcerned that, in CJ's opinion, the college did not have sufficient resources to do SLOA well and would not be able to meet the new accreditation standards during the next site visit. CJ explained, “Assessment and SLOs [are] not really their priority." At CJ's college, they were still trying to get all the faculty to fill out their SLOA reports. Louisa, describing recent college presidents' perspectives on SLOs and the role of leadership in general as lowering faculty morale, claimed, "Both of them didn't see the value in it... [they only] knew it had to be done for accreditation." In the past, with supportive administrative leadership, it was different. Louisa shared, "We wanted to be the best." Louisa was 
discouraged and stepped out of her coordinator role as a result. At Stephen's college, the administration was described as "still kinda clueless about what to do with outcomes... [On] the administrative side... people are just waiting to be told what to do." Stephen also described a college that remained polarized over SLOA, and he was stepping down as well.

Coordinator participants who described supportive administrative leadership also described more productive and positive faculty engagement with SLOA. Naomi's experience was more positive. When she assumed the position of SLO coordinator, the vice president of instruction made it a point to let Naomi know she had her full supportand then followed through with the appropriate actions. Naomi's college president publicly set student success standards and openly stated that she wanted to find ways to do this while addressing faculty concerns that SLOA might lead to lowering academic quality. Naomi described a process where administration worked with the academic senate, classified staff, and student leadership to achieve buy-in on SLOA, with everyone working together. Naomi then described SLOA as a positive process, with the only struggle they really experienced as one of bandwidth — everyone at the college was "initiative crazy" and had to remind themselves not to take on too much and spread themselves too thin. At Naomi's college, faculty follow-through on SLOA reporting was taken for granted; it was part of the college culture, and now they are working on better integrating SLOA into the teaching practice. 
Athena did not describe difficulties with administration or a negative posture of administration toward SLOA. She did describe SLOA as "a way of life here... fully part

of the institutional culture." She credits this to an institutional connection between SLOA and faculty interest in working on equity issues and closing achievement gaps.

\section{Administrative Support for Faculty Leadership and Engagement}

Taking steps to build campus-wide buy-in was facilitated by open administrative support for faculty engagement. This included administrative recognition of faculty leadership. Two coordinators described being encouraged to step into the role of SLO coordinator based on their previous work with improving student learning. Louisa was identified by a "very visionary VP of Instruction" who recognized that her work with student-centered learning made her a good candidate to take on SLOA coordination. Naomi was identified by a colleague as a good candidate and then was openly supported by the administration in her new role. Stephen described faculty as more likely to engage in SLOA when administrators were viewed as providing resource support instead of viewed as compliance enforcers.

\section{SLOA Provided Opportunities for Faculty Leaders to Emerge}

Most of the coordinator participants in this study were already faculty leaders prior to becoming the college-wide SLO coordinator. Coordinator participants described the additional responsibilities and insights gained by serving in a college-wide leadership role. These descriptions included details about how the coordinators gained both 
confidence and a wider institutional perspective. These wider perspectives then shaped their actions as leaders.

Athena described how she gained a wider perspective when she became a department chair and assumed responsibility for reinvigorating her department. Responsible for handling student complaints, she realized that students were experiencing an unevenness in teaching and learning that left room for improvement. When she transitioned from department chair to SLO coordinator, she gained additional insight about the uneven experiences of students in different departments across the college. As a result, Athena could describe different areas of the college where SLOA was working and why and could advocate on behalf of SLOA. CJ was asked to serve as SLO coordinator after proving her leadership skills on the accreditation committee. The combination of her accreditation expertise with the insights gained as SLO coordinator led her to recognize the weaknesses in the college's SLOA capacity and to advocate to her college president for additional resources. Louisa was asked to take on SLOs in recognition of her learning community work. After hiring outside experts to come in and give presentations, she realized that she could do this herself: "I knew more than anyone else, therefore I was the expert." She was able to use her expertise to push the learning outcomes work to be focused on student-centered learning from the beginning. Naomi was a leader in professional development prior to becoming SLO coordinator. As a result, her leadership emphasized the need for professional development to assist faculty in becoming better at 
using SLOA to improve teaching. Stephen also used his previous leadership experience tn inform his SLOA coordinator role. trading on the goodwill he had accumulated to promote SLOA in areas of the college where it was unpopular.

\section{Faculty Participants Validated These Findings}

An analysis of faculty participants' responses revealed themes that paralleled those developed from the coordinator interview data. Faculty participants also described the positions taken by leadership as a determining factor in setting the institutional tone toward SLOA. When faculty described or recognized a negative administrative role in supporting SLOA, they also described a more negative campus culture toward SLOA.

At Toni's college, the leadership-including chairs and deans- took a disciplinarian approach. Toni stated that it was "really about cracking the whip... that [was] the administrative attitude, one of punishment." This made her job more difficult. At Richard's college, "It became a union battle." Once the union and the administration were in conflict, faculty stepped back: "They [got] turned off immediately" (Richard). Laura described the differences between two colleges at which she worked. At one, the SLO coordinator was supportive and open to critical dialogue and exploration and faculty were more engaged. At the other, college leadership just wanted the box checked: “However you wanted to check that box, they didn't care." Summer's administrative leadership was less engaged as well: “It's all just a matter of everybody's doing the bare 
minimum... and some aren't even doing that. Nobody wants to talk about it. Nobody wants to commit wholly to it. It's just this thing of contention."

However, when administrative and faculty leadership supported the process, faculty described a more positive experience with SLOA. Starbuck appreciated that the tensions between faculty and administrators were worked out in the beginning. By the time the larger body of faculty became involved, "it was a very creative process and it was very collaborative and it was very much about how [they could] make [themselves] better teachers." John explained that not only did faculty and administrative leadership take intentional steps to engage faculty, both the academic senate and the faculty union were supportive from the beginning. His school developed a reputation for being ahead of the game in using outcomes to improve the student experience.

In addition, faculty who engaged in SLOA began to recognize that their work at the college was intertwined with the work of others. This insight broadened their perspectives and their actions. When Mary began to work with her department's SLOs she realized that the SLOs were less useful than they could be. As a result, she recognized that she "was really ready to become department chair" so that she could change the SLOs. Mary added with satisfaction, "It's taken me a couple years to get into that position, and I've now changed them all." Mary also recognized that more leadership was still needed, especially to bring part-time faculty into the conversation. She shared, "That's a matter of people being all over the place, and me not having enough time. I 
wish I had more leadership capacity there." The SLO experience prompted Mary to think about the resources of the college more broadly:

If I see an achievement gap that mirrors the college itself, how can I work with other student services to provide proper support? Could I talk with counselors at TRIO, counselors at EOPS? Do they have ideas that I don't have?

Several of the faculty participants in this study were in the process of transitioning into the coordinator position. Even before their positions were official, they were thinking about how they would handle some of the challenges they knew existed. Richard described preparing for his new role by reviewing the SLO reports submitted prior to the last accreditation visit and found that "no one did anything since." From his newfound perspective, he expressed frustration because coordinators "have no teeth." He shared, "We're going to get dinged with accreditation... Every time we go on warning, every time these things happen, it hurts them. It hurts our students." Starbuck anticipated a steep learning curve when she became SLO coordinator. She knew there was more resistance among the faculty than she had experienced so far. She shared, "I'm going to start seeing the big picture more. I am going to see how these statewide things function... that might give me a different perspective." Summer was surprised when she became a point person for SLOA. She shared:

I can't believe how much resistance there is out there for measuring SLOs.... It's really brought out for me an awareness of some of the 
dysfunction that's on campus... I'm glad that I have that point of view now... before I got involved. It was like being a kid where just everything in the world seemed so happy. Then, once you grow up and you start to understand all the complexities of the world... you feel more mature.... It's only hardening my resolve to do more... I think that's a good thing. Toni also moved from faculty to coordinator. She, too, had to harden her resolve: "If something goes wrong, you want answers and you want accountability... it's forced me to really step up my game in terms of protecting my interests and people respecting my boundaries and respecting what I bring to the table."

\section{The Roles of Coordinators in Promoting Strategically-integrated Dialogue}

Coordinators did bring critical skills, insights, and practices to the table that furthered productive engagement in SLOA. Most important was that coordinators, with their institutional perspective and faculty experience, recognized the importance of dialogue and created college-wide dialogue essential to promoting engagement in SLOA.

The term strategically-integrated dialogue is intended to encapsulate the different levels and arenas of dialogue intentionally connected by SLO coordinators to support SLOA as a tool to improve teaching and learning. The SLO coordinators facilitated several layers of dialogue with the intention of sharing ideas and information across specific areas of the college. The SLO coordinators helped design assessment practices that included steps for dialogue between faculty teaching the same course to discuss 
course outcomes, faculty within the same department to discuss program-level outcomes, and faculty from within a school or division to discuss teaching and learning across different disciplines. At each stage, a report could be produced that documented conversations for later evaluation and follow up.

The SLO coordinators also facilitated assessment committees that discussed broader institutional data and practices. Sometimes these committees evaluated the quality and consistency of faculty reports and combined them into institutional summaries of SLOA progress. Other campus committees might also discuss these summaries.

Faculty valued dialogue that focused on the results of assessment in their own classrooms because it led to conversations about teaching and learning. Faculty found the dialogue at times scary, uncomfortable, reassuring, and inspiring, but also, most importantly, an instigator of change. The SLO coordinators facilitated those conversations, comforted and mentored faculty, and helped change resistance into engagement. The reporting and use of data requirements of the accreditation standards facilitated SLO coordinators' effectiveness in creating change. These mandated requirements provided an additional role for coordinators in which they were also accountable for maintaining the assessment process agreed to by the institution. The creation of strategically-integrated dialogue was a combined function of mandated SLOA requirements and facilitation by SLO coordinators serving as change agents. 
The coordinators in this study, with a more institutional perspective, also identified dialogue as the key ingredient to making SLOA successful. This success extended beyond improvements to in-class teaching practices to improving the experiences of faculty and students within departments and schools of study, with the hope of improving the institution as a whole. Athena recognized the importance of systematic dialogue when she insisted that "any time that people are building something together and talking about and systematically revisiting it, the prize is those students reaching [the] ultimate end goal."

In pursuit of this goal, coordinators fulfilled a set of roles that fell under an umbrella of inherent accountability. While serving in a leadership role as a faculty peer, they created a structure of dialogue, reporting, and feedback that built accountability into the system and met the accreditation standards. Coordinators set expectations around the SLOA process that kept the focus on teaching and learning. Coordinators facilitated dialogue between faculty within the same department and across disciplines and schools. In the process, coordinators gained insights about the strengths and weaknesses their institutions faced. Coordinators responded to those insights with systematic planning around dialogue that retained its focus on teaching and learning. To accomplish this, coordinators learned how to manage resistance on one hand while serving as mentors on the other. They fulfilled these objectives by prioritizing SLOA over their existing relationships at the college, their personal and family time, and even their health. This 
combination of important functions fulfilled by coordinators facilitated the implementation of SLOA in a manner that the coordinators believed successfully improved teaching. The willingness of coordinators to prioritize the facilitation of SLOA, and the belief that these processes would improve teaching and outcomes for students, also aligned with previous findings that coordinators and faculty tended to be socially engaged prior to teaching in a community college and connected their work to their goals of improving society.

Setting expectations around SLOA. Coordinators facilitated setting institutional expectations around the purposes and processes of SLOA. In the process, coordinators gained an institutional perspective of the strengths and weaknesses of departments and processes across the institution. They focused the attention of faculty on teaching and learning, and they recognized that for SLOA to be successful, dialogue between and across specific groups needed to occur.

Setting institutional expectations. Coordinators facilitated the conversations necessary to gain faculty and institutional buy-in to participating in SLOA. Gaining buyin included recognition that SLOA involved an increased level of collaboration, not only among faculty within departments, but also between various departments and divisions at the institution. Athena described the necessary attitude toward successful engagement in SLOA: 
Doing SLOs means that you're interested in how you're going to get students to those competencies and that is about not being the lone, atomized practitioner... but really enriching your experiences by sharing ideas and taking ideas from others and making it your own.

As a coordinator, Athena recognized the following:

The programs here on campus that are doing [dialogue about SLOA] are the ones we see growth in... and the struggling departments on campus are the ones where people are just not talking to each other about how they can focus and direct students in a positive manner.

To facilitate these conversations, there needed to be sufficient agreement across the college on the institutional expectations about the purposes and processes of SLOA. Other coordinators shared this insight. At Naomi's institution, "the first thing [they] did as a committee... [was to] write a philosophy about... the purpose of assessment... and identify early on what... resources [they were] going to need to engage in this process." That philosophy was agreed to by the administrators, the academic and classified senate presidents, and the student body president. At Louisa's institution, the "faculty senate decided what methods [they] were going to use," but the process began with "using inquiry," and "relationship-building." She felt that this was "a really good example of [their] college doing things the right way." Her institution facilitated the processes by creating a handbook and common instructions for all faculty to use as 
guides. Because Louisa led this effort, she "combined it with student-centered learning," a focus she recognized as a logical outcome of SLOA. Stephen shared a similar insight even if he felt he was less than successful in helping faculty understand the connections between different activities, "that the purpose of [them] doing this over here in May is so that on fall opening day, when [they] get that information, [they] can talk about it and then make changes."

\section{SLO coordinators acted on newly acquired perspectives. The SLO}

coordinators, with an institutional perspective and greater awareness of accreditation requirements, al so became aware of the strengths and weaknesses of their institutions. Stephen attended a state training and "learned enough to know that at [his] college, [they were] not doing anything near what [they] should be doing... just to meet the standard... to actually have some meaningful data" to facilitate program conversations. As leaders, SLO coordinators acted on these insights. CJ quickly realized that her college lacked the resources and the processes of strategic dialogue and SLO reporting structures to meet the new 2014 standards. As a result, she began to advocate to the administration, including the college president, for more resources. CJ wished the administration "would make it mandatory, in the sense of making sure that things [were] done, not just relying on a faculty coordinator."

Other coordinators acknowledged the difficulty of being responsible for an institutional process while not being able to exercise any direct authority over the 
personnel who needed to do the work. Coordinators needed to be persuasive and motivational to be effective. Louisa had to make sure she was the faculty's "coach and not in any way engaged in" enforcement. For Naomi,

it was really important that, as the selected steering committee, [they] were able to provide those types of guidelines and to have the administration buy into it too... and help [them] to implement it and lend some strength to it.

Using processes to create engagement and design. The issue of persuasion was partially handled through the processes themselves. Coordinator participants described different levels of coordinator positions. Institutional-level coordinators, such as the five coordinator participants in this study, had responsibilities that included a higher level of facilitation and strategizing. Department and discipline specific coordinators, or "leads" or "liaisons" or "points," were assigned to facilitate discipline-specific SLOA. The leads or liaisons were linked together through trainings and dialogue with an institutional SLO coordinator. In this way, information was shared across the college. At Stephen's institution, the SLO coordinator had support from discipline-specific SLO points. The SLO points played an important role separate from the SLO coordinator. The SLO points were "not necessarily outcomes advocates, but they [were] outcomes resources" assigned to assist specific departments and to facilitate faculty participation. Where the SLO coordinator might be focused on facilitating SLOA to meet accreditation requirements, SLO points refocused conversations with faculty about SLOA as an "assessment tool for 
measuring these objectives that [they have] established" for classes in the department. At CJ's institution, these individuals, while not referred to as points, served the same function.

Coordinators intentionally designed activities to create dialogue around SLOA that focused on teaching and learning. Flex days - the days before the start of a new semester - often provided an opportunity when all faculty were on campus to have discussions. Stephen and Louisa identified flex days as the most effective for planned conversations. Naomi planned conversations and invited specific groups of people to facilitate productive dialogue throughout the year. She also facilitated the identification of funding to pay adjunct faculty for their participation and "to make sure they're in touch with... the full-time faculty members in the department." This connection promoted participation "for some adjunct faculty, [because] they finally [felt] validated." Now when she arranges group discussions of SLO assessments, "[she] always make[s] sure to invite some adjunct faculty, because [she] want[s] them to be part of this conversation." Naomi also plans conversations to strategically and intentionally cross discipline boundaries, and strengthen faculty understanding of how their teaching practice fits within the larger institution. She shared:

What I try to do is to get faculty across the disciplines and to get a combination of part-time and full-time... the point of it — and this is from my perspective as a GE committee member... is to have cross-disciplinary 
conversations... If we're assessing critical thinking, how does it manifest in your particular discipline? What are the teaching strategies you use? How do you go about evaluating it? What are major assignments that you give?

Louisa's college created an assessment committee that "looks at everybody's assessment report" and combines the findings into an annual report shared and discussed across the college. In addition, the dialogue process itself also set expectations and encouraged engagement among additional faculty. Athena pointed out that when faculty are engaged in systematic conversation, "it's that process that makes it difficult to leave a faculty member behind." At Louisa's institution, the academic senate designed a process where each faculty member was required to present, within their department, the assessment they implemented that semester, the rubric used to measure the outcomes, and the results. Making the practices of each faculty member transparent was effective in changing expectations. Louisa shared:

There were some adjuncts and full-time faculty who had been giving the same assignment for 25 years and there it is in a book with a rubric and next to it is this really exciting assignment [from someone else]... and you know what? The next time it was different.

Athena noted that the savvy departments gathered data that helped them focus on the important dialogue and "less on the effort to get the data." She also noted that in those 
more constructively productive departments, resistant faculty were "pulled along" by the dialogue. While coordinators identified other methods (e.g., increased professional development, teaching trainings, assigning faculty mentors, or the tenure review process) as alternate means of improving teaching and learning, CJ stated that "student learning outcomes [were] perhaps the anchor that [brought] this all together." However, sometimes frustration showed. For Athena, the seeming inability of some faculty to recognize SLOA as a means of further engaging in good teaching was surprising: "I was stunned as the SLO coordinator with responses like, 'I don't know how to do this.' Really? This is teaching. This is teaching."

Focusing attention on teaching and learning. Part of the coordinators' responsibility was to keep the focus on teaching and learning by designing processes that required dialogue about outcomes and data. Athena and Naomi also recognized the importance of faculty discussing practice together to align standards and expectations about student performance across courses. For Athena, as a department chair, it provided an opportunity to discuss,

a lot of the issues around teaching and learning that are in your face. The students are sitting in your office, with... complaints... around the unevenness of the student experience when it comes to taking a class with this instructor versus taking a class with this instructor. 
Naomi had statistics that reinforced Athena's point about the variance in teaching methods:

One of the primary predictors of a student's success is which instructor they take... we had success rates as low as $50 \%$ and we had them as high as $95 \% \ldots$ There's a big space to engage in those conversations around classroom practices.

The process of identifying core outcomes for each discipline and agreeing on standards and assessment criteria required dialogue within the department to come to mutual understandings and agreement. Athena noticed that when departments at her institution decided to narrow their outcomes down to four, it required "a lot of thoughtful conversation about what [they were] editing out. She shared: "It is focus and direction that the students and California state is asking for... you have a better program when you're thinking about those outcomes."

Naomi also recognized SLOA "as one means to engage in those types of conversations... [and asked], 'How does that translate into our practices? How does it translate into classroom policies and procedures?"' CJ agreed that SLOA is one tool that helps focus attention on teaching and learning. She worked with the reading adjuncts on her campus to learn how to do SLOs: "Once they got it... it helped them understand... what changes they needed to do in their teaching." 
Naomi recognized that not every area was engaged in effective assessment. She shared, "They say it's a waste of time [and] ... when you look at their assessment," it is true. Using a rubric she designed, she began to visit individual departments to help them "figure out something that's [going to] work for [them and be] worth [their] time." Coordinators also recognized that discussing SLOA results in committee meetings assisted in considering institutional solutions for problems that extended across courses, departments, and divisions. Sometimes the benefit of discussion in a committee meeting dedicated to a specific topic was that SLOA could be connected to other teaching and learning goals that faculty already shared. Key topics for SLOA committee meetings included professional development, basic skills, and curriculum. For Stephen, professional development opportunities were effective "because the people that [were] there want[ed] to be there....they [were] open to the ideas." Naomi stated:

[We were] trying to make [institutional SLO] assessment into something that's professional development oriented, so people emerge not only with an understanding of how to apply the rubric, and how to refine their assignments to student assessment purposes, but also that they gain some insight about what's happening in other disciplines.

At Naomi's institution, SLOA goals informed discussions in the basic skills committee about encouraging students to take English and math first, which "then... 
becomes foundational for other GE content courses." For Stephen, the curriculum committee also served this function. He shared:

You have this bully pulpit of talking about what's important in curriculum, and it's easier to talk about [SLOs] because the context of course objectives and your course outline, the materials that you use, the assignments you choose-it's easier to make the connection to what student learning outcomes do.

These strategic conversations included reaching outside the colleges for additional expertise and support. Naomi gleaned some of her ideas from off-site workshops "when [they] were new to SLOs and assessments" that helped her plan a college-wide dialogue about the purpose of SLOA prior to its actual implementation. Athena recognized that in the CTE programs, conversations with industry advisory boards and industry representatives with insights on changing work demands were critical in keeping faculty focused on students' changing learning needs. CJ pointed out that the reading adjuncts needed to engage in small group discussions, and when "each one shared their best practices... they all tried to learn from each other" about their teaching. When that was not enough, she brought in a speaker to provide fresh insight. Louisa was a consultant hired by other colleges to provide suggestions for improvement to their overall processes. She advocated for conversations that crossed boundaries between divisions and "even bigger places for people to talk." Athena was on a partnership resource team and, as a 
result of visiting other colleges, recognized that her college "[was] not alone in having large swaths of the institution" in need of some assistance in gaining insights about the value of dialogue to improve teaching and learning.

\section{Faculty Interview Data Validated Coordinator Interview Data}

Faculty interview data validated the emphases on setting expectations, focusing the conversations around teaching and learning, and facilitating cross-disciplinary dialogue. Faculty valued the dialogue. Laura described criticizing a process and "rather than seeing it as an attack, [the SLO coordinator] always factored it in, gave me thoughtful feedback... in terms of helping me to... re-evaluate the way I teach." For Mary, "it [was] all about dialogue." Faculty acknowledged that the role of the coordinator might be "number one in kind of holding us — our feet to the fire" (John). Faculty also appreciated that it "was really nice to be part of that [SLOA] process and to see that it wasn't that teacher accountability thing that we always hear about that actually makes

teachers want to cry" (Starbuck). Faculty appreciated the efforts to keep quality high. The process as a whole helped to "hold the college-level line of 'this is what's expected of you,' while at the same time helping teachers identify where they need to create better assessment methods and teaching in their own classroom" (Laura). John acknowledged that the process “provided focus. Because we're tracking three different SLOs, it really said, 'Well, in this area you're not doing as well as other areas.'” 
The process of dialogue was also effective. Mary provided an example of how the dialogue process with others provided insights when she responded to the idea of using multiple choice tests to assess student learning: "I just think that's horse shit. I just can't imagine that's really an assessment of a student learning outcome." Then she talked herself through the process of dialogue to which she was accustomed on her campus and realized how a strategic and focused conversation could take something she considered ineffective and make it useful and effective: "Well... unless there is some sort of a process of evaluating how that's taught, and how that's re-taught, and how that's reengaged, and then finally, how it's tested, I suppose... I'm already talking myself into it." Strategic dialogue with faculty from other departments and divisions was seen as valuable. Laura recognized that participating on committees with people from different backgrounds could help faculty "in realizing certain privileges that they don't realize they have." Mary acknowledged that it would benefit her to collaborate with the student services division: "Could I talk with counselors at TRIO, counselors at EOPS? Do they have ideas that I don't have?" Starbuck shared:

There are ways that faculty can do [dialogue] with each other, but... it also needs to be structural, I think it needs to be institutional, the institution needs to say, "This is what we support," [even though] some faculty will resist it because they... don't want to go to any more meetings. 
Faculty recognized the coordinators' role in persuading faculty to participate. They appreciated the mentorship and acknowledged both the workload and personal toll Mary recalls her institution's coordinator telling them, "We can make these SLOs work for us, pedagogically, but we have to be willing to work with them. We have to stop raging against the machine." Richard described the coordinator's role:

I almost see it like a one-on-one thing. It's to slowly begin to change the conversation..."Okay, come on, what don't you like about SLOs? We can talk about it... let me try to work with your frustration and have a conversation to try to bring you around, just like I do with my students."

For Laura, there was a moment of clear insight:

There was a moment, and that was a conversation with [the SLO coordinator]. The real moment was realizing that history could be taught well. If you design SLOs that align with an engaged curriculum... then you can actually become, I think, a history teacher-that exists, but it's a new thing really.

Both the coordinator and faculty participants in this study valued the learning process that SLOA provided. Laura hoped "when [she is] a veteran teacher, that [she] will be constantly called into question and double checked by methods like the student learning outcomes. I just hope that something will always keep me on my toes." Athena acknowledged SLOA's success: 
It changed my view on how I teach it and how I measure it. So it is really interesting how everyone is coming to develop their own instrumentation on that and it really comes down to, "It's the dialogue that makes it meaningful."

\section{Coordinators Managed Faculty Resistance}

Coordinators played an important role in managing resistance by helping faculty gain insights about how SLOA can encourage important dialogue about teaching and learning and by serving as mentors. In the process, coordinators witnessed a lessening of resistance to SLOA.

Helping faculty gain insights. Coordinators used their peer relationships with faculty and continued their role as faculty to appreciate and help manage the frustration faculty felt. The new reporting requirements were an additional responsibility facing faculty. Still, coordinators attempted to persuade resistant faculty of the benefits of the work. Athena identified with this struggle:

I have thought about it a lot... I still have a lot of grief and anxiety over how often we have to report it.... Managing a large superstructure... to manage the documentation that we are doing this work. That's distasteful. There's nobody that doesn't think that's distasteful.... But, the actual doing of the work, of putting together a set of outcomes that lead to a program of study for your students, that should be invigorating for everybody and I think it can be. 
Stephen agreed, identifying the reporting requirements as an element that exceeded previous expectations placed on faculty. Both Athena and Stephen identified benefits to the SLOA process that faculty had started to appreciate. Stephen described the transition that faculty make once they engage in the process as one where faculty transition from, "Okay, I'm getting paid to do it. I might as well" to "I did that, and look what happened. Now I want more." After one training session with a faculty member, Steven shared his experience:

Boy, she was like a kid in a candy store. She was, like, "If I did that, then I could know this, and I could change this assignment and this handout, and I could change this approach" [and] I said, "You're getting' it."

Serving as mentors. Coordinators helped faculty make this transition by serving as mentors who both trained faculty and reassured them in the process. CJ worked with anyone who needed help figuring out how to do any part of SLOA, whether it was designing an assessment or using the reporting software, and she helped faculty understand the purpose of SLOA. She shared the example of a construction technology course:

These are adjuncts... they know their trade. But their educational background is not... instruction... they are not really polished with the SLO part or assessing.... We go over the course outline and we talk 
about... what it is that they do in the classroom that addresses SLOs, and then we come up with an activity where they can measure.

For CJ, these were "Aha!" moments that she repeatedly witnessed with faculty.

Naomi described intentionally attempting to shift the dialogue with faculty, helping them "look at [their] assessment then and ... figure out something that's going to work for [them] that's going to be worth [their] time." She reached out to faculty in the social sciences, imploring them: "You guys are experts. If anything, you could be helping the campus move forward because most of us are experts in our disciplines and not in research."

Coordinators were sometimes a comforting presence. Louisa reassured faculty when they expressed doubts such as, "I was taught to lecture, and now you are asking me to do some alternative." CJ acknowledged, "I think it's scary for people... particularly for adjuncts because they are afraid they are going to lose their teaching assignments." The SLO leads at Stephen's college comforted faculty as well. He stated:

They'll get pushback from faculty... they're trained and they know what to say ... but because they are [within the department], that helps legitimize [SLOA] for more of the on-the-fence faculty who then can say, "Oh, that's all you want me to do? That's all it takes? Okay, I can do that." That's a big benefit... a role model of a faculty person who is not afraid of SLOs and who is there to help. 
Witnessing a lessening of resistance. All the coordinator participants described a lessening of resistance to SLOA at their institutions. CJ stated, "It has become a norm that they know we are assessing." Naomi shared a similar sentiment:

People just understand it's part of our functioning of our campus, and it is one of the primary means we're using to be able to evaluate student learning. Also, it's plugged into all our processes, our annual program documents, our comprehensive program review. It's all connected now. Toni, a faculty participant in this study who also served as a coordinator at her institution, pointed out:

Right now, it's at the point where faculty are really seeing how positive it is. Even the people who do it kicking and screaming, once they do it, they're like, "Wow." It's bringing a lot of stuff to light here, and so they get excited about teaching and learning.

Giving themselves up. The benefits gained by the institution also came at a personal cost to coordinators. Coordinators described feeling unwelcome and often overlooked. CJ acknowledged that, while her door is open to everyone all day, "there isn't a lot of enthusiasm about wanting to learn new things. There are those opportunities but there isn't a large number of people knocking at the door saying, 'Oh, can you train me on this?"' The previous day, a faculty member who had made an appointment for assistance never showed up and "they left the other person out to dry." Louisa is stepping 
down because "it feels like it's become compliance-driven and the disaggregating data drove [her] over the wall. That was it." Stephen explained, "You do have such a wide array of faculty opinions about outcomes that you can be talking to one person one minute who's all gung ho and then you turn the corner and [to] the next person-you're the devil." Stephen was also stepping down and shared:

I'll blame myself for not fighting the fight because I gave up. About three months ago, I said, "I'm killing myself. I can't do this anymore." I'll do the work, and I'll provide the opportunity, but I'm not going to advocate to get people over here.... I'm sure there are plenty of SLO coordinators like me who get to that point where they're like, "I can't fight this fight anymore. My hair's falling out. I'm gaining weight. My kids don't talk to me anymore. Right?" Student learning outcomes and being involved in this has been the most challenging professional experience of my 16-year career now. It truly has. I guess closing thoughts on it-it has tested my professionalism. It's tested my sanity, and I don't mean that jokingly. It really did... just because of the intensity that people have about this. It has certainly tested relationships. People that—“Oh, yeah. We're tight.” Hm$\mathrm{mmm}$. Not when you start getting into these rooms. My sympathies go to SLO coordinators across the land who do this. 


\section{Faculty Participants' Data Partially Validated These Findings}

Interview data provided by faculty participants paralleled the data from coordinator interviews. Faculty participants also described dealing with resistance, especially around the compliance nature of SLOA. Faculty participants recognized the connections between SLOA, their teaching practice, and goals to improve student learning. However, where coordinators emphasized solutions to improve learning inside the classroom, faculty emphasized solutions outside the classroom.

All of the faculty participants described resistance as a substantial component of the institutional attitude toward SLOA. Richard described faculty who simply did not see any need to engage; instead, "it was like pulling teeth," especially once the union realized that participation in SLOA was going to be used as part of faculty evaluations. Mary described a similar atmosphere, "There's a lot of, 'I don't care."” One of Mary's peers told her to "write whatever you want." Summer was surprised by "how much resistance there is out there for measuring SLOs. We're just, 'No. No. We're not going to do it.'” Mary illustrated the problem with making SLOA an accreditation mandate and she echoed Louisa's complaint when she described other college teachers' reactions to SLOA requirements as, "It's such crap. All they want you to do is fill out these forms. It's just a hoop... has nothing to do with learning and teaching. Just shut the door and do what you want." Michael described coordinators who supported SLOA based on compliance requirements: "They push it, and not for philosophical reasons, but simply to 
be approved by the state." Richard's colleagues did not like being threatened by accreditation and responded with, "Let them. If they want, you know what, screw them." He also pointed out the widespread faculty recognition that there was no way for anyone to know if faculty fudged the data or just entered grades instead of SLOA results: "They can just go in and plug in anything." This recognition furthered the sense among faculty that the exercise was pointless: "We don't know if they really assessed anything."

Faculty participants also remarked on SLOA as a symbol of a lack of respect for faculty as professionals. Requiring SLOA as an accountability measure implied that faculty were not doing their best work. Michael found that "people hate them... [they] find it offensive." Toni reflected on the national attitude toward teaching and toward faculty professionals in general, an attitude that blames education professionals for historic and deeply embedded social ills. She then added that making SLOA reporting an accreditation requirement: "It just added insult to injury."

Faculty participants, like coordinators, emphasized the importance of establishing institutional buy-in for SLOA, engaging in professional development that addresses SLOA as action research, and providing support for meaningful dialogue about teaching and learning, time for focused dialogue, and compensation. However, whereas coordinators emphasized the reassigned time necessary to support a network of SLO coordinators, points, and leads, faculty participants focused more on direct compensation for their time. In addition, whereas coordinators described a need to connect SLOA to the 
instructors' values to drive changes to teaching practice, faculty participants emphasized the need for the institution to be looking for solutions to improve learning outside the classroom.

Faculty participants identified the establishment of institutional buy-in for SLOA as key to facilitating faculty engagement. Summer, the one adjunct faculty participant in the study, was aware of the need for institutional buy-in for SLOA to incentivize faculty to engage in extra work. In her opinion, "creating an atmosphere where everyone feels like they can participate and understands the value and contributes is going to get you a lot further than anything else." Part of Laura's desire to get involved was recognition that she might be able to help defuse a polarized atmosphere and create wider buy-in for the SLOA process. Her experiences at a previous college, where she witnessed the effectiveness of departments that had achieved widespread buy-in, informed her decision. Starbuck appreciated the benefits of stepping into a SLOA environment "after it was well entrenched." By the time she arrived, "it was a very creative process and it was very collaborative and it was very much about how we make ourselves better teachers." Mary also appreciated the widespread buy-in at her college. "It's part of our campus culture, and it's part of our campus practice." In her division, faculty built a sense of team belonging. She shared, “Conversations are rich here. They're really interesting. They're even fun." 
Like coordinators, faculty participants described a desire for professional development focused on increasing faculty's capacity to engage in SLOA as action research. John found most of the professional development on his campus ineffective: "They bring in guest speakers... [to share] 'the things we now believe." He is less interested in the latest idea or belief and more interested in data proving that the idea produced results. He would prefer professional development focused on gaining an understanding of how real improvements are made, how to experiment, and how to share results: "We have to get every faculty member to be like a scientist."

Whereas coordinator participants described a network of individuals compensated with reassigned time for work as SLO coordinators, faculty participants focused on more direct compensation for their time and expertise in producing SLOA results, especially for adjuncts. Starbuck recalled being paid to participate in SLOA activities as an adjunct faculty. Summer insisted that there have to be incentives: "If you don't, they're not going to do it." Toni was well aware that many faculty at her school were adjuncts. Some programs at her school were taught entirely by part-timers. She knew adjuncts usually taught at multiple institutions, spent a great deal of time on the freeway, and were paid only a portion of what full-time faculty were paid for each course. Plus, when a course was taught by only part-timers, often a full-timer had to step in and help coordinate the assessments - making even more work for that person. Toni's frustration was clear; 
administrators might insist that everyone needed to collaborate, "but on the ground, that [was] not possible."

Faculty participants also identified dedicated time for dialogue about SLOA as an important facilitator of engagement. Starbuck appreciated the full Saturday that her division dedicated to SLOA activities. Although Mary appreciated her division-level meetings, she also hoped for a regular "college hour" to be implemented, a time when there were no classes and everyone was available to engage in even broader dialogue.

Faculty participants also recognized the connections between SLOA and their own goals as teachers. However, whereas coordinators emphasized connecting SLOA to faculty values to gain buy-in to use SLOA to improve teaching, faculty participants emphasized the value of SLOA in identifying solutions to learning problems located outside their classrooms. Richard appreciated that SLOA provided better data on whether or not his students were understanding the concepts he was attempting to convey. John noted that, without engaging in and presenting SLOA within program review, faculty plans for program development were not going to be approved. However, Summer and Laura both clearly identified student underpreparedness as an underlying cause of low SLO achievement-not necessarily their teaching practices. Summer shared: I try so hard to work with them... and I'm looking at these objectives and these outcomes assessments, and I see that these students are routinely failing regardless of what the medium is or how I'm trying to help them apply things. I 
just wish that there were better resources, better outreach, just better ways to track these students and make sure that they're getting the support they need.

Too often, Laura found that her SLO assessments were measuring whether or not students were prepared for class, not whether or not they could achieve college-level outcomes. She supported both the implementation of prerequisites and the addition of resources in the student learning center to improve student learning. John appreciated the new tutoring center on campus and Mary's work with SLOA led her to consider how she could reach out to programs within student services to support students.

Faculty did recognize the toll SLO coordinators experienced. John described the coordinator who was also stepping down at his institution: "She's become so tired." Toni, a faculty participant who also served as a coordinator, stated, "It's forced me to really step up my game in terms of protecting my interests and people respecting my boundaries and respecting what I bring to the table, and that this is a learning process for all of us."

\section{Summary}

Participants all identified the role of leadership, in a variety of forms, as important to the successful functioning of SLOA. When administrators were disengaged from SLOA, lacking apparent understanding or support, coordinators described a more negative campus climate around SLOA. When administrators openly supported SLOA, coordinators described a more positive campus climate around SLOA. 
The stances of the faculty union and academic senate also influenced campus climate around SLOA. The union's role was mentioned frequently. Coordinators identified union resistance to SLOA as effective in promoting faculty resistance to participation. The highest level of resistance in campus climate was described when both the faculty union and the academic senate both demonstrated resistance to SLOA.

Attitudes toward SLOA varied by department at each campus. Leaders in each department, particularly the department chair, influenced the level of support for SLOA among the department's faculty. When the department chair did not support SLOA, it was more difficult to create engagement. When the department chair did support SLOA, engagement was much more successful.

SLOA also provided the opportunities for faculty to take on additional leadership roles, especially the role of institutional SLO coordinator. The SLO coordinators served an integral role at the institution in creating and maintaining a system of strategicallyintegrated dialogue that supported engagement. By recognizing that faculty needed to share information about teaching and learning for SLOA to be successful, SLO coordinators created and relied on a structure and processes that facilitated key conversations between faculty within departments and across divisions. Coordinators could use SLOA data to drive committee conversations in professional development, basic skills, and accreditation. Because they were faculty peers, coordinators could successfully bridge the space between the needs of the institution to increase the attention 
paid to teaching and learning to fulfill accreditation requirements and the interests of faculty in the teaching and learning aspects of their profession. The central element of this success was dialogue.

However, while SLO coordinators emphasized using SLOA to change instruction with the goal of improving teaching so that student learning improved, faculty emphasized different solutions to improving student learning that relied less on improved teaching strategies and more on outside of class support for students. 


\section{CHAPTER 7: DISCUSSIONS AND RECOMMENDATIONS}

Institutions of higher education in the United States continue to grapple with the challenge of improving student success (Hutchings, 2010; Kuh et al., 2015). The use of SLOA has increased at community colleges across the nation (Kuh et al., 2015) and has gained wider acceptance at community colleges in California (ASCCC, 2010). There is also evidence that SLOA changed instructional practice, course design, and program development (Cameron et al., 2002; Jennings et al., 2006) At the same time, sufficient evidence that SLOA improved learning remains elusive (Kuh et al., 2015). One explanation for the lack of evidence that SLOA improves learning is insufficient faculty engagement (Hutchings, 2010; Kuh et al., 2015). This study explored the experiences of faculty intentionally engaged in SLOA in order to identify facilitators and barriers to the use of SLOA to improve teaching and learning. The findings for this study identify SLOA at the course level as a means to improve teaching. However, study participants identified other means to improve learning. These means reside outside the classroom and aim at addressing the impacts of poverty.

Purposefully selected faculty participants held advanced degrees in the social and behavioral sciences, disciplines devoted to the study of human behavior and social systems. SLO coordinators brought college-wide perspectives informed by an attention to institutional accountability and experiences working with faculty from a wide range of disciplines. By better understanding the experiences of these faculty members and SLO 
coordinators both barriers and facilitators to further faculty engagement in SLOA were discovered. Interviews with eight faculty members and five institutional SLO coordinators were the basis of findings for this study. The original intent of the study was to use the faculty interview data to discover common themes in their experiences that shed light on the barriers and facilitators they faced. These themes were reinforced by a separate analysis of the coordinator interview data. During the process of analyzing the coordinator interview data, other unexpected themes, such as the role of the SLO coordinator and importance of strategically-integrated dialogue, were discovered. The overall question that motivated this study, “does SLOA work?' was explored through the following four research questions:

1. Why do faculty members become engaged SLOA practitioners?

2. What are the important behaviors, attitudes, and actions of the engaged practitioner when engaged in SLOA?

3. What do engaged faculty believe about SLOA, teaching, learning, and achievement gaps?

4. What are the important behaviors, attitudes, processes, or structures at an institution that influence engagement in SLOA?

This chapter discusses the findings for each of the four research questions in relationship to the conceptual framework and makes recommendations. The recommendations derive from: 
- the alignment of participant values and motives for teaching with the mission of the California Community College system

- the clarification in the findings that SLOA improves teaching, but not learning

- evidence that a system of strategically-integrated dialogue connects data and faculty expertise with college-wide reflection on student needs

This study conducted a broad and detailed exploration of the full range of experiences of faculty engaged in SLOA. Suggestions for further research are intended to extend this exploration to discover means to use faculty insights gleaned from the practice of SLOA to improve learning and overall student success.

The Interpretation of the Findings

This study found that the conceptual framework, illustrating the combination of faculty cognitive frameworks, effective change processes, and institutional context, worked to explain why and how some faculty members engaged in SLOA. The discussion below emphasizes the major findings for this study. First, SLOA does get at the "black box" of instructional practice and provides a means of professional development for faculty to hone their teaching craft. However, an equally important finding is that the methods needed to support student learning involve more than instructional changes. Findings suggest that institutions may need to broaden inquiry to include data-supported changes to the programmatic, divisional, and institutional design of learning supports for students. Leadership support is key to success. Strategically- 
integrated dialogue, as a means of connecting faculty, who have expertise at the course level, to the larger educational programmatic and design conversations, can be a valuable tool for facilitating change across the institution. Finally, the mission of the California Community College system, to provide education to all who can benefit from it, is furthered and supported when corresponding faculty motives, also aimed at societal improvement, are recognized and valued by the institution.

\section{SLOA Works as a Change Process}

Fullan's $(2006 \mathrm{a}, 2006 \mathrm{~b}, 2008)$ theory of change identified key elements leading to effective change as including peer-guided, reflective focus on local results by local practitioners. The SLOA process aligns with this change theory. An analysis of faculty participant interview data demonstrated that SLOA was effective in changing teaching practice in ways that aligned with research-based best practices in higher education (Coggshall, 2012; Hunzicker \& Lukowick, 2012; Yoo, 2013). SLOA does get at the "black box of instructional practice" (Fullan, 2008, p. 5).

Faculty engaged in a reflective process with colleagues, guided by SLO coordinators, using local SLOA data as a focus for dialogue. Faculty collaboratively identified major learning outcomes for their courses. These outcomes focused less on the mastery of specific course details and more on the development of higher order, critical thinking skills. Faculty then aligned course content and activities with those outcomes, and revised assignments, instructions, and assessment rubrics to make these learning 
goals and the learning process clearer to students. Faculty also restructured the use of class time, asking students to familiarize themselves with course content outside of class and then engage in dialogue with classmates in class. This rearranged course structure placed lower order information review outside of class and higher order critical thinking activities inside of class, using dialogue with peers as a key part of the learning process. Faculty also ensured that class materials, as well as their own time and expertise, were easily available to students.

\section{Faculty believed SLOA improved teaching practice by changing the role of}

faculty. Faculty also perceived SLOA as an effective tool for driving changes to teaching practice. As anticipated by Fullan (2006a), faculty described reflecting on their assessment data, then making changes to their teaching practice incrementally, based on new insights gained over time. These insights challenged their previously held assumptions about student learning. And faculty perceived themselves as better instructors as a result. Overall, faculty described placing increased emphasis on recognizing the needs of students. They changed both content and teaching practice in ways that increased student engagement.

As anticipated by Tagg (2012), by making changes to how they approached their teaching practice, faculty recognized a change in their roles as instructors. This change shifted the emphasis of their role away from what institutions and faculty traditionally highly value: discipline expertise, and toward less highly valued teaching expertise. 
SLOA required that faculty be more scientific in their approach to course design and more knowledgeable about their students' abilities and interests. Faculty needed to be clearer in the alignment between their course outcomes, activities, and assessments. They needed to use assessment data to drive teaching practice. They needed to be able to reassess outcomes and write reports that articulated the connections between teaching practice and outcomes assessment. This scientific method of driving change was identified as a new approach for faculty participants. Participants in this study did perceive a responsibility to teach well and considered teaching improvements part of their professional responsibility. However, the data collection on and report writing about their teaching practice, and the making of those reports public, was a new responsibility and an additional professional service that faculty provided to the institution. As such, SLOA required time that could be otherwise spent on deepening discipline expertise, creating a shift in professional focus.

Perceived causes of faculty resistance. This change in role was perceived as the root of resistance engaged in by other faculty. Tagg (2012) presented several reasons why faculty members resist change. One reason faculty resisted change was the "endowment effect," or the idea that faculty valued what they already had. According to Tagg, faculty members in higher education were respected for the level of disciplinary expertise they brought to an institution. Faculty members expressed and built on this expertise through research publications, not through teaching acumen, and so SLOA was seen as a means 
of focusing faculty members' energies and talents away from highly valued discipline expertise and toward less valued teaching expertise.

A continuation of Tagg's (2012) exploration of reasons why faculty resist change is the idea that academic autonomy, considered part of academic freedom by faculty participants, is sacred. Study participants described hearing faculty complaints that SLOA is a challenge to academic freedom. This challenge to academic freedom was presented as a rationale to resist engagement in SLOA. Participants in this study did not have this attitude with one exception: The demands on their time required by participation in SLOA detracted from attention to further developing their own discipline expertise.

\section{Faculty Did Not Perceive Learning Improvements as a Result of SLOA}

SLOA, as a logic model, assumed that improved teaching practices led to improved student learning. However, identified changes to and recognition of improvements in teaching practice did not lead faculty to believe that SLOA improved learning. In addition, there was a lack of empirical data connecting SLOA to improved learning. Their own classroom and college-wide SLOA data did not show improved learning results. And several participants were aware of the lack of overall research data to support connections between SLOA and learning improvement. In addition, SLOA, as a change process, removed the teaching focus from other important long-term learning outcomes. The development of deeper reading and critical thinking skills required more than one semester to develop. Student educational self-advocacy required more time to 
develop. Faculty saw their classes as "one brick in a road," or "planting seeds," in the student development journey.

Faculty placed the conditions for learning preparedness outside the classroom. Inadequate K-12 preparation meant that SLOA tended to reveal areas where students were not prepared for college level work. Inadequate access to life resources such as stable housing, food, childcare, and healthcare created barriers to learning in the present. To improve learning outcomes, students needed more support outside the classroom. Students coming from communities experiencing high levels of violence needed even further supports. These challenges were recognized by faculty participants as rooted outside the classroom. Expecting faculty inside the classroom to address these challenges through changes in teaching practice trivialized the deeply-embedded consequences of systemic poverty. Although faculty participants acknowledged the benefits of SLOA to their own teaching practice, they also expressed strong skepticism about the validity of holding higher education as a whole, and teachers specifically, accountable for educational outcomes.

\section{Faculty Responses to Using Disaggregated SLOA Data to Close Achievement Gaps Evolved}

The mandate to use SLOA to close achievement gaps was still new (ACCJC, 2014). Only a few of the community colleges in California had been evaluated by accreditors under this new mandate at the time of this study. Most of the participants had 
not yet been required to look at achievement gaps in their own SLOA data and were responding to questions about the potential use of SLOA to close achievement gaps theoretically. Bensimon (2005) theorized that equity-minded faculty, faced with disaggregated assessment data revealing achievement gaps within their own classrooms, would be moved to make changes to address those gaps.

Faculty participants did demonstrate reflection on aggregated SLOA results and, with insights gained over time, changed their teaching practices. Still, most faculty placed the cause of achievement gaps, similar to the challenges to learning improvements, outside the classroom and onto both the disparate learning experiences that children experience in the K-12 system and the widespread effects of poverty. If the solutions to learning improvements resided outside the classroom, then the solutions to the achievement gaps resided outside as well. However, over the course of the interview, some faculty responses to the potential of using SLOA to address achievement gaps evolved from visceral denial to reflection on possibilities.

Faculty responses to direct questions about achievement gaps were mixed. Approximately half of the participants responded that SLOA might be useful in closing achievement gaps. Others began their responses with a strong negative reaction or an admittance of discomfort with the topic. One participant at first predicted that such data might make him feel violently ill, and that he might have to reconsider who he was. A few participants discussed the topic with candor. Over the course of an interview, 
participants demonstrated a willingness to consider the potential of SLOA to help close achievement gaps. Their answers evolved. This type of reflection was similar to the reflection that lead to challenges of previously held assumptions about teaching and learning. Faculty participants already demonstrated the capacity to respond to such challenges with changes to their teaching practice. It is possible that faculty, applying SLOA with the intent of closing achievement gaps, will continue to apply reflection and experimentation to their teaching practice. This could lead to further changes in teaching practice that would continue to improve the student learning environment and possibly close achievement gaps. However, key to some of the responses was the recognition that changes to institutional and societal policies and practices that contribute to opportunity and achievement gaps need to be considered.

\section{Leadership Matters}

Participants in this study repeatedly and consistently discussed the importance of leadership in setting the tone, influencing levels of engagement with, and determining the expectations around SLOA at the college. Rogers (2003) identified the motivation of others as a function of leadership. Fullan's (2002; Fullan \& Knight, 2011) description of effective leadership supported Rogers (2003), recognizing the importance of a sense of purpose, support for problem-solving strategies, and accountability as key features of effective leadership. Because participation in SLOA is largely viewed as a mandate from an outside authority, leadership at the college is needed to support the creation of an 
agreement to support SLOA, similar to a social contract, by all participants at the institution.

In part due to the participants' roles at the colleges and the varied size of the colleges themselves, the parameters of leadership in the interview responses were illdefined. Many different factors potentially influenced each participant's definition of leadership. The participants themselves viewed SLOA from a wide variety of leadership perspectives. They included new faculty members looking up to mentors within their department, experienced faculty members who had served in institutional-level leadership positions previously, department chairs responsible for performance evaluations and program development, chairs of committees on accreditation and curriculum, and institutional SLO coordinators. Some participants had served in leadership positions at the state level. Some were focused on their working relationships with faculty members in their departments. Others felt comfortable walking into the college president's office to share their perspectives.

Participants were also in transition. One was pursuing a full-time tenure-track job Others were considering retirement. Some faculty were on the verge of stepping into SLO coordinator positions, while a few coordinators were on the verge of stepping down. In general, participants serving in a leadership role did so out of necessity. No one else was volunteering and the participant had some previous experience that would help them fulfill the new responsibilities. 
While not clearly defined, leadership was acknowledged by the study participants as important to the implementation of SLOA. Participants in this study tended to group people serving in leadership roles together. Participants referred to administrators as a group, referring to "administration" and rarely singling out any individual. There were exceptions to this: Single administrators who demonstrated support for SLOA were acknowledged. At the department level, the department chair was singled out as an influential leadership position. When participants described administration as supportive of SLOA, they also tended to describe the campus climate as supportive of SLOA. The reverse was also true. When administration was described as absent from or punitive toward faculty in regards to SLOA, the campus climate tended to also be described as unsupportive of SLOA.

\section{The SLO Coordinator Guiding Strategically-integrated Dialogue Created Change}

Both Rogers (2003) and Fullan (2006b; Fullan \& Knight, 2011) identified the importance of peer-facilitated dialogue as a key element of successful change within a social system. Rogers' emphasis on communication as the central element in successful change and Fullan's (2006a) description of "permeable connectivity" as "pursuing strategies that promote mutual interaction and influence within and across" (p. 11) the various levels of a social system parallel the function of the strategically-integrated dialogue created by SLO coordinators. 
Facilitating dialogue across the college was a role fulfilled by the SLO coordinators. The actions of the SLO coordinators in this study paralleled important functions of the change agents identified by Rogers (2003) and the coaches identified by Fullan and Knight (2011). The SLO coordinators fulfilled Rogers' (2003) description of a change agent when they acted as leaders in a middle position between the needs of the institution and the needs of the faculty. The SLO coordinators used this position to set institutional expectations around SLOA. They combined their knowledge of accreditation standards and institutional resources with their relationships with faculty to design sustainable assessment systems. The systems of communication and reporting created by SLO coordinators promoted dialogue between faculty members, within departments, within divisions, and across various areas of the institution. These systems also included the creation of reports summarizing faculty-generated data and reflections. Summaries were shared with committees that further reflected upon and could take action on faculty member findings. By designing assessment processes that included steps for the intentional sharing of and reflecting upon information, mutual understandings developed and connections were maintained between the different elements of each college.

Fullan and Knight (2011) emphasized the importance of coaches who directly supported teachers to improve learning. The SLO coordinators and the leads, liaisons, and points that they trained, worked with faculty in groups and individually to design assessments and assignments, interpret data, and create mutual understandings that 
improved the teaching process. The SLO coordinators also recognized the benefits of creating an integrated system of communication and reporting: The process pulled in departments and faculty members who might not have otherwise participated. As faculty peers, SLO coordinators also maintained the focus on teaching and learning by connecting SLOA with faculty values.

Rogers (2003) and Fullan (2006a; Fullan \& Knight, 2011) identified influence and motivation of others as an important function of the change agent or coach. The SLO coordinators fulfilled this role as they faced and managed faculty resistance. As they negotiated institutional needs with the goals and values of faculty members, SLO coordinators met with both groups and individuals as peers. In these meetings, SLO coordinators attempted to shift the focus of SLOA from a compliance requirement mandated by the accreditation agency to a process and conversation that could improve teaching and learning. They did this by sharing information about and examples of SLOA, providing professional development opportunities, and finding resources that alleviated the workload for faculty. In these conversations, SLO coordinators connected the benefits of SLOA to the genuine faculty values such as improved teaching and learning. The SLO coordinators managed resistance by helping faculty gain insights about the value of SLOA. Coordinators served as individual mentors, coaching faculty through the assessment process and role modeling inquisitive behavior about discovering best teaching practices. 
Rogers (2003) also described change agents as demonstrating and acting with empathy. When SLO coordinators made sacrifices-often unsustainable-to create a system of strategically-integrated dialogue and to promote greater faculty engagement, they also acted with empathy. Coordinators modeled professionally engaged behavior, leveraged professional relationships, gave up personal family time, and sometimes sacrificed their own health. Their actions were aimed at changing the way the system functioned. They did this because they believed that doing so was in the best interests of the institution, the faculty, and the students.

\section{Engaged Practitioners Met the Criteria for Roger's Early Adopters}

Participants in this study all identified themselves as engaged in SLOA with the intent to improve teaching and learning. Participants all shared some characteristics with Rogers' (2003) early adopters. These characteristics included an openness toward new ideas, a willingness to work collaboratively and take risks, a favorable attitude toward science, self-efficacy, and empathy. Rogers theorized that participants are more likely to engage in change when the innovation aligns with pre-existing social values, is easy to use, and produces concrete results.

The participants in this study came from a wide variety of prior employment backgrounds, from grocery store manager to chef. They also shared a commitment to social change and a high level of civic volunteerism from aiding homeless shelters to providing guide dogs for the visually-impaired. Participants were self-described 
community college advocates. They described personal experiences attending community college and a belief that access to higher education was a tool for social improvement. The actions taken by the participants as they worked with students, and the reasons they provided for taking those actions, demonstrated a high level of empathy and commitment. Faculty used personal time to help students, learned more about the students they served, and participated in the data gathering and reporting requirements of SLOA that were added to their job responsibilities. The rationales provided for these actions revealed that participants viewed SLOA as a means of continuing their social improvement efforts. They connected their motives for civic engagement with the opportunity community college teaching provided to continue their work towards social improvement. Participants perceived SLOA as a means to improve their teaching practice with the goal of using instruction as a means to social improvement. Participants recognized the value of dialogue in making SLOA effective. They demonstrated this recognition through their willingness to attend additional meetings and professional development activities. The penumbra of this analysis identified the combined participants as empathic.

Faculty also made connections between their goals to improve their teaching with their goals to improve society. Their descriptions of SLOA revealed this purpose. Participants were asked to describe SLOA as if they were explaining it to someone who had no knowledge of teaching and assessing in higher education. I expected faculty to explain that SLOA was a system of continuous quality improvement enacted through 
identifying the core outcomes for a course and then devising assessment methods to measure how well students achieved those outcomes. I anticipated responses to be a concrete explanation of the connections between the goals of the class, descriptions of assignments that would measure those goals, and explanations of what might be done with that assessment data. Based on that data, faculty members would change their teaching methods, assignments, etc.

Participant responses did not fit this expectation. Faculty participants responded more philosophically. While SLOA was described as a means of aligning the learning outcomes for a course more directly with the content and assignments as well as creating and supporting a student-centered learning environment, these descriptions focused on SLOA as a means of quality assurance. This helped faculty learn to teach, then encouraged them to continue to try new teaching strategies and to identify and address gaps in student learning. Participants described SLOA essentially as a conscientious and reflective teaching method that focused on meeting students' needs in a way that promoted development of positive social values. Similar to Rogers' (2003) early adopters, faculty used SLOA as an innovation to make improvements to the larger social system. By doing so, faculty directly connected their own value system with the goals of the community college system overall. 


\section{Implications and Recommendations}

The findings in this study have important implications related to key concerns about the quality of California's community colleges. These concerns include closing both opportunity and achievement gaps and creating more equitable educational outcomes for all Californians, encouraging faculty members to engage effectively in improvements to teaching practice, and identifying strategies that support effective changes to the structure and delivery of education that improve student success.

\section{Equity Implications}

Faculty engagement in SLOA has been identified in the literature as key to improving student learning (Hutchings, 2010) and closing achievement gaps (Spellings, 2006). California, by requiring the inclusion of SLOA data in the Student Equity Plan, accreditation requirements, and funding structures, is effectively directing over 60,000 full and part-time community college faculty (CCCCO, 2016a) to use SLOA. By rewarding activities that address or impact achievement gaps, the funding and accreditation systems are requiring that faculty use SLOA to address both opportunity and achievement gaps.

In California, resolving academic achievement gaps is urgent (CED, 2013). Over the last 35 years, the proportion of the state population coming from underrepresented groups doubled (CED, 2013). Black and Latino students are less likely to enroll in college, less likely to test into transfer-level coursework, and less likely to graduate or 
earn a certificate from college than their White and Asian peers (Moore, Offenstein, \& Shulock, 2011). In addition, California grants proportionally fewer baccalaureate degrees than most states (Geiser \& Atkinson, 2010). Latinos, the fastest growing population group in the state are awarded the fewest degrees (Moore et al., 2011). Lower educational achievement of underrepresented students is exacerbated by strong correlations between poverty and lower academic achievement (Reardon, 2011). In California, Black and Latino students also experience higher rates of poverty than other students (CED, 2013). Cohen's (2005) recognition that SLOA contained an inherent criticism of faculty ineffectiveness and bias remained true for this study. Participants interpreted the SLOA mandate as a criticism of their existing practices. However, faculty participants and SLO coordinators also recognized that SLOA did reveal weaknesses in teaching practice. In addition, an analysis of the reported actions taken by faculty in this study revealed that even those faculty who were intrinsically motivated to improve their practice prior to SLOA, ended up making further specific changes as a result of engagement in SLOA. These changes aligned with best practices in teaching in higher education. The $3 \mathrm{CSN}$ Theory of Change that describes a change process similar to SLOA remains a potential tool for faculty professional development and sharing of best teaching practices.

But changes to teaching practice alone, even if they transform faculty, will not transform our institutions into more successful agents of social improvement. A broader equity implication for the use of SLOA to close achievement gaps needs to focus on the 
reluctance of faculty participants to assume responsibility for, and the lack of evidence that SLOA improves, learning outcomes. If SLOA does not improve learning outcomes, SLOA alone cannot close achievement gaps. The participants in this study strongly suggested that we look at institutional and societal change to achieve these goals.

\section{Leadership Implications}

Participants in this study, all engaged SLOA practitioners, called on college leaders to engage in and lead the dialogue around student learning and success. California Community College leaders can use this research to understand the potential and limitations of SLOA and the experiences of faculty responding to shifting expectations. By better understanding the values of faculty, leaders can provide appropriate supports to encourage further engagement in SLOA that leads to institutional improvements.

In addition, by better understanding the components necessary for systemic improvement, leaders can provide the resources necessary to connect what faculty learn in the classroom with changes to institutional policy and practice necessary for student success. Faculty recognized SLOA as a tool that provided insight into student learning and identified barriers to student success. The connection of these faculty insights, gained through SLOA, to the processes of institutional decision-making needs to be strengthened. College leadership can use this knowledge to provide the structures and resources necessary to expand opportunities for reflection on the system of educational delivery at the college. These reflections should question assumptions about learning at 
the institutional level in the same way that reflection on SLOA leads to questioning of assumptions about learning at the course level. This is a paradigm shift that requires leadership to accomplish. The structure provided by a system of strategically-integrated dialogue has already proven an effective tool for facilitating change that leadership can support.

\section{Recommendations for Improving Teaching and Learning and Closing Achievement}

\section{Gaps}

The findings in this study revealed that SLOA effectively improved teaching practice. However, improvements to student learning remained elusive and leadership was called upon to support and lead institutional dialogues aimed at bridging the gap between improved teaching and a lack of improved learning. The recommendations arising from this study focus on two areas: improvements in teaching and extensions of discussions about improving learning.

\section{Expand professional development in SLOA to improve teaching practice with} opportunity and achievement gaps in mind. The qualifications for being hired as a community college faculty member do not require coursework in teaching practice. Many faculty learn on the job, in the classroom. This leaves too many faculty without sufficient access to professional training in teaching even while faculty are being asked to become more scientific in their teaching practice and course design. This study demonstrated that SLOA is an effective means for developing teaching acumen. 
Both faculty and SLO coordinators identified a need for increased access to professional development aimed at improved teaching practice. SLOA provides a change process that encourages faculty to be scientific in their teaching practice, impacting the "black box of instruction" effectively. SLOA should be supported within each college department and across divisions. Faculty also need to engage in dialogue beyond their own institutions. The 3CSN professional development resource, and its Theory of Change calling for a transformation of faculty through reflection on local data and dialogue, provides faculty with a broader network of peers all exploring improvements together. Expanding reflection opportunities and interweaving the dialogue process among the statewide system of community colleges can build systems of "permeable connectivity," characterized by feedback loops between groups that create mutual agreement and understanding, that extend beyond the individual institution.

This recommendation includes some specifics:

- Invest in professional development focused on skills that promote SLOA as action research. Participants in this study revealed a need for professional development aimed at developing action research skills. Faculty needed assistance developing quality assessments, using and interpreting data, and effectively connecting improvement plans to the assessment data, then reassessing. 
- Invest in professional development that increases all college employees' capacity to address opportunity and achievement gaps. Participants in this study revealed a contradiction between their commitment to social engagement and a strong desire to improve learning for all students while also struggling to comfortably discuss opportunity and achievement gaps. This discomfort reveals a need to increase understanding of the causes of achievement gaps, research on best practices to close achievement gaps, and how to apply research findings to their own practices. Bensimon's (2005) theory that equity-minded faculty, reflecting on their own local achievement gaps, will be moved to make changes to their practice is supported by the evidence in this study that faculty, reflecting on SLOA data, did change their teaching practice. While this study focused on faculty perceptions, students interact with and learn from many college employees, not only faculty. Frequently the first person a student encounters at the college is a staff member. This person makes important recommendations on how a student should proceed. An extension of the same reflective practice to all college personnel, informed by evidence about opportunity and achievement gaps, may also lead to further appropriate changes to other college wide practices.

2. Consider alternate methods in addition to improved teaching practices, such as evidence-based changes to institutional policies and practices, to address concerns about student learning and achievement gaps. The participants in this study represent 
experienced SLO coordinators and faculty advocates in the social and behavioral sciences. Together they provided a specific combined expertise in the study of human behavior, social change, and institutional implementation of new practices. As such, they described a disconnect between improved teaching and improved learning. Instead, they identified alternative explanations for lower than desired student success and the existence of achievement gaps that are located outside of the classroom. Such a finding requires that institutions intentionally look beyond the classroom to find solutions. Data-informed reflection on the impact of institutional policies and practice needs to be invested in. SLOA data can inform this exploration and faculty participation is necessary. There are a number of examples where such exploration has already been fruitful: Recently Governor Brown signed Assembly Bill 705, necessitating that all California community colleges provide a 1-year pathway for all students to complete transfer level English and math. This decision was based on institutional and system-wide data on the disproportionate impact of English and math placement tests on under-represented minorities combined with data that a shorter pathway, with more learning supports built in, lead to greater achievement overall and narrowed achievement gaps. A second example is Assembly Bill 19, the California Promise Program, which makes the first year of college tuition free for all entering freshman who enroll full time. This policy is based on success data demonstrating that full time students have higher success rates than part time students 
and that the cost of tuition is a barrier for many students. While these are both policy changes implemented at the state level, they are examples of changes based on data provided by individual colleges who piloted the practices first. These policy and practice changes will require that each college engage in a dialogue about effective implementation. An additional emerging conversation is on the adoption of a pathways framework for restructuring the delivery of education at the programmatic or institutional level. The pathways framework asks colleges to explore data on student course-taking patterns and devise ways for students to complete educational pathways more efficiently. For example, an Associate's degree requires a minimum of 60 units to earn. However, data shows that too many students are taking 80 or more units without completing all the requirements for any specific degree. College-wide conversations about the underlying causes of these course-taking patterns could lead to structural solutions at the program, division, or institutional level. In addition, there are examples of support programs, such as TRIO or EOPS, that are very successful at helping students both overcome challenges and reach their educational goals notwithstanding what happens within any particular course taken. The data provided by these programs needs to be considered by each institution and by the system of higher education as a whole. Faculty insights, gained through SLOA, should guide implementation of any changes. 
3. Invest in the system of strategically-integrated dialogue. Reflection upon the data and consideration of implementation of solutions is where the system of strategicallyintegrated dialogue is essential to effective change. An investment in strategicallyintegrated dialogue would provide sufficient reassigned time and professional development for faculty peer coordinators and liaisons, leads, or points along with increased trainings for all faculty and staff. Strategically-integrated dialogue creates the data and reflection system that connects faculty experts, who are using SLOA to identify gaps in student knowledge, to the conversations about the institutional planning. These connections can identify the most effective supports for students.

Keep this conversation going as a continuous reflective process that informs adjustments to practice and policy as the needs of students change. This system supports institutional change regardless of the specific change effort desired. It is important, in supporting strategically-integrated dialogue, to recognize the coordinator's role and the time involved:

- One of the essential features of a successful peer coordinator was that this person negotiated the space between the needs of the institution and the values of faculty (Fullan \& Knight, 2011; Rogers, 2003). However, it was also important that peer coordinators share the values of the faculty members they were trying to persuade or motivate. This peer relationship, and its role in managing resistance, is supported by Rogers (2003) and Fullan and Knight (2011). In addition, 
participants in this study described SLO coordinator roles and responsibilities that could not be sustained. Three of the five coordinators in this study were stepping down due to a required level of sacrifice that was both acknowledged by the coordinators and recognized by the faculty participants. Research suggests that the role of the coordinator is central to the success of SLOA, and potentially other changes, in higher education (Livington \& Zerulik, 2013; Marsh et al., 2015; Wildey et al., 2003). To negotiate this space, peer coordinators need sufficient training in assessment, software tools, research methods, and data analysis. In addition, a case study identifying a successful assessment liaison system (Willard et al., 2004) described multiple avenues of support for coordinators, including professional development, support from the assessment and research offices, and remuneration for extra time spent in trainings.

- Intentionally structure institutional time to prioritize dialogue about changes aimed at increased student learning and success. Both Rogers (2003) and Fullan and Knight (2011) recognize the importance of intentional dialogue, facilitated by peers, for effective change. Faculty and coordinators also recognized the value of strategically-integrated dialogue in promoting engagement in SLOA, keeping the focus on teaching and learning, addressing resistance, and creating synergy among and between disciplines and departments that have the potential to improve the student experience. Dedicated flex days and increased numbers of 
department meetings, with time spent on data-driven reflection, strategies considered for improvement, and assessment of those strategies will support the institutional commitment to changes that improve student success. Emphasizing the place of student success within regular college-wide committee work by mapping the route of success data through the institutional decision-making processes and the role of the data in final outcomes reinforces the institutional expectation that student success, and improvement strategies based on student success, play an important role in the mission of the college to deliver higher education to all students.

4. Expand faculty hiring criteria. Include desired faculty qualifications focused on teaching expertise, collaborative working styles, and civic engagement into hiring decisions. Dedicated faculty with the capacity to fulfill their roles in helping students traverse the challenges and benefits of higher education will be key to any successful efforts to improve educational outcomes in California's community colleges. The individuals in this study identified as engaged SLOA practitioners. However, most of them exhibited an intrinsic motivation for social improvement aligned with the goals of the Master Plan for Higher Education in California (CED, 2013) that pre-existed their employment at a community college. Using hiring criteria to identify individuals who are already intrinsically motivated to teach with greater reliance on collaboration 
and innovation, could increase the proportion of faculty authentically engaged in SLOA (Wang \& Hurley, 2012).

\section{Limitations of the Study}

This study is limited in several ways. The inclusion of only 13 participants from a limited number of disciplines limits the possibility to generalize from the findings. While the coordinator participants were assumed to be familiar with faculty who were resistant, less engaged, or from disciplines other than the social and behavioral sciences, by including only "true believers," the findings do not directly represent the experiences of faculty who were not engaged in SLOA. In addition, while leadership was explored as a theme, it was not defined well enough in advance and thus leadership as a concept is subject to Kezar's (2013) criticism of being too underdeveloped to be as meaningful as it could have been. One criticism of existing studies on SLOA implementation is that they do not connect evaluations of implementation with direct evidence of SLOA's effectiveness in improving student learning. This study is subject to the same limitation.

\section{Recommendations for Further Study}

This study focused on the perceived experiences of engaged SLOA practitioners who each self-identified as a true believer in the use of SLOA to improve teaching. Research on the effectiveness of SLOA would benefit from studies that compare the experiences of engaged practitioners with resisters. In addition, this research is based on self-reported descriptions of faculty practice and perceptions. Research that incorporates 
evaluations of classroom practice and student learning results would provide a stronger triangulation of results to either support or dispute the findings of this study. However, the findings revealed a gap in the assumption that SLOA would improve both teaching and learning. While teaching practice did improve, learning outcomes did not.

Experienced faculty with sincere intentions to improve society found that course-level SLOA was insufficient to improve learning. Studies that explore the most effective outside-of-class student supports or that question the impact of broader policies and practices are needed. Finally, whereas Rogers (2003) and Fullan and Knight (2011) identify the importance of leadership in driving change, Kezar (2013) revealed an underdevelopment of the concept of leadership that permeates empirical studies on the implementation of SLOA. Further research on effective leadership strategies for the successful functioning of SLOA are called for.

\section{Reflections on the Research Process}

During the course of this research I transitioned from a faculty member in the Social Sciences to the role of Academic Senate President, representing 1600 faculty, as my institution worked to reaffirm our accreditation under ACCJC's new Restoration process. I was the only Academic Senate President in the state to lead faculty through such a process. The context included high stakes accountability and an urgency to move the institution past an ACCJC vote to terminate our accreditation based on the 2002 accreditation standards to being one of the first institutions to fully meet the newer, more 
outcomes-focused, 2014 accreditation standards. During two years as Academic Senate President, I gained institutional perspective on the strengths and weaknesses of my college. I initiated and helped implement a policy of directing 1600 faculty to assess an outcome for every student in every section of every course every semester until our accreditation was reaffirmed. I knew the workload was beyond the contractual expectations of faculty. I suspected the type of work was beyond the traditional role of faculty. But I also knew that the accountability required by the accreditation standards might be the most effective tool for beginning the engagement process with those faculty who had so far chosen not to. After helping complete the 2016 self-evaluation, I transitioned again into an administrative position, applying yet another lens to my ideas about teaching, learning, and institutional policy and practice.

I have had several opportunities to reflect on the SLOA implementation decision. Today I believe I would still make the same decision to expand SLOA reporting, but not every student, every semester. As a tool for professional development, SLOA is effective in putting students' needs at the very center of the teaching process. SLOA elevated the discussion about what faculty do into a reflective dialogue about one's own performance beyond anything I ever experienced in the existing faculty evaluation process, including the tenure review process, in my 16 years of teaching. The interview process and visits to ten separate community colleges increased my appreciation for the role of institutional leadership, structure, culture, and policy in shaping practice and thus student success. At 
colleges across the state, SLOA data and strategically-integrated dialogue provided the student voice in the reflection process about best practices in teaching in community colleges. Enhancing and deepening this process can provide the information necessary to pivot and adjust, both in the classroom and as an institution. These practices directly align the role of faculty with the mission of community colleges. These practices also create institutional structures and cultures better able to respond to the needs of students as we work to prepare them for success in an ever-changing economy and society.

\section{Conclusion}

Improving student success and closing opportunity and achievement gaps at community colleges in California is a high priority. While learning outcomes have been used with the goal of improving the overall student experience in college, the mandate for all faculty to participate is relatively new. This study of the experiences of engaged practitioners revealed that SLOA works to improve teaching. Engaged faculty members are open to change, collaboration, and learning about teaching by reflecting on local results and engaging in dialogue with their colleagues. A system of strategicallyintegrated dialogue facilitates this process. Still, weaknesses in the system were also described. Substantial resistance on the part of some faculty remained. Leadership at all levels of the institution needed more capacity. And, direct evidence demonstrating that SLOA works to improve student learning remains elusive. However, except for the lack of direct evidence of improved student learning, the weaknesses in the system were 
described as having abated over time. The structure for strategically-integrated dialogue strengthened. Resistance weakened. More faculty engaged. Assessment improved.

Both the successes of SLOA and strategically-integrated dialogue have the potential to inform more recent requirements that SLOA be used to help close achievement gaps. While participants in this study revealed a lack of clarity on the potential of using SLOA to close achievement gaps, it is possible to imagine that a similar trajectory will take place. Leadership will gain capacity. Dialogue will continue to expand and deepen. As such, SLOA provides the opportunity for community colleges to lead the way in conversations about differential opportunities in our nation.

Participants in this study recognized this potential in SLOA. While most were already engaged in other teaching and learning improvement methods, their engagement in SLOA led to specific changes, revealing that there remained room for improvement in their own practice. Participants acknowledged these improvements. This same potential can be applied to the use of SLOA to continue to drive change. Mary, a faculty member who readily identified herself as a social reformer, identified SLOA as a "best bet" for improving the student experience. $\mathrm{CJ}$, a coordinator with an institution-wide perspective on professional development, accreditation, and learning outcomes, identified SLOA as the "anchor that brings it all together." 
This study revealed that engaging faculty in SLOA works to create a synergy of well-educated, dedicated, socially engaged professionals collaborating on action research directed at social improvement. 


\section{REFERENCES}

Academic Senate for California Community Colleges. (2004). The 2002 Accreditation Standards: Implementation. Retrieved from http://www.asccc.org/sites/default/files/publications/AccreditationPaper_0.pdf

Academic Senate for California Community Colleges. (2007). Agents of change: Examining the roles of student learning outcomes and assessment coordinators in California community colleges. Retrieved from http://asccc.org/sites/default/files/publications/Agents_of_Change_0.pdf

Academic Senate for California Community Colleges. (2010). Guiding principles for SLO assessment. Retrieved from http://asccc.org/sites/default/files/publications/SLO-paper-Fall2010_0.pdf

Accrediting Commission for Community and Junior Colleges. (ACCJC). (2004). Accreditation standards. Retrieved from https://eric.ed.gov/?id=ED469900

Accrediting Commission for Community and Junior Colleges (ACCJC). (2014). Accreditation standards. Retrieved from http://accjc.org/eligibility-requirementsstandards-policies/\#accreditation-standards

Accrediting Commission for Community and Junior Colleges (ACCJC). (2017). About. Retrieved from https://accjc.org/about/ 
Accrediting Commission for Community and Junior Colleges (ACCJC). (2017). Guide to Evaluating and Improving Institutions. Novato, CA: Author. Retrieved from https://accjc.org/wp-content/uploads/Guide-to-Evaluating-and-ImprovingInstitutions_May2017.pdf

American Association of University Professors. (2006). 1940 statement of principles on academic freedom and tenure with 1970 interpretive comments. Retrieved from https://www.aaup.org/file/1940\%20Statement.pdf

Aspen Institute, The. (2013). Defining excellence: Lessons from the 2013 Aspen prize finalists. Washington, DC: College Excellence Program, Author. Retrieved from http://www.aspeninstitute.org/sites/default/files/content/docs/pubs/DefiningExcell ence_2.pdf

Bailey, T. R., Jaggars, S. S., \& Jenkins, D. (2015). Redesigning America's community colleges: A clearer path to student success. Cambridge, MA: Harvard University Press.

Baker, J. H., \& Sax, C. L. (2012). Building a culture of evidence: A case study of a California community college. Journal of Applied Research in the Community College, 19(2), 47-55.

Baxter, P., \& Jack, S. (2008). Qualitative case study methodology: Study design and implementation for novice researchers. The Qualitative Report, 13, 544-559. Retrieved from http://nsuworks.nova.edu/tqr/vol13/iss $4 / 2$ 
Bennett, M., \& Brady, J. (2012). A radical critique of the learning outcomes assessment movement. Radical Teacher, 94, 34-47. Retrieved from http://muse.jhu.edu/article/485092

Beno, B. (2013, November). Accreditation and measures of quality. Paper presented at the meeting of California Association of Institutional Researchers, Napa, California. Retrieved from http://www.cair.org/wpcontent/uploads/sites/474/2015/07/76_Beno.pdf

Bensimon, E. M. (2005). Closing the achievement gap in higher education: An organizational learning perspective. New Directions for Higher Education, 2005(131), 99-111. doi:10.1002/he.190

Bensimon, E. M. (2007). The underestimated significance of practitioner knowledge in the scholarship on student success. Review of Higher Education, 30, 441-469. doi: $10.1353 /$ rhe 2007.0032

Bensimon, E. M., \& Malcom, L. (Eds.) (2012). Introduction. In E. M. Bensimon \& L. Malcom (Eds.), Confronting equity issues on campus: Implementing the equity scorecard in theory and practice (pp. 1-16). Sterling, VA: Stylus. 
Bontenbal, J., Buechner, M., Mcginnis, B., \& Wulff, D. (2014). Developing a culture of evidence. Paper presented at the 2014 Accreditation Institute, La Jolla, CA. Retrieved from http://www.asccc.org/sites/default/files/Developing\%20a\%20Culture $\% 20$ of $\% 20 \mathrm{E}$ vidence.pdf

Bresciani, M. J. (2009). Evaluating the efficiency, effectiveness and sustainability of outcomes-based program review. Journal of Faculty Development, 23(1), 30-39.

Cabrillo College. (n.d.-a). Assessing instructional student learning outcomes. Retrieved from https://docs.google.com/file/d/0B0pmzS3N0DyBcDRPeVdnYmtGbDA/edit

Cabrillo College. (n.d.-b). Cabrillo College SLO Assessment Workbook. Cabrillo College. Retrieved from https://docs.google.com/file/d/0B0pmzS3N0DyBcDRPeVdnYmtGbDA/edit California Assembly Bill 1725 (1988). Retrieved from http://www.asccc.org/sites/default/files/1988\%20AB\%201725\%20Community\%2 0College\%20Reform\%20Act\%20\%28Vasconcellos\%29.pdf

California Community College Chancellor's Office (CCCCO). (2012). Focus on results: Accountability reporting for California community colleges. Retrieved from http://extranet.cccco.edu/Portals/1/TRIS/Research/Accountability/ARCC/ARCC $\% 202012 \% 20$ March\%20Final.pdf 
California Community College Chancellor's Office (CCCCO). (2014). Student equity plan. Retrieved from http://extranet.ccco.edu/Portals/1/SSSP/StudentEquity/Student_Equity_Plan_fina 1.doc

California Community College Chancellor's Office (CCCCO). (2015). Report of the California Community Colleges Chancellor's Office task force on accreditation. Retrieved from http://californiacommunitycolleges.cccco.edu/Portals/0/FlipBooks/2015-TaskForce-on-Accreditation/\#/0

California Community College Chancellor's Office (CCCCO). (2016a). Student equity. Retrieved from http://extranet.cccco.edu/Divisions/StudentServices/StudentEquity.aspx California Community College Chancellor's Office (CCCCO). (2016b). Student success scorecard. Retrieved from http://scorecard. cccco.edu/scorecardrates. aspx?CollegeID=000\#home California Community College Chancellor's Office (CCCCO). (2017a). Datamart. Faculty \& staff demographics report. Retrieved from http://datamart.cccco.edu/Faculty-Staff/Staff_Demo.aspx 
California Community College Chancellor's Office (CCCCO). (2017b). Datamart. Annula/term student count report. Retrieved from http://datamart.cccco.edu/Students/Student_Term_Annual_Count.aspx California Community College Chancellor's Office (CCCCO). (2017c). Student success scorecard: Transfer level achievement. Retrieved from http://scorecard.ccco.edu/scorecardrates.aspx?CollegeID=000\#home California Community Colleges Success Network (3CSN). (2014a). Building the success network one link at a time. Retrieved from http://3csn.org/files/2011/09/2014Newsletter-10.02.14.pdf

California Community Colleges Success Network (3CSN). (2014b). California Acceleration Project. Retrieved from http://cap.3csn.org/

California Community Colleges Success Network (3CSN). (2014c). Teaching habits of mind to history students. Retrieved from http://hom.3csn.org

California Community Colleges Success Network (3CSN). (2014d). Reading apprenticeship in social science. Retrieved from http://ra.3csn.org/why-readingapprenticeship-2/reading-apprenticeship-in-social-science/

California Community Colleges Success Network (3CSN). (2017). Theory of change. Retrieved from http://3csn.org/about/theory-of-change/ 
Cameron, J., Stavenhagen-Helgren, T., Walsh, P., \& Kobritz, B. (2002). Assessment as critical praxis: A community college experience. Teaching Sociology, 30, 414429. http://www.jstor.org/stable/3211502

Coggshall, J. (2012). Toward the effective teaching of new college- and career-ready standards: Making professional learning systemic. Research-to-Practice Brief. National Comprehensive Center for Teacher Quality, 28 pp.

Cohen, A. M. (2005). UCLA community college review: Why practitioners and researchers ignore each other (even when they are the same person). Community College Review, 33, 51-62. doi:10.1177/009155210503300104

Committee for Economic Development. (2013). Boosting California's postsecondary education performance: A policy statement and call to action. Washington, DC: Author. Retrieved from http://www.ltg.ca.gov/docs/CED\%20California\%20Rpt6.pdf

Community College League of California (CCLC). (2011). California Community Colleges. Retrieved from http://www.allgov.com/usa/ca/departments/education/california_community_colle ges?agencyid $=201$

Community College Research Center (CCRC). (n.d.). Community college FAQs. Retrieved from http://ccrc.tc.columbia.edu/Community-College-FAQs.html 
Completion by Design. (n.d.). Completion by design: Student success starts with holistic design. Retrieved from www.completionbydesign.org

Creswell, J. W., \& Plano Clark, V. L. (2011). Designing and conducting mixed methods research ( $2^{\text {nd }}$ ed.). Los Angeles, CA: Sage.

Eaton, J. S. (2015). An overview of U.S. accreditation. Washington, DC: Council for Higher Education Accreditation. Retrieved from http://chea.org/userfiles/uploads/Overview\%20of\%20US\%20Accreditation\%2020 15.pdf

Elmore, R. (2004). School reform from the inside out: Policy, practice, and performance. Cambridge, MA: Harvard Educational Press.

Ewell, P. T. (2009). Assessment, accountability, and improvement: Revisiting the tension (NILOA Occasional Paper No. 1). Urbana, IL: University of Illinois and Indiana University, National Institution for Learning Outcomes Assessment. Retrieved from http://www.learningoutcomeassessment.org/occasionalpaperone.htm

Ewell, P. T. (2011). The new "ecology" for higher education: Challenges to community college accreditation. Paper prepared for the Accrediting Commission for Community and Junior Colleges Western Association of Schools and Colleges. Retrieved from http://www.hartnell.edu/sites/default/files/u285/challenges_to_community_collge _accreditation.pdf 
Felix, E. R., Bensimon, E. M., Hanson, D., Gray, J., \& Klingsmith, L. (2015).

Developing agency for equity-minded change. New Directions for Community Colleges, 2015(172), 25-42. doi:10.1002/cc.20161

Fraenkel, J. R., Wallen, N. E., \& Hyun, H. H. (2012). How to design and evaluate research in education. New York, NY: McGraw-Hill.

Fullan, M. (2001). Leading in a culture of change. San Francisco, CA: Jossey-Bass.

Fullan, M. (2002). The change leader. Educational Leadership, 59(8), 16-20.

Fullan, M. (2006a). Change theory: A force for school improvement (Seminar Series Paper No. 157). Melbourne, Australia: Centre for Strategic Education. Retrieved from http://michaelfullan.ca/wpcontent/uploads/2016/06/13396072630.pdf

Fullan, M. (2006b). The future of educational change: System thinkers in action. Journal of Educational Change, 7, 113-122. doi:10.1007/s10833-006-9003-9

Fullan, M. (2008). The six secrets of change. Retrieved from http://michaelfullan.ca/wpcontent/uploads/2016/06/2008SixSecretsofChangeKeynoteA4.pdf

Fullan, M., \& Knight, J. (2011). Coaches as system leaders. Educational Leadership, $69(2), 50-53$ 
Gallagher, M. (2008). Improving institutional effectiveness: The relationship between assessing student learning outcomes and strategic planning in California community colleges. Journal of Applied Research in the Community College, 15(2), 101-108.

Geiser, S., \& Atkinson, R. C. (2010). Beyond the master plan: The case for restructuring baccalaureate education in California (CSHE Report No. 16.10). University of California, Berkeley, Center for Higher Studies in Education. Retrieved from http://cshe.berkeley.edu/publications/beyond-master-plan-case-restructuringbaccalaureate-education-california

Ginwright, S. A. (2004). Black in school. New York, NY: Teachers College Press.

Graves, J. A. (1995). Student learning in college: A study of faculty views (Doctoral dissertation). Retrieved from ProQuest Dissertations and Theses Global database. (UMI No. 9608595)

Huber, M., and Hutchings, P. 2005. The Advancement of learning: Building the teaching commons. San Francisco: Jossey-Bass.

Hunzicker, J., \& Lukowiak, T. (2012). Effective teaching and student engagement in the college classroom: Using the Instructional Practices Inventory (IPI) as a tool for peer observation and self-reflection. Journal on Excellence in College Teaching, $23(1), 99-132$. 
Hutchings, P. (2010). Opening doors to faculty involvement in assessment (NILOA Occasional Paper No. 4). Champaign, IL: National Institute for Learning Outcomes Assessment. Retrieved from www. learningoutcomeassessment.org/documents/PatHutchings 000.pdf

Jenkins, D., \& Kerrigan, M. R. (2008). Evidence-based decision making in community colleges: Findings from a survey of faculty and administrator data use at Achieving the Dream colleges. New York, NY: Columbia University, Community College Research Center. Retrieved from http://ccrc.tc.columbia.edu/publications/evidence-based-decision-making.html

Jennings, P. K., Rienzi, B., \& Lyda, L. (2006). Assessing student learning: A case study. Teaching Sociology, 34, 286-295. doi:10.1177/0092055x0603400307

Juszkiewicz, J. (2015). Trends in Community College Enrollment and Completion Data, 2015. Washington, DC: American Association of Community Colleges. Retrieved from http//www.aacc.nche.edu/Publications/Reports/Documents/CCEnrollment 2015.pdf

Kezar, A. (2013). Institutionalizing student outcomes assessment: The need for better research to inform practice. Innovative Higher Education, 38, 189-206. doi: $10.1007 /$ s 10755-012-9237-9 
Kezar, A., \& Maxey, D. (2012). Missing from the institutional data picture: Non-tenuretrack faculty. New Directions for Institutional Research, 2012(155), 47-65. doi:10.1002/ir.20021

Kezar, A., Maxey, D., \& Eaton, J. (2014). An examination of the changing faculty: Ensuring institutional quality and achieving desired student learning outcomes (CHEA Occasional Paper). Washington, DC: Council for Higher Education Accreditation. Retrieved from https://www.chea.org/userfiles/Conference\%20Presentations/Examination _Changing_Faculty_2013.pdf

Kuh, G., \& Ikenberry, S. (2009). More than you think, less than we need: Learning outcomes assessment in American higher education. Urbana, IL: University of Illinois and Indiana University, National Institute for Leaming Outcomes Assessment. Retrieved from http://learningoutcomesassessment.org/documents/fullreportrevised-L.pdf

Kuh, G. D., Ikenberry, S. O., Jankowski, N. A., Cain, T. R., Ewell, P. T., Hutchings, P., \& Kinzie, J. (2015). Beyond compliance: Making assessment matter. Change: The Magazine of Higher Learning, 47(5), 8-17. doi: $10.1080 / 00091383.2015 .1077661$ 
Kuh, G., Jankowski, N., Ikenberry, S., \& Kinzie, J. (2014). Knowing what students know and can do: The current state of student learning outcomes assessment in U.S. colleges and universities. Urbana, IL: University of Illinois and Indiana University, National Institute for Learning Outcomes Assessment. Retrieved from http://www.learningoutcomeassessment.org/knowingwhatstudentsknowandcando. html

Livingston, C. H., \& Zerulik, J. D. (2013). The role of the assessment coordinator in a division of student affairs. New Directions for Student Services, 2013(142), 15-24. doi: $10.1002 /$ ss. 20045

Long, T., \& Kurleander, M. (2009). Do community colleges provide a viable pathway to a baccalaureate degree? (NBER Working Paper Series No. 14367). Cambridge, MA: National Bureau of Economic Research. Retrieved from http://www.nber.org/papers/w14367

Marrujo-Duck, L. (2014). Faculty responses to accreditation mandates. Unpublished manuscript.

Marsh, J. A., Bertrand, M., \& Huguet, A. (2015). Using data to alter instructional practice: The mediating role of coaches and professional learning communities. Teachers College Record, 117(4), 1-40. 
May, D., Susskind, D., \& Shapiro, N. S. (2013). Faculty grassroots leadership in science education reform: Considerations for institutional change, culture, and context. Creative Education, 4, 22-31. doi:10.4236/ce.2013.47A2005

McClellan, E. F. (2016). What a long, strange trip it's been: Three decades of outcomes assessment in higher education. Political Science \& Politics, 49, 88-92. doi: $10.1017 /$ S 1049096515001298

McNeice-Stallard, B. E., \& Stallard, C. M. (2011). Measuring sustainability of outcomes assessment. Journal of Applied Research in the Community College, 19(1), 1-8.

Miles, M. B., Huberman, A. M., \& Saldaña, J. (2014). Qualitative data analysis: A methods sourcebook ( $3^{\text {rd }}$ ed.). Thousand Oaks, CA: Sage.

Moore, C., Offenstein, J., \& Shulock, N. (2011). Consequences of neglect: Performance trends in California higher education. Sacramento, CA: California State University, Sacramento. Retrieved from http://files.eric.ed.gov/fulltext/ED524218.pdf

Parcell, A. (2012). More to most: Scaling up effective community college practices. Durham, NC: MDC. Retrieved from http://www.mdcinc.org/sites/default/files/resources/More\%20to\%20Most.pdf

Peterson, M. W., \& Einarson, M. K. (2001). What are colleges doing about student assessment? Does it make a difference? Journal of Higher Education, 72, 629669. doi:10.2307/2672898 
Prince, M. J., Felder, R. M., \& Brent, R. (2007). Does faculty research improve undergraduate teaching? An analysis of existing and potential synergies. Journal of Engineering Education, 96, 283-294. doi:10.1002/j.2168-9830.2007.tb00939.x

Reardon, S. F. (2011). The widening academic achievement gap between the rich and the poor: New evidence and possible explanations. In R. Murnane \& G. Duncan (Eds.), Whither opportunity? Rising inequality, schools, and children's life (pp. 91-116). New York, NY: Russell Sage Foundation.

Reid, P. (2014). Categories for barriers to adoption of instructional technologies. Education and Information Technologies, 19, 383-407. doi:10.1007/s10639-0129222-z

Rodesiler, C. A., \& McGuire, J. M. (2015). Ideas in practice: Professional development to promote universal design for instruction. Journal of Developmental Education, $38(2), 24-26,28-31$.

Rogers, E. M. (2003). Diffusion of innovations ( $5^{\text {th }}$ ed.). New York, NY: Free Press.

Rodgers, M., Grays, M. P., Fulcher, K. H., \& Jurich, D. P. (2013). Improving academic program assessment: A mixed methods study. Innovation in Higher Education, 38, 383-395. doi:10.1007/s10755-012-9245-9

Sahin, I., \& Thompson, A. (2006). Using Rogers' theory to interpret instructional computer use by COE faculty. Journal of Research on Technology in Education 39, 81-104. doi:10.1080/15391523.2006.10782474 
Scott, C., Parsley, D., \& Fanz, T. (2014). Connections between teacher perceptions of school effectiveness and student outcomes in Idaho's low-achieving schools. Washington, DC: U.S. Department of Education. Retrieved from http://ies.ed.gov/ncee/edlabs/projects/project.asp?ProjectID=374

Shields, C. M. (2010). Transformative leadership: Working for equity in diverse contexts. Educational Administration Quarterly, 46, 558-589. doi: $10.1177 / 0013161 \times 10375609$

Spalter-Roth, R., Kisielewski, M., \& Van Vooren, N. (2013). The victory of assessment? What's happening in your department? The AY 2011-2012 Department Survey (Department Survey Series No. 2). Retrieved from http://www.asanet.org/research-and-publications/research-sociology/researchbriefs/victory-assessment-whats-happening-your-department-ay-2011-2012department-survey

Spellings, M. (2006). A test of leadership: Charting the future of U.S. higher education. Washington, DC: U.S. Department of Education. Retrieved from http://www2.ed.gov/about/bdscomm/list/hiedfuture/reports.html

Sun, H. C., Hao-Chang, S., Chen, K. N., Tseng, C., \& Tsai, W. H., T. (2011). Role changing for librarians in the new information technology era. New Library World, 112(7/8), 321-333. doi:10.1108/03074801111150459 
Tagg, J. (2012). Why does the faculty resist change? Change: The Magazine of Higher Learning, 44(1), 6-15. doi:10.1080/00091383.2012.635987

Thaler, R. (1980). Toward a positive theory of consumer choice. Journal of Economic Behavior \& Organization, 1, 39-60. doi:10.1016/0167-2681(80)90051-7

Turner, C. S. (2015). Lessons from the field: Cultivating nurturing environments in higher education. Review of Higher Education, 38, 333-358. doi: $10.1353 /$ rhe 2015.0023

Umbach, P. D., \& Wawrzynski, M. R. (2005). Faculty do matter: The role of college faculty in student learning and engagement. Research in Higher Education, 46, 153-184. doi:10.1007/s11162-004-1598-1

Van Horne, S., \& Murniati, C. T. (2016). Faculty adoption of active learning classrooms. Journal of Computing in Higher Education, 28, 72-93. doi:10.1007/s12528-0169107-z

Wang, X., \& Hurley, S. (2012). Assessment as a scholarly activity? Faculty perceptions of and willingness to engage in student learning assessment. Journal of General Education, 61, 1-15. doi:10.1353/jhe.2012.0005

Whicker, M. L., Kronenfeld, J. J., \& Strickland, R. A. (1993). Getting tenure: Survival skills for scholars. Thousand Oaks, CA: Sage. 
Wildey, A. R., Vanek, G. T., \& Trevisan, M. S. (2003). Assessment coordinators: Professional characteristics and institutional support. Assessment Update, 15(3), 6-7. doi:10.1002/au.153

Willard, W. A., Dearing, F., \& Belair, S. J. (2004). Community college strategies: Assessment Update, 16(3), 11-13. doi:10.1002/au.163

Wilson, W. J. (2009). More than just race: Being Black and poor in the inner city. New York, NY: W.W. Norton.

Yin, R. K. (2011). Qualitative research from start to finish. New York, NY: The Guilford Press.

Yoo, J. H., Schallert, D. L., \& Svinicki, M. D. (2013). Effective teaching in an age of accountability: Mapping the views of college students and instructors. Journal on Excellence in College Teaching, 24(4), 107-131. 


\section{APPENDIX A}

\section{Interview Questions for Faculty Participants}

1. How/Why did you come to teach in a community college?

2. How/Why did you become engaged in SLOA?

3. How would you describe what you do when you use SLOA to improve student learning to someone who is not a teacher, who knows nothing about it - but wants to understand?

4. If I had been a student in your class prior to you becoming engaged in SLOA - what would I have been doing? What did you expect of students outside of class? How about today?

5. How has your class preparation changed - from designing syllabi to preparing for class sessions? Why did you make those particular changes?

6. What, if anything, is most different about you as a teacher as a result of engagement in SLOA? Why? Are you more effective? For all students? Why do you think that is so?

7. How would you describe the balance of responsibility between yourself and your students when they are struggling? Why do you place those responsibilities on students?

8. How do you perceive the institutional culture in regards to SLOA? 
9. In what ways does analyzing achievement gaps affect your teaching improvement strategies? Why?

10. On balance, does the effort that you put into SLOA fully pay off in improved student learning? Why do you think this is so?

11. What could your college do to build on/complement your efforts in order to further improve student learning? Why would those things be effective?

12. How valuable are these SLOA skills to your professional goals? Why? 


\section{APPENDIX B \\ Interview Questions for SLO Coordinators}

1. How/why did you become engaged in student learning outcomes assessment?

2. What kinds of things do faculty do when they are engaged in student learning outcomes assessment that leads to demonstrated learning improvement?

3. Have you seen changes in faculty attitudes toward SLOA? Why do you think that is?

4. How do you perceive the institutional culture in regards to SLOA?

5. What more could your institution do to support faculty engagement in SLOA?

6. Are there other strategies besides SLOA that you think would better improve student learning?

7. What about the role of students? What are the expectations of students and their role in the learning process? Have these expectations changed?

8. Which programs at your college are most successfully engaged in outcomes assessments that lead to learning improvements? Why do you think that is?

9. Which programs are most resistant to SLOA? Why do you think that is? 


\section{APPENDIX C}

\section{Demographic Questionnaire and Survey}

\section{ASSESSMENT and DEMOGRAPHIC SURVEY}

This survey will also be evaluated, please be as thorough as possible.

Data will be entered under pseudonym and the form immediately destroyed.

On a scale of 1 to 10, how involved are you in writing the SLO reports for your discipline?

I follow instructions and turn in assessment data to someone else

\section{(circle the appropriate number)}

$1 \ldots . .2 \ldots . .3 \ldots . .4 \ldots . .5 \ldots . .6 \ldots . . . . .8 \ldots . . . . .10$
I help design and collect the assessments and write the report

On a scale of 1 to 10, how do you perceive your direct supervisorial support for SLO work?

My supervisor just wants the report

written

$$
1 \ldots . . . . .3 \ldots . . .4 \ldots 5 \ldots . \ldots 6 \ldots 7 \ldots . . . . . . . . .10
$$

My supervisor fully supports SLO work, helps review SLO data and suggests improvements

On a scale of 1 to 10, how would you rate your department's culture around SLOs?

\begin{tabular}{|l|l|l|}
\hline $\begin{array}{l}\text { My department } \\
\text { resists SLOS and } \\
\text { there are lots of } \\
\text { complaints }\end{array}$ & $1 \ldots . .2 \ldots . . .3 \ldots 4 \ldots . .5 \ldots . .6 \ldots . . .7 \ldots . .8 \ldots 9 \ldots . . .10$ & $\begin{array}{l}\text { My department actively } \\
\text { uses SLOs to attempt } \\
\text { improvements }\end{array}$ \\
\hline
\end{tabular}

On a scale of 1 to 10 , how would you rate your college's culture around SLOs?

\begin{tabular}{|c|c|c|}
\hline $\begin{array}{l}\text { My college does the } \\
\text { minimum for } \\
\text { accreditation }\end{array}$ & 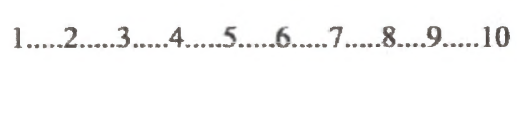 & $\begin{array}{l}\text { My college actively } \\
\text { connects SLOs to } \\
\text { improvement plans }\end{array}$ \\
\hline
\end{tabular}

Community colleges are now being asked to disaggregate SLO data in order to close learning and achievement gaps among student groups. On a scale of 1 to 10 , how successful might this effort be?

\begin{tabular}{|c|c|c|}
\hline $\begin{array}{l}\text { Not at all - achievement } \\
\text { gaps are not related to } \\
\text { the classroom } \\
\text { experience }\end{array}$ & 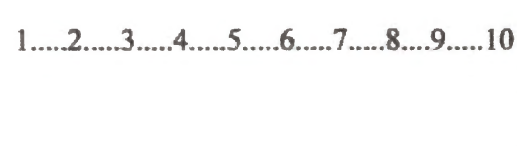 & $\begin{array}{l}\text { Absolutely - working with } \\
\text { disaggregated SLO data } \\
\text { will improve the classroom } \\
\text { experience }\end{array}$ \\
\hline
\end{tabular}

Please describe the rationale behind previous question about disaggregated data? 


\section{About you:}

Educational background:

Area of emphasis for BA:

for MA:

for Doctorate:

Area of emphasis for other additional coursework or study?

Work Experience:

What types of work experiences have you had outside of teaching community college?

Teaching Experience:

Years at part-time status:

Years at tenure-track or tenured status:

Please list all departments you have taught courses in and all courses taught:

\section{Research publications:}

How many articles/papers have you published in your teaching discipline?

in Assessment?

\section{Conference Attendance:}

How many conferences have you attended in your field of study/teaching discipline?

Which professional organizations do you belong to?

How many conferences have you attended in the area of assessment or professional development aimed at improving teaching practice?

What types of professional development activities in assessment or teaching practice have you attended?

(check all that apply)

SLO assessment workshops

SLO interpreting data workshops

Software training for using assessment data

Cultural competency workshops

Learning style workshops

$\begin{array}{ll}\text { at your college: } & \begin{array}{l}\text { you traveled: } \\ \text { off-site } \\ \text { on-site }\end{array} \\ \begin{array}{ll}\text { off-site } \\ \text { off-site } \\ \text { on-site } \\ \text { on-site }\end{array} & \begin{array}{l}\text { off-site } \\ \text { off-site }\end{array} \\ \text { on-site } & \end{array}$


Community of practice or faculty inquiry group

on-site
on-site
on-site
on-site
on-site
on-site

off-site

Habits of mind/Growth mindse

off-site

Teaching Basic Skills

Closing achievement gaps

Student success strategies

Others:

please list topics:

off-site

off-site

off-site

off-site

Of the above activities, put a star next to those that most helped you use SLOs to make improvements.

Almost there, Community Service or Hobbies:

Please list any types of volunteer work or hobbies that you have participated in:

Second to last question: Age: Gender Identity:

Ethnic Identification:

Finally, is there anything else you would like to add? 